\title{
Contaminant Release from Storm Water Culvert Rehabilitation Technologies: Understanding Implications to the Environment and Long-Term Material Integrity
}

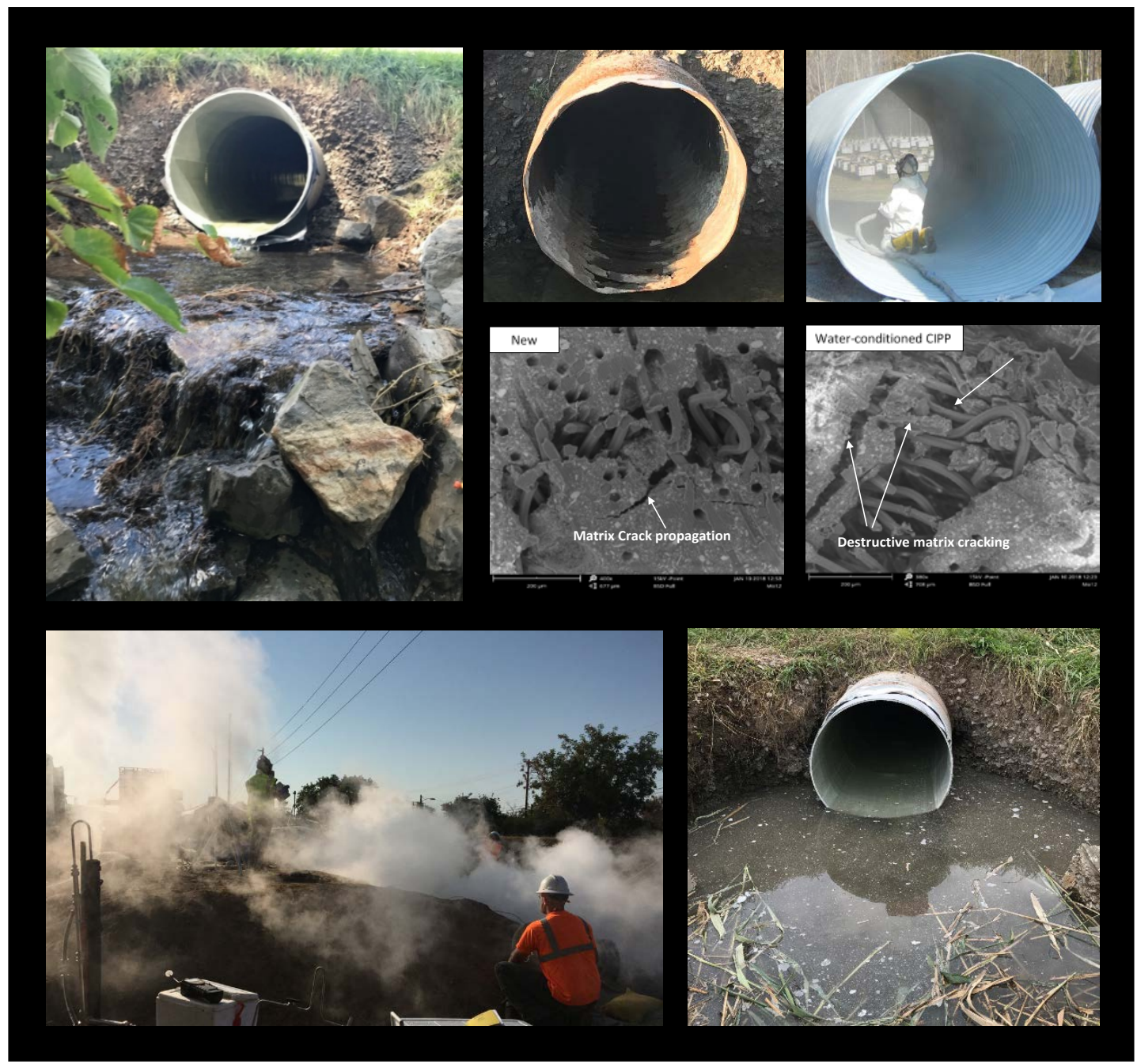

October 31, 2019

Andrew J. Whelton, Kyungyeon Ra, Seyedeh Mahboobeh Teimouri Sendesi, Md Nuruddin, Xianzhen Li, John A. Howarter, Jeffrey P. Youngblood, Chad T. Jafvert, Nadezhda N. Zyaykina

FHWA TPF-5(339) • DOI: $\underline{10.5703 / 1288284317089}$

\section{PURDUE}




\section{Recommended Citation}

Whelton, A. J., Ra, K., Teimouri Sendesi, S. M., Nuruddin, M., Li, X., Howarter, J. A., Youngblood, J. P., Jafvert, C. T., \& Zyakyina, N. N. (2019). Contaminant release from storm water culvert rehabilitation technologies: Understanding implications to the environment and long-term material integrity (U.S. Federal Highway Administration Transportation Pooled Fund (TPF)-5(339)). West Lafayette, IN: Purdue University. https://doi.org/10.5703/1288284317089

\section{Authors}

Corresponding Author: Andrew J. Whelton, Ph.D., Associate Professor, Lyles School of Civil Engineering, Division of Environmental, \& Ecological Engineering, Purdue University, (765) 494-2166, awhelton@purdue.edu, CIPPsafety@purdue.edu

Kyungyeon Ra, Seyedeh Mahboobeh Teimouri Sendesi, Xianzhen Li, Graduate Research Assistants, Lyles School of Civil Engineering, Purdue University

Md Nuruddin, Graduate Research Assistant, School of Materials Engineering, Purdue University

John A. Howarter, Ph.D., Associate Professor, School of Materials Engineering and Division of Environmental and Ecological Engineering, Purdue University

Jeffrey P. Youngblood, Ph.D., Professor, School of Materials Engineering, Purdue University

Chad T. Jafvert, Ph.D., Professor, Lyles School of Civil Engineering and Division of Environmental and Ecological Engineering, Purdue University

Nadezhda N. Zyakyina, Ph.D., Director, Environmental Engineering Laboratories, Lyles School of Civil Engineering, Purdue University

\section{Acknowledgments}

The study advisory committee members are thanked for their guidance and assistance. The authors sincerely appreciate the support and assistance received from the project manager, Bridget Donaldson, Associate Principal Research Scientist at the Virginia Transportation Research Council, as well as the California Department of Transportation (CALTRANS) (Sean Penders, Paul Davies), Kansas Department of Transportation (KDOT) (John Hobelman) North Carolina Department of Transportation (NCDOT) (Matthew Lauffer, Charles Smith, Stephen Morgan, Ryan Mullins), New York State Department of Transportation (NYSDOT) (Brian Carmody, Mark Saunders, Carl Kochersberger), and Ohio Department of Transportation (OHDOT) (Jeffrey Syer, Jonathan Prier).

California State University, Sacramento researchers (Brian Currier, Kelly McCamman, Nathan Devai, and Kirk Van Rooyan) as well as Purdue University's Environmental Health and Safety Department and Radiological and Environmental Management program are thanked for their assistance. Contributions and feedback from Purdue University student Emily Conkling, Dr. Brandon Boor, and Dr. Shannahan is also appreciated. Input on worksite safety and monitoring provided by Dr. Ryan Lebouf and Dr. Rachel Bailey at the U.S. National Institute for Occupational Safety and Health (NIOSH), and the California Department of Public Health is appreciated.

The following states are thanked for their participation in the construction specification survey: Alabama, California, Colorado, Delaware, Florida, Idaho, Indiana, Iowa, Kansas, Kentucky, Louisiana, Maine, Massachusetts, Michigan, Minnesota, Montana, North Carolina, Nevada, New Mexico, New York, Ohio, Oregon, Pennsylvania, South Dakota, Tennessee, Texas, Utah, Vermont, Virginia, Washington, Wisconsin, and Wyoming. Georgia, Mississippi, and West Virginia are thanked for their documentation and discussions. Data provided by third parties were presented as-is. The CIPP contractors are thanked for their collaboration.

\section{Notice}

The contents of this report reflect the views of the authors, who are responsible for the facts and the accuracy of the data presented. The contents do not necessarily reflect the official views or policies of the sponsoring agencies or the Federal Highway Administration. This report does not constitute a standard, specification, or regulation. Some participating pooled fund state transportation agencies were in the process of reviewing and modifying their policies and procedures during the study. Others may choose to make changes after this study is complete. 


\section{FOREWORD}

This report, referred to as the six state lining study, provides recommendations to limit environmental contamination, improve worksite safety, and better understand product quality for polymer based spray-on and cured-in-place-pipe (CIPP) storm water culvert liners. The primary audience is local, state, federal, and tribal government staff who choose to better understand current knowledge about environmental contamination associated with these practices and upgrade their construction specifications, project oversight, and testing needs. Results of this study also have value for consultants, municipalities, environmental regulators, and worker safety agencies, and lining contractors.

This report compiles information from several peer-reviewed scientific documents that were created and published during the course of the pooled fund study. The authors chose to have parts of the study peer-reviewed before inclusion in this report so that additional independent expert reviews that were not selected by the authors, the funding agencies, and industry could be incorporated. The reviewers were selected by each peer-review journal and were not selected by the project team. This approach was also conducted, in part, because little peer-reviewed scientific information was available about the environmental impacts of these technologies. All testing results and methods used during this project can be found in the peer-reviewed documents and summaries are available here.

During this project, the safety of workers, transportation agency employees, and the general public at lining installation sites was raised as concern by several organizations, including state and federal agencies. The initial field work associated with this study was not intended to address worksite safety. Though, due to previously unreported hazards which were encountered by the project team at multiple field sites, it became apparent characterizing worksite safety including the provision of recommendations was necessary. During the conduct of this study, the U.S. National Institute for Occupational Safety and Health (NIOSH) conducted a health hazard evaluation with a CIPP company through their health hazard evaluation program. NIOSH found styrene exposure exceeded an occupational chemical exposure standard (NIOSH 2019). Another chemical they identified emitted into air was divinylbenzene. In the final health hazard evaluation report, the NIOSH provided worksite safety recommendations for the CIPP process evaluated. Also during the conduct of the present study, the U.S. Occupational Safety and Health Administration (OSHA) conducted its own investigation and concluded that chemical exposure contributed to the fatality of a 22-year old sanitary sewer CIPP worker at a worksite in 2017 (OSHA 2018). For these and other reasons, discussion of worksite safety observations and results have been mentioned in this report.

The following peer-reviewed published papers contain some information from or directly related to this pooled fund study:

1. Considerations for emission monitoring and liner analysis of thermally manufactured sewer cured-in-place-pipes (CIPP). 2019. Journal of Hazardous Materials. (HAZMAT). 371, 540549. https://doi.org/10.1016/j.jhazmat.2019.02.097. This has videos online, a manuscript file and supplementary material (SM) file.

2. Evaluation of the physical, chemical, mechanical, and thermal properties of steam-cured PET/polyester cured-in-place pipe. 2019. Journal of Composite Materials. 53 (19), 2687-2699. https://doi.org/10.1177/0021998319839132. This has a manuscript file and supplementary material (SM) file.

3. Outdoor manufacture of UV-cured plastic linings for storm water culvert repair: Chemical emissions and residual. 2018. Environmental Pollution. 245, 1031-1040.

https://doi.org/10.1016/j.envpol.2018.10.080. This has video files, a manuscript file, and supplementary material (SM) file.

4. Critical review: Surface water and storm water quality impacts of cured-in-place pipe repairs. 2018. Journal of the American Water Works Association. 110 (5), 15-32. https://doi.org/10.1002/awwa.1042. This has a manuscript file.

5. Worksite chemical air emissions and worker exposure during sanitary sewer and storm water pipe rehabilitation using cured-in-place-pipe (CIPP). 2017. Environmental Science \& Technology Letters. 4 (8), 325-333. https://doi.org/10.1021/acs.estlett.7b00237. This has videos online, a manuscript file and supporting information (SI) file. 
6. In vitro toxicity assessment of emitted materials collected during the manufacture of water pipe plastic linings. 2019. Inhalation Toxicology. 31 (4).

https://doi.org/10.1080/08958378.2019.1621966. This has a manuscript file and supporting information (SI) file. 


\begin{abstract}
Millions of miles of existing U.S. storm water culverts are critical for roadway safety but much of this infrastructure requires repair. State departments of transportation (DOT) are increasingly choosing to rehabilitate culverts with spray-on and cured-in-place pipe (CIPP) lining processes. These culvert lining practices involve the manufacture of a new plastic liner inside a damaged culvert. DOTs are selecting these outdoor plastic manufacturing methods partly to avoid open-trench excavation, which can cause traffic disruption and work zone traffic safety issues. This study was conducted to better understand current knowledge about culvert lining caused environmental contamination, final product quality, and recommend improved construction specifications, project oversight, and testing requirements to limit undesirable consequences. Literature reviews, a survey of construction specifications and special provisions for 32 transportation agencies, as well as field- and bench-scale testing for CIPP projects in California, New York, and Virginia, were completed. During this project, the safety of workers, transportation agency employees, and the general public at lining installation sites, was raised as a concern by state and federal agencies. Due to previously unreported hazards which were encountered at multiple CIPP field sites, the provision of worksite safety recommendations for DOTs was added to this study. Recommendations are provided for spray-on lining and CIPP lining culvert repair projects that can (1) limit environmental contamination, (2) improve worksite safety, and (3) aid DOTs in better understanding the quality of their new liners.
\end{abstract}

Keywords: culvert; rehabilitation; maintenance; safety; lining; environment; water quality 


\section{EXECUTIVE SUMMARY}

\section{Contaminant Release from Storm Water Culvert Rehabilitation Technologies}

\section{Introduction and Approach}

The project objectives were to determine: (1) The scope of the chemical release problem for in-situ culvert lining processes across departments of transportation (DOT) (i.e., the extent of use of these technologies and the scale of their impacts to water quality); (2) The effectiveness of existing construction specifications at minimizing contaminant release from rehabilitated culverts; and (3) The degree to which the structural integrity and longevity of rehabilitated culverts are compromised by chemical leaching. Results of this project were intended to enable DOTs to make informed decisions with regard to culvert rehabilitation selection and specification development.

A literature review was conducted for both sprayon lining and cured-in-place-pipe (CIPP) lining processes. Spray-on lining practices reviewed included cementitious mortar, epoxy, polyurea, and polyurethane. After the review of construction specifications for 32 transportation agencies revealed spray-on lining was less used than CIPP, the project team then focused field- and bench-scale testing on CIPP linings in California, New York and Virginia. Uncured resin tubes used for CIPP manufacture in California and New York were collected and analyzed. CIPP contractors in Virginia did not provide the project team a sample of their resin tube. CIPP specimens were exhumed from all sites and analyzed in the laboratory. Water samples were collected from New York and Virginia field sites. Water samples at CIPP field sites in California were collected and analyzed by California State University, Sacramento under a separate contract administered by CALTRANS.

\section{Findings: Literature Review and Construction Specification Survey}

Both spray-on lining and CIPP lining practices involve the chemical manufacture of plastic liners outdoors. To accomplish this, raw materials must be brought onsite and handled. Before, during, and after each liner is manufactured, the materials are often physically cut. These practices may provide opportunities for pollutants to be released into air, water, and soil during setup, product manufacture, cleanup, and after contractors leave the worksite.

The literature review revealed no incidents of water contamination for spray-on lining, but CIPP lining associated contamination has been documented. This absence of spray-on contamination may be due to spray-on lining being less used by DOTs compared to CIPP and/or engineering and administrative controls associated with spray-on lining practices that inhibit water contamination. Water contamination incidents associated with CIPP lining have been documented in 13 states (AL, CA, CO, CT, FL, GA, MI, MN, OR, PA, VT, WA, WV) and Canada. CIPP associated water contamination has been found in states where field studies were conducted (AL, CA, NY, VA).

CIPP lining associated contamination has been primarily due to the release of uncured resin, solvents, manufacturing byproducts, and wastes during and after construction. Odor, fish kill, downstream drinking water contamination incidents, and violations of state water pollution laws have been reported. The few field- and bench-scale studies available indicated that styrene has often been the only contaminant tested for but a variety of other volatile organic compounds (VOC) as well as semi-volatile organic compounds (SVOC) can been released into water. Levels have exceeded aquatic toxicity thresholds for freshwater indicator species and U.S. Environmental Protection Agency (EPA) drinking water health-based limits. Sometimes chemical contamination was detected for several months after outdoor CIPP manufacture. In one study, CIPP condensate waste was found to be acutely toxic to Daphnia magna organisms and dissolved them at room temperature within 24 hours. After diluting the condensate waste by a factor of $10,000,100 \% D$. magna mortality occurred in 48 hours, which also showed non-styrene compounds were responsible for acute toxicity. Waste discharge to the ground has been documented with CIPP manufacturing activities. Chemical release is likely influenced by formulation, manufacture conditions, and environmental conditions. A list of degradation products (32) for initiators used for past CIPPs (Perkadox ${ }^{\circledR}$, Trigonox ${ }^{\circledR}$, Butanox $^{\circledR}, \quad N, N$-Dimethylanaline ${ }^{\circledR}, \quad$ Norox $^{\circledR}$ ) was created, along with a list of chemicals found in uncured resins used for CIPP, leaching from CIPP after manufacture, and chemicals extracted from CIPP specimens (that may leach). 
Of the 32 states who responded to the project team's construction specification survey, only 3 states had spray-on lining specifications while 23 states had CIPP lining specifications. Agency construction specification requirements for CIPP varied widely where some agencies had little to no requirements, some agencies required testing for a single chemical, and other agencies specified a specific U.S. EPA water testing method for multiple chemicals (specific to that method). A comparison of construction specifications is described in this report.

\section{Findings: Field- and Bench-Scale Testing during this Study}

Water testing was conducted at multiple CIPP manufacturing sites and chemicals were identified in uncured resin materials, extracted from the new CIPPs, and detected post-installation in the environment. A variety of VOCs and SVOCs that had not been looked for or been reported in prior CIPP studies were found in the present study. Some of the chemicals found inside the CIPPs were not present in the uncured resin tube, indicating that they were created during manufacture. Many chemicals found in the present study had water quality standards for at least one of the states participating in the study. This means their discharge to waterways is likely not permitted to exceed a specific concentration (Table C1). Other chemicals detected and quantified did not have state water quality standards (Table C-2), but could cause aquatic toxicity according to prior studies.

Chemical testing of uncured resin tubes used for outdoor CIPP manufacture revealed many chemicals not listed on the material safety data sheets (SDS). Some of these chemicals also had state water quality standards, while water quality standards were not found for others but aquatic toxicity thresholds for those chemicals were found. Field testing at those sites revealed some of those unlisted chemicals entered rinse water after CIPP manufacture. This discovery indicates that agencies should not solely rely on SDSs to identify the chemicals that require testing during and post-CIPP manufacture. In parallel studies, other materials were found being emitted into air during CIPP manufacture, including partially cured resin and particulates. These were not listed on SDSs and have the potential to deposit onto nearby land and waters. Other chemicals emitted into the air and waters during the present study and parallel studies were not listed on SDSs.

Agencies who desire to determine if a CIPP lining project caused chemical water contamination should require water testing. Agencies should use the results of this study to have a discussion with their applicable environmental regulator (i.e., Clean Water Act Administrator). These discussions should focus on determining the appropriate water testing chemical analyses before and after CIPP manufacture. More details about this action are provided in the Section 7 of this report.

At CIPP manufacturing sites, chemical contamination was found in standing water, rinse water, and storm water immediately after and 22 days after CIPP manufacture, depending on the site. The maximum styrene level found in the field was detected immediately after manufacture $(2.32 \mathrm{mg} / \mathrm{L})$ in NY. This level was less than what was found by others in prior studies and incidents (maximum found in the literature was well above styrene's $320 \mathrm{mg} / \mathrm{L}$ water solubility limit indicating uncured resin may have been present). Multiple water samples collected immediately after plastic manufacture however exceeded the most stringent state styrene water quality limit used for comparison (0.005 mg/L). Water quality limits used for comparison were those found in state codes for the participating agencies of this study. While the $0.005 \mathrm{mg} / \mathrm{L}$ limit (and other $0.050 \mathrm{mg} / \mathrm{L}$ limit also in NY) do not apply to the specific NY study sites because of the specific class of water, it was used for comparison purposes to illustrate that regulatory limits vary between and within states and these differences often depend on the specific class of waters (i.e., trout stream drinking water source, etc.). The maximum styrene level found in the present study also exceeded the acute aquatic toxicity threshold for algae, but not rainbow trout or Daphnia magna. Monitoring was conducted up to three weeks for a single CIPP and water exiting the culvert was found to contain $0.382 \mathrm{mg} / \mathrm{L}$ styrene. Rinse water collected after CIPP manufacture at a dry culvert in Virginia was also contaminated by the CIPP and also contained styrene $(53 \mu \mathrm{g} / \mathrm{L})$ and other compounds.

During the present study, floating debris, uncured resin, and partially cured resin was discovered in rinse water and storm water after some CIPP's were manufactured. This observation has been documented by other investigators over the past 10 years in other states. It was also discovered that CIPP dust generated during cutting can prompt water contamination. Laboratory testing showed that "pinch" of CIPP cutting particulate in a static $40 \mathrm{~mL}$ water solution generated an aqueous styrene concentration of 16 $\mathrm{mg} / \mathrm{L}$ in 48 hours. The static leaching experiment was halted after 48 hours so it remains unknown if greater styrene levels would have occurred if the stagnation period was continued. Particulate is a common byproduct generated at steam, hot water, and ultraviolet (UV) light CIPP manufacturing sites. 
Other chemicals with state water quality standards were also present in the particulate, but only styrene in water was examined. In laboratory experiments, some of this particulate settled in the water column while other materials remained suspended. In the field, particulates were observed to be suspended, flowed downstream, and adhered to nearby vegetation. This cutting material was identified as a source for chemical pollution, and had been observed at other field sites for the present study and in images from prior studies by others. Though, the present study is the first known characterization of the cutting particulate leaching potential.

Preventing CIPP particulate from entering the environment (air, water, soil) and settling in waterways should reduce the overall environmental impact of this outdoor plastic manufacturing activity. Once particulate release is prevented, along with preventing the release of uncured and partially cured resin, testing associated with CIPP manufacturing sites can more likely measure the chemical leaching from the CIPP itself. Until that time however, testing results from the present study and those of past studies are likely an indicator of the overall plastic manufacturing activity not solely due to leaching from the new CIPP.

Based on the totality of evidence reviewed in the literature and testing conducted during the present study, water contamination likely occurs at other CIPP plastic lining manufacturing sites in and outside these states. Detection of CIPP caused water contamination in the present study is not unique, as CIPP associated water contamination incidents have continued to occur over the past 10 years. Though, actions are recommended in the present study to prevent this from continuing to occur. The literature clearly shows that different states have different chemical water quality limits so a testing result representing water quality noncompliance in one state may be acceptable in another state. Results indicate a need for chemical testing at all CIPP manufacturing sites to measure impact. If contamination above the environmental regulator's informed threshold is discovered, environmental regulators should be notified, followup testing and possibly site remediation may be necessary. Changes to reduce chemical release from residual and CIPPs themselves may also be necessary.

CIPP short- and long-term leaching is likely influenced by the amount of residual left inside the CIPP and limiting this amount should be considered in CIPP design. The amount of chemical residual that remained in CIPPs after the contractor completed their work different significantly. For example, new CIPPs manufactured in California with steam contained $1.02-2.21 \mathrm{wt} \%$ of volatile material. If this result is representative of an entire CIPP, a $45 \mathrm{~cm}$ [18 in] $\mathrm{x}$

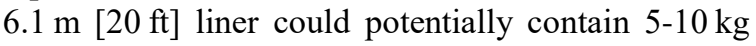
[11-22 lbs] of residual chemical. Other CIPPs exhumed in New York and Virginia and characterized during this project revealed more than $9 \mathrm{wt} \%$ of volatile material remained in a CIPP.

Short-term water exposure to a CIPP did not change strength significantly although initial crack formation and debonding was observed. Also found was that CIPP structural integrity and longevity was not compromised by short-term chemical leaching. Additional work should be conducted to examine the role of aging duration, the presence of defects (i.e., pinholes, blisters, fins), chemical leaching, and aging environment on long-term CIPP structural integrity and longevity.

\section{Recommended Construction Specification and Special Provision Upgrades and Oversight}

\section{Detailed specification recommendations are included in Section 7}

Because spray-on lining and CIPP lining are plastic manufacturing activities conducted outdoors, construction practices that limit chemical release and environmental monitoring should be applied. A list of construction specification language for spray-on lining projects and a separate list for CIPP lining projects can be found in Section 7 of this report. Appendix A contains details regarding how CIPPs can be characterized after manufacture. Appendix B contains a list of confirmed and possible construction activities associated with air, water, and soil contamination.

State water quality discharge limits should be considered where the lining practice may be used. Different states have different water quality standards and criteria. While gross contamination (i.e., floating debris, oil, scum and other floating materials entering the waters as a result of human activity in amounts sufficient to be unsightly or cause degradation) is a violation under the Clean Water Act, allowable chemical levels discharged onsite and into nearby waters can depend on each state.

Another challenge with environmental monitoring is that little information exists regarding the chemicals used, created, and released at CIPP manufacturing sites. For example, not all chemicals listed in the enclosed report may be used, created, or released at a single CIPP manufacturing site due to contractor formulations and practices. But, evidence from past contamination incidents and post-CIPP 
installation monitoring shows there can be potential for chemical discharge and leaching into the environment at CIPP manufacturing sites, so environmental monitoring is necessary. Waste from CIPP cutting processes can also pose an environmental hazard. Further, partially cured resin, particulate, organic vapors, and water vapor were found being discharged into air at steam CIPP exhaust in a parallel study. The fate of these materials in the environment (i.e., whether they deposit on land or waterways) has not yet been studied. Some deposition is likely based on their observed properties. It is recommended these materials are captured and not permitted to be discharged to the environment.

During this study, it became clear to the project team that CIPP contractors, CIPP textbooks, trade association literature, and a popular industry CIPP inspector training course did not make clear the host of chemicals that were being used, created, and released into the environment (or their magnitudes). For this reason, it is recommended agencies who contract for CIPP manufacturing to conduct their own independent environmental testing. Testing is needed to better understand the impact of the outdoor plastic manufacturing process on the environment. Testing is also needed to document the effectiveness of pollution prevention actions. With this testing data, agencies can then better understand which technologies and conditions require additional restrictions to protect the environment. The goal would be to avoid short- and long-term environmental degradation.

To further identify which contaminants should be monitored at CIPP manufacturing sites, the following is recommended.

1. Infrastructure owners (i.e., transportation agencies) should seek CIPP environmental monitoring advice from their respective state or federal environmental agencies who permit pollutant discharges to water, land, and air. For water, this falls under the National Pollutant Discharge Elimination System (i.e., Clean Water Act). These permitting agencies, with the assistance of this report and other information, can provide more informed guidance about the pertinent legal requirements associated with land, water, and air quality impacts. The state agency responsible for solid and hazardous waste disposal should also be contacted as CIPP manufacturing process (hot water, steam, UV), have previously shown to generate wastes. These agencies can also provide clarification about whether or not any specific practices for the state must be added to construction specifications. Recommended specifications in Section 7 of this report as well as Tables C-1 and C-2 could be used to facilitate discussion with the environmental agencies. The required list of chemicals to test for and the testing methods themselves should be discussed. NIOSH can also be consulted to identify which chemicals should be tested for to validate pollutant emission capture systems are operating successfully.

2. Infrastructure owners could then pass on that requirement to CIPP contractors and/or approach credentialed testing labs to determine the cost of the activity. Specific water sampling locations and numbers of samples to be collected are listed in the specifications. Any failure to meet standards and the need for remediation at a CIPP manufacturing site should be resolved between the contractor and state environmental agency.

3. It is recommended that agencies find a thirdparty organization to conduct water testing for each CIPP manufacturing site. This organization should not be the CIPP contractor or an organization subcontracted to /paid by the CIPP contractor. This would help avoid persons collecting water samples inappropriately (which the project team observed) as well as actual or perceived conflicts of interest.

Both the state environmental agency and state transportation agency have similar interests in protecting the environment. The state environmental agency however may have greater expertise and familiarity with state water quality standards and chemical monitoring. In particular, these organizations often oversee waste discharge associated with product manufacturing companies that for waterways, air, and land. CIPPs are plastics that are manufactured onsite and outdoors. Therefore, the authors recommend that state environmental agencies should provide direction on what actions may be required for monitoring these outdoor plastic manufacturing sites. This includes both water and air monitoring as well as treatment and disposal options for air, water, and waste. 


\section{Recommended Future Work}

Additional work should be considered to better understand and limit chemical contamination caused by spray-on lining and CIPP lining activities. For the spray-on lining practice, additional testing is needed to understand what compounds are used and can be released into the environment. Water samples should be screened for a wider range of compounds than previously conducted. Samples of the uncured resin and recently manufactured lining should also be chemically extracted and analyzed.

For the CIPP lining practice, chemical extraction of new liners according to NYSDOT's requirement and making those results available would help other agencies understand what chemicals are used, created, and remain in the CIPP after installation. Additional studies should (a) Document a more complete list of chemicals generated during CIPP installation and their toxicities, (b) Determine evidence-based waste handling practices and identification of the necessary time required before placing the CIPP into service to limit chemical leaching, (c) Document chemical leaching from CIPPs over time, after facilitated curing (UV, steam, and/or hot water exposure) has occurred, with the rate of leaching examined as a function of facilitated curing time (and temperature, where appropriate), (d) Determine the necessary time required before returning each pipe to service to minimize contaminant release from the worksite and the CIPP.

Further work is needed to determine the time required for CIPP leaching to decrease after a newly manufactured composite below accepted chemical concentrations, and limits for some chemicals may differ between states. The relationship between water quality impacts caused by the CIPP after installation and chemical emission into the air during CIPP manufacture should be investigated. Development of environmental sampling methods and approaches to better characterize chemical air emissions, chemical air mixture exposures, and short- and long-term health impacts should be initiated. The role of the temperature gradient down the length of thermally cured liners liner and through the pipe wall on physical, chemical, and mechanical properties should be investigated. The sensitivity of final CIPP properties to variations in pressure, curing temperature, and exposure duration should be addressed by independent testing.

To understand worker chemical exposures and the types and masses of chemicals emitted, their phases, exposure duration, and the mixture's toxicological impacts should be investigated. Finally, organizations that contract for CIPP technology use, oversee construction, or send people near these manufacturing sites need to be aware of the human health and environmental risks associated with the installation. Also needed is awareness of the evidenced-based practices to mitigate health risks to their employees, the public, and the environment. The outdoor plastic lining manufacturing processes likely can be used without endangering human health and the environment if appropriate controls were implemented. 


\section{Table of Contents}

FOREWORD

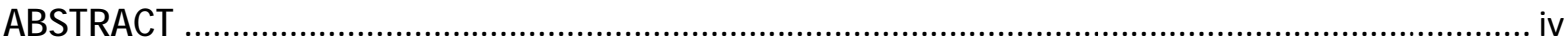

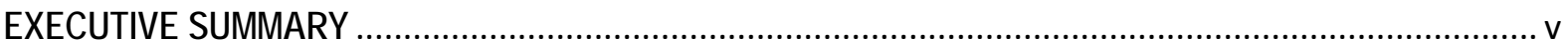

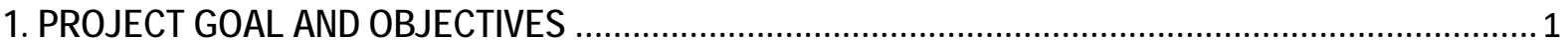

1.1 Background

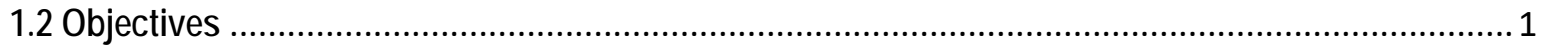

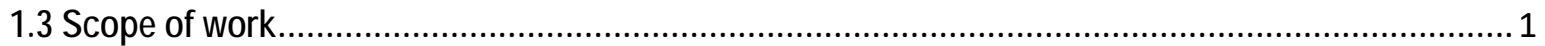

2. SPRAY-ON LINING: INCIDENTS AND TRANSPORTATION AGENCY CONSTRUCTION SPECIFICATION SURVEY

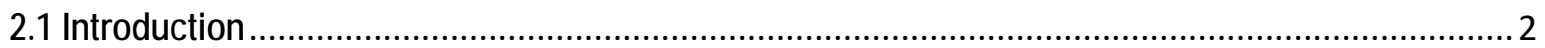

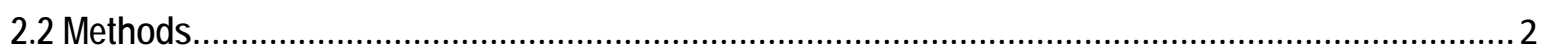

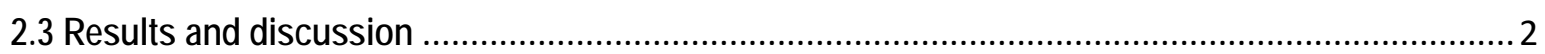

2.3.1 Water contamination incidents: Literature and media reports ........................................... 2

2.3.2 Laboratory- and field-scale studies: Water quality impacts................................................. 2

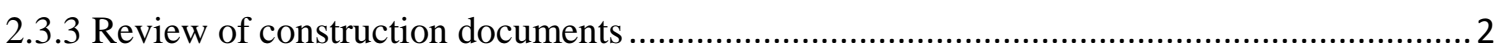

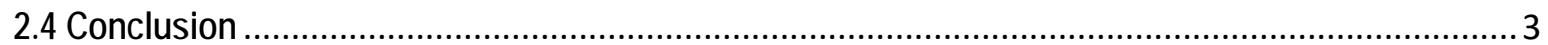

3. CIPP LININGS: INCIDENTS AND TRANSPORTATION AGENCY CONSTRUCTION SPECIFICATION

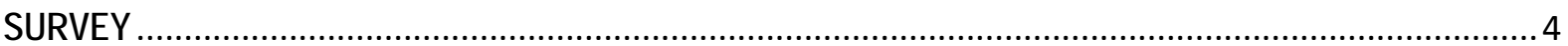

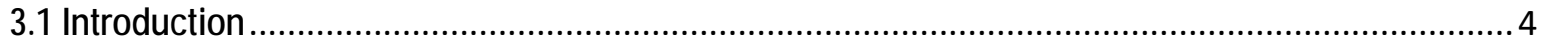

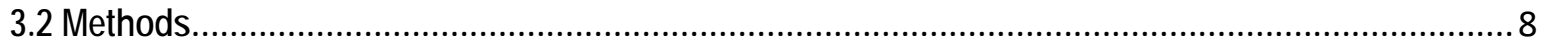

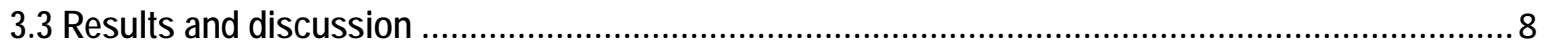

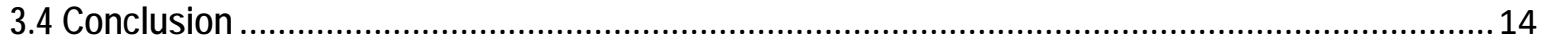

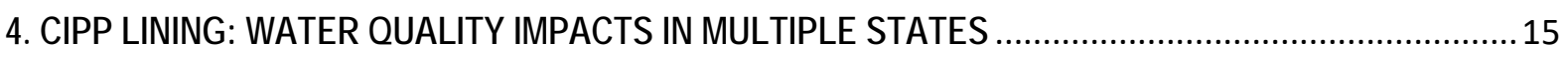

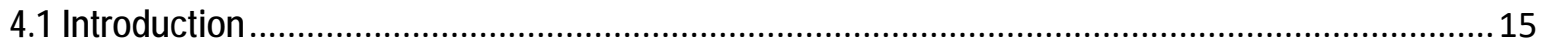

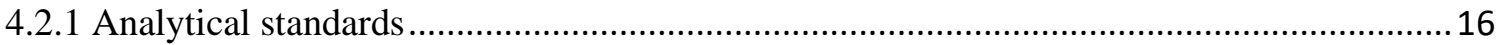

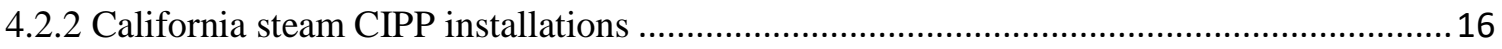

4.2.3 New York and Virginia UV CIPP installations ............................................................ 17

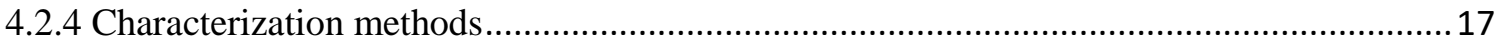

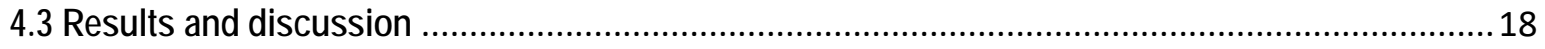

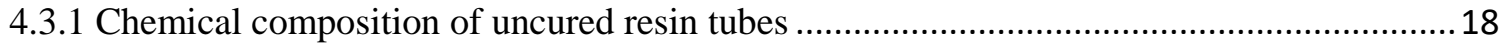

4.3.2 Chemicals extracted from the CIPPs after they were installed ............................................19

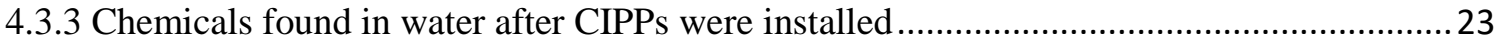




\section{LABORATORY ACCELERATED AGING AND MATERIAL INTEGRITY TESTS FOR LONGEVITY OF THERMALLY-CURED AND UV-CURED CIPPS}

5.1 Introduction .29

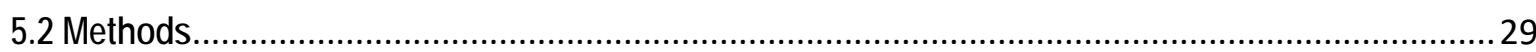

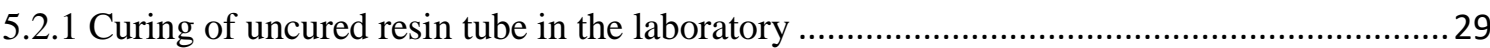

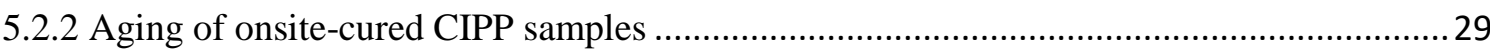

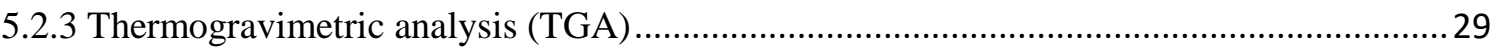

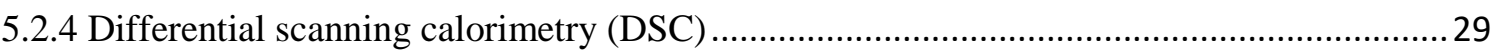

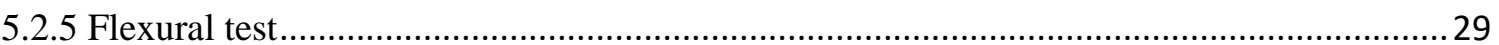

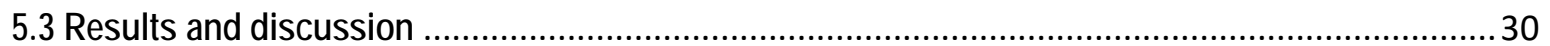

5.3.1 Physical and mechanical properties of the exhumed CIPP .................................................. 30

5.3.2 Thermal behavior: Exhumed CIPPs vs. oven cured CIPP material ....................................... 31

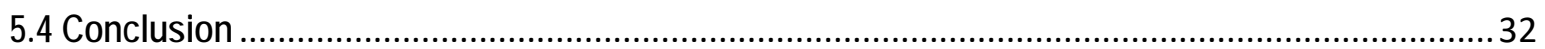

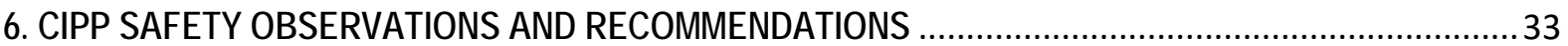

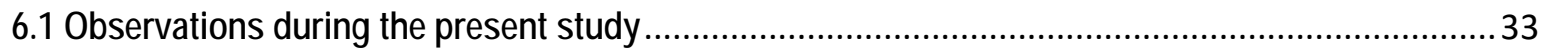

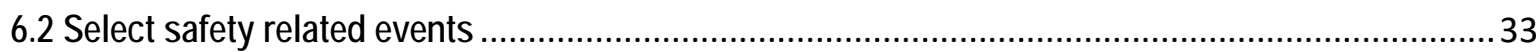

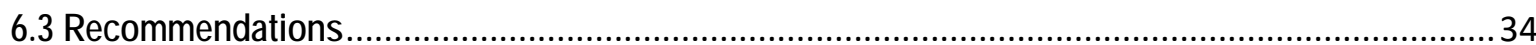

6.3.1 What is a health hazard evaluation and how do I request one?..........................................34

6.3.2 When a CIPP worker, consulting engineer, or municipal employee who visits a worksite has a health concern or safety questions, whom should they contact? .........................................35

7. CONSTRUCTION SPECIFICATION AND SPECIAL PROVISION RECOMMENDATIONS .........................36

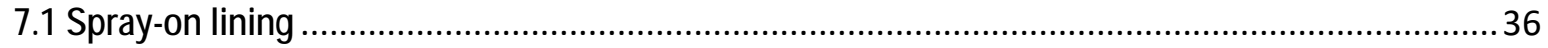

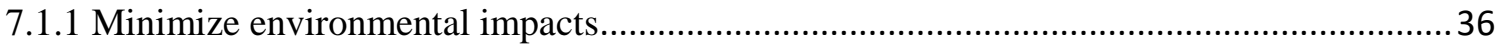

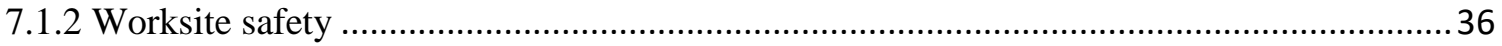

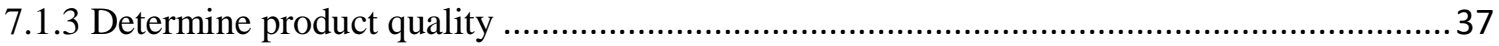

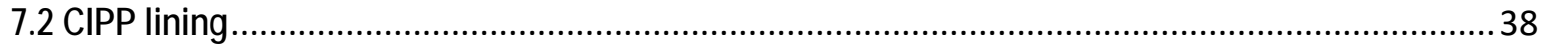

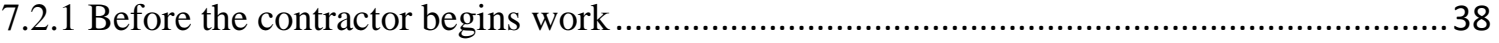

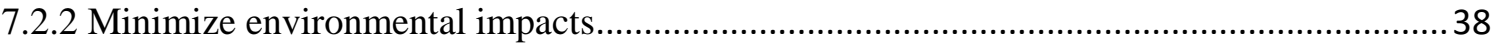

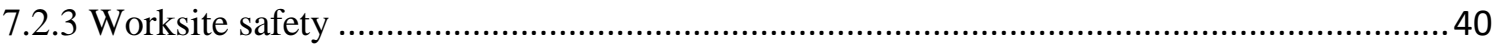

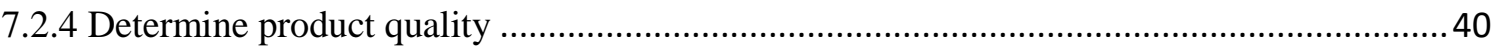

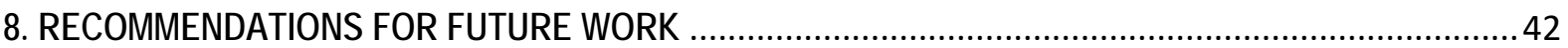

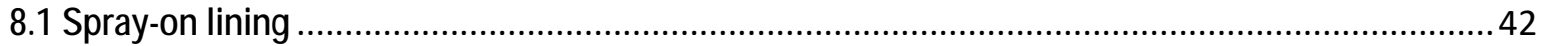

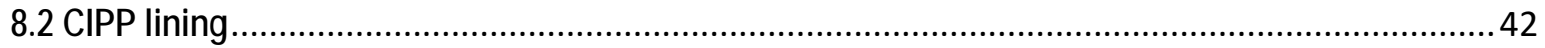

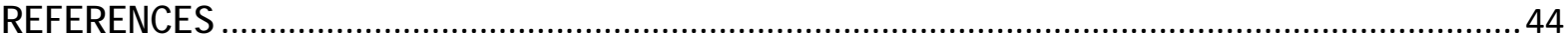


APPENDIX A. METHODS FOR CHARACTERIZING CIPPS TO DETERMINE CHEMICAL LEACHING POTENTIAL, STABILITY, AND RESIDUE CONTENT

APPENDIX B. CONFIRMED AND POSSIBLE CONTAMINATION SOURCES AT CIPP SITES. 54

APPENDIX C. LISTS OF CURRENTLY KNOWN CHEMICALS ASSOCIATED WITH CIPP USE AND STATE WATER QUALITY LIMITS 


\section{PROJECT GOAL AND OBJECTIVES}

\subsection{Background}

Storm water culverts are critical roadway safety assets which divert water from thoroughfares. In the next five years alone, more than \$3.6 trillion must be invested in U.S. transportation infrastructure. Annually, departments of transportation (DOT) install more than 12 million feet of storm water culverts and more than 1 million existing culverts require repair. Aging culverts pose several risks because unexpected failures can cause traffic disruption, environmental and property damages, and loss of life.

Aged culverts are increasingly being rehabilitated using in-situ methods, where advanced polymeric materials such as spray-on linings and cured-in-place pipe (CIPP) lining processes are created and installed in the field. CIPP is considered the most widely used trenchless pipeline rehabilitation method in the world, and has become a common method for rehabilitating storm water culverts maintained by DOTs. In-situ methods are attractive because they avoid open-trench excavation, traffic disruption, and work zone safety issues.

Culvert infrastructure owners face two major rehabilitation challenges due to the absence of data. First, studies by a subset of DOTs have discovered that during and after installation of advanced polymeric materials such as spray-on and CIPP lining processes can release chemicals of concern into the water conveyed by the culverts. Fish kills from CIPP projects have been reported in the U.S. and Canada. Numerous additional anecdotal accounts from the U.S and other countries have been reported regarding adverse effects to the environment and wastewater facilities. While several DOTs have previously moved to upgrade their specifications, the performance of individual specification construction controls remains unknown. At the time this study was initiated, DOTs did not have the information needed to select from a field-validated set of culvert rehabilitation construction controls. Moreover, DOTs could not strategically identify construction controls for culvert rehabilitation technologies that enter the marketplace in the future.

Second, infrastructure owners lack information on the degree that chemical leaching affects polymeric material long-term structural performance. Recent studies have shown some of the chemicals released into the environment by culvert rehabilitation polymeric materials are product ingredients intended to promote material strength and durability. Evidence from other polymeric material - water infrastructure applications demonstrates that polymer composition is largely responsible for material longevity. The impact of losing these compounds on the performance of culvert rehabilitation materials remains unknown.

\subsection{Objectives}

The primary project objectives were to determine the following: (1) The scope of the problem across DOTs (i.e., the extent of use of these technologies and the scale of their impacts to water quality); (2) The effectiveness of existing construction specifications at minimizing contaminant release from rehabilitated culverts; and (3) The degree to which the structural integrity and longevity of rehabilitated culverts are compromised by chemical leaching. Results of this project were intended to enable DOTs to make informed decisions with regard to culvert rehabilitation selection and specification development.

\subsection{Scope of work}

The following activities were carried-out as part of this study:

1. Survey state DOTs to determine (a) proportion of projects using technologies with polymer components (i.e., CIPP, coatings, liners, polymer-enhanced materials) and (b) document any construction specifications in place for these methods.

2. Conduct water quality testing from culvert rehabilitation sites in multiple states to determine implications to the aquatic environment and construction specifications.

3. Determine the relationship between chemical leaching, decreased liner structural integrity, and longevity through laboratory accelerated aging tests and analyses of exhumed materials from the field.

4. Use the findings to provide DOTs a final report that includes recommended construction specifications to minimize environmental impacts and maximize performance, and future research needs. 


\section{SPRAY-ON LINING: INCIDENTS AND TRANSPORTATION AGENCY CONSTRUCTION SPECIFICATION SURVEY}

\subsection{Introduction}

Spray-on linings have sometimes been used to rehabilitate storm sewer pipes and culverts. This technology involves the application of an inorganic or organic coating to the inner pipe surface. Common coatings include cement and polymer based materials such as polyurea, polyurethane, and epoxy (FHWA 2010). For cementitious linings, the aggregate, cement and water are mixed before entering the spray hose, which is then directed to the pipe wall. For polymer based coatings, the raw materials are mixed onsite and pumped through hoses to spray onto the pipe walls. Once the lining is applied, the pipe may be pressure grouted before the pipe can be used (Panofsky 2014). For polymer linings, a resin-catalyst mixture is pumped through hoses and applied. The curing method is specific to the material used and the new liner is inspected before the pipe returns to service. Spray-on linings typically cure under ambient conditions (Ellison et al. 2010). Though, chemicals can also be emitted into the air during the spray-on installation process (Donaldson \& Whelton 2012).

\subsection{Methods}

A literature review was conducted to identify available bench- and field-scale research studies pertaining to spray-on chemical emissions. Scientific databases, foundation research reports, conference proceedings, trade association literature, American Water Works Association (AWWA) and American Society of Testing and Materials (ASTM) standards, trenchless technology textbooks, and state DOT research reports were reviewed. Thirty-five state DOTs were contacted as part of this study. DOTs were identified from their prior support, participation in, or conduct of in-situ water quality impact studies, states in proximity to those states, prior publication of reports that evaluated CIPP or spray-on liner use for storm sewer culvert repair, and states where in-situ pipe lining related contamination incidents were known. Each agency was asked for a copy of their current spray-on liner (cement mortar and plastic coatings including polyurea, polyurethane and epoxy) storm sewer pipe construction specifications, and any documented special provisions for pipe rehabilitation. In addition, literature and media reports were reviewed to identify previous surface water contamination incidents associated with spray-on liner installations.

\subsection{Results and discussion}

\subsubsection{Water contamination incidents: Literature and media reports}

Neither literature or media reports were found for spray-on liner water contamination incidents. This may be due to the nature of spray-on liner construction activities and differences in environmental conditions. The less wide-spread use of spray-on technology across states contacted may also be a contributing factor.

\subsubsection{Laboratory- and field-scale studies: Water quality impacts}

Only two studies that investigated spray-on culvert liner water quality impacts were found (Donaldson \& Whelton 2012, Whelton et al. 2012). Field- and lab-scale tests were conducted using one cementitious and one polyurea spray-on liner installed for VDOT for monitoring purposes. Biochemical oxygen demand, chemical oxygen demand (COD), total organic carbon (TOC) and water $\mathrm{pH}$ levels were monitored for both materials. Specific to cementitious liner samples, metals, alkalinity, volatile organic compounds (VOCs), and semi-volatile organic compounds (SVOCs) were characterized. For the polyurea liner, diphenyl diisocyanate (MDI), methylenedianiline (MDA), total nitrogen (TN), and VOCs were characterized. No water quality impacts were detected in the field for either lining site. At the lab-scale, the same cementitious liner elevated water $\mathrm{pH}$ and alkalinity, and the same polyurea liner released chemicals that reduced water $\mathrm{pH}$ as well as increased COD, TOC, and TN levels. Based on these evaluations, VDOT created specifications for sprayon liners to reduce the potential for water quality impacts.

\subsubsection{Review of construction documents}

Among 32 states that responded to the project team's inquiries, only three states (DE, MT, VA) provided construction documents for spray-on lining methods. Two of the three states also used CIPP, while DE did not use CIPP. The most common spray-on lining methods listed were cementitious (2 states), polyurethane (1 state), epoxy (1 state), and polyurea (1 state).

VA provided the most detail regarding spray-on liner construction practices, and their special provision was similar for cementitious and polyurea lining. Curtains were required to prevent overspray, along with continuous installation monitoring and water sample collection. For cementitious lining, contractors were required to rinse the lining with water until the $\mathrm{pH}$ level was less than 9. More specific water testing was required for polyurea; water samples were to be collected within 3 feet of pipe ends before and after installation (within one week after installation), 
and samples were to be analyzed for total methylene diphenyl diisocyanate (MDI), methylenedianiline (MDA), and total cyanide. Aqueous concentrations that should not be exceeded were $1,000 \mathrm{mg} / \mathrm{L}$ for MDI and $39 \mathrm{mg} / \mathrm{L}$ for MDA in accordance with $40 \mathrm{CFR}$ Part 136. Total cyanide [Standard Method 4500], COD [EPA method 410.3], and TN [EPA method 351.2] testing were also required. VA water testing methods were based on prior field- and lab-scale studies (Donaldson \& Whelton 2012, Whelton et al. 2012). In those prior studies, cementitious lining was shown to cause $\mathrm{pH}$ and alkalinity to increase, while polyurea caused $\mathrm{pH}$ to decrease, and contributed nitrogen (TN) and carbon (TOC) compounds to the water. Neither DE nor MT required curtains to prevent overspray or required water testing.

\subsection{Conclusion}

Lab-and field-scale spray-on liner water quality impact studies found were conducted by VA. Labscale study showed cementitious and polyurea sprayon liners altered water quality differently while fieldscale study did not find water quality impacts. The cementitious liner increased water $\mathrm{pH}$ and alkalinity concentration and chemical leaching from polyurea liner decreased water $\mathrm{pH}$, and increased COD, TOC, and TN levels. Overspray was observed during both liner installations that may contaminate the nearby environment. No studies were found that examined water quality impacts caused by polyurethane and epoxy liners used for storm sewer pipes or culverts.

Three states provided information related to spray-on liner use, but only one state required water testing before and after liner installation and temporary curtains to prevent overspray. The special provision for cementitious and polyurea was similar, but the water testing required for polyurea was more specific. The other two states did not provided information regarding water quality impacts. Recommended spray-on lining specifications can be found at the end of this report. These specifications should be revised as more information becomes available from bench- and field-scale studies. 


\section{CIPP LININGS: INCIDENTS AND TRANSPORTATION AGENCY CONSTRUCTION SPECIFICATION SURVEY}

\subsection{Introduction}

CIPP is sometimes used to rehabilitate storm water culverts. The CIPP manufacturing process involves the chemical manufacture of a new plastic liner inside an existing damaged pipe (Figures 1 and 2). This in-situ process helps avoid open-trench excavation, damaged pipe replacement, and roadway shutdowns (Piratla \& Pang 2017, Morrison et al. 2013). During manufacture, a tube that contains uncured resin is inserted into the damaged host pipe or culvert. Depending on the application, the tube can contain other materials such as initiators, fillers, felt, plastic films and coatings, and reinforcements. Next, the tube is transformed into a CIPP by hot water, steam, or ultraviolet light exposure (Figure 1). This process facilitates initiator degradation and polymer chain crosslinking. Because many pipes across the United States need to be repaired, CIPP technology use is expected to increase in coming years (Stratview Research, Inc. 2017).

Because the process involves chemical manufacture of plastic outdoors, chemical release into the environment is a concern. Since 2004, 16 water contamination incidents associated with sewer CIPP installations have been documented. Incidents occurred in 13 states (AL, CA, CO, CT, FL, GA, MI, $\mathrm{MN}, \mathrm{OR}, \mathrm{PA}, \mathrm{VT}, \mathrm{WA}, \mathrm{WV})$, at an unreported location, and in Canada (Table 1) (Ra et al. 2017, Walmer 2019, PA DEP 2019a, PA DEP 2019b, Spiniello 2008). Since the publication of the Ra et al. (2017) literature review, an incident in Pennsylvania was documented which resulted in a fish kill in a nationally known trout stream (Walmer 2019, PA DEP 2019a, PA DEP 2019b). At the time this report was finalized, the Pennsylvania incident was under law enforcement and environmental investigations. A 2008 incident in West Virginia was also not reported in Ra et al. (2017), but was included in the present report (Spiniello 2008).

Most chemical contamination incidents found were attributed to contractors improperly handling materials, some involved a fish kill, drinking water contamination, others were first detected by nearby populations and prompted responses by multiple state agencies. Downstream drinking water source and system contamination has been documented associated with CIPP sewer culvert applications. CIPP manufacture can generate wastes. Wastes generated by CIPP processes have been associated with wastewater treatment plant (WWTP) upsets (Sullo 2012, Henry 2007). It was previously reported that some New York WWTPs banned the discharge of CIPP wastewater to the sanitary sewer (Whelton et al. 2013). Multiple organizations reported that CIPP wastewater could be discharged to the sanitary sewer if its styrene concentration was less than $2.1 \mathrm{mg} / \mathrm{L}$ (BWSC 2019), $2 \mathrm{mg} / \mathrm{L}$ (Loendorf \& Waters 2009) and $0.4 \mathrm{mg} / \mathrm{L}$ (MENP 2004), and even $25 \mathrm{mg} / \mathrm{L}$ (SCRIT

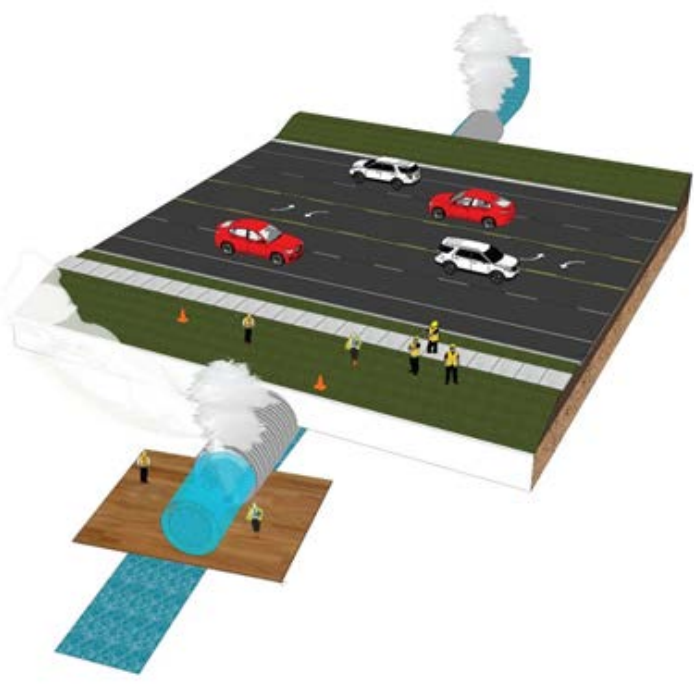

Figure 1. Generic schematic showing possible chemical emissions into the air while cured-in-place pipes (CIPP) are being installed for a storm sewer pipe. The type and magnitude of the contaminants emitted into air, water, and on land may depend on the materials used, manufacturing practices, environmental, and site conditions. 
2016). Though, no studies were found that identified the exact level that styrene would negatively impact sanitary sewer systems. Styrene is a common chemical used in the manufacture of some CIPPs, is "reasonably anticipated to be a human carcinogen" (U.S. NTP 2011), and is toxic to aquatic organisms at more than $0.072 \mathrm{mg} / \mathrm{L}$ (U.S. EPA 2006). However, styrene is not the only chemical that can be released from CIPP manufacturing sites and CIPPs. The type and magnitude of chemicals released is likely formulation dependent and influenced by manufacture and environmental conditions.

While styrene based resins are popular, nonstyrene resins also are available (Doherty et al. 2017). The potential impact of chemicals released from CIPP manufacturing sites to receiving waters has been mentioned in industry literature (NASSCO, Inc. 2009, Salem \& Najafi 2008, Najafi \& Gokhale 2004), but lacked supporting data, primarily focused on styrene, and some past incidents indicated industry assertions about contamination were incorrect ( $\mathrm{Ra}$ et al. 2017). In the past, concerns regarding CIPP caused environmental contamination prompted temporary technology bans in the Commonwealth of Virginia (Griffin 2008), State of California (CTC 2012), and Canada (CTC 2012).

To understand what chemicals can be released from CIPP storm sewer installations several field- and bench-scale studies have been conducted. Since CIPP technology entered the U.S. more than 30 years ago, less than 9 CIPP storm sewer studies were found. These have involved monitoring chemical emission at 19 steam installations, 5 hot water installations, and 4 ultraviolet (UV) light installations. In summary, most studies only focused on styrene release into water likely because it is a popular monomer, "reasonably anticipated to be” a carcinogen (U.S. NTP 2011), exhibits toxicity to aquatic life, and has a health-based drinking limit and surface water quality standard in some states. Where original testing data were reviewed, other compounds such as endocrine disrupting compounds, carcinogens, hazardous air pollutants and compounds with limited toxicological data have also been associated with CIPP manufacture for storm sewers and found in nearby waterways and soil. VOCs and SVOCs have also been found in condensate waste generated during steam-installation (Tabor et al. 2014). Air testing has also found that styrene was emitted (AirZone 2001, Ajdari 2016, Teimouri et al. 2017, NIOSH 2019; Ra et al. 2019), but other VOCs and SVOCs were emitted also during steam-installations as summarized by others (Teimouri et al. 2017, Ra et al. 2019). Chemical residual of a non-disclosed vinylic monomer used for liner manufacture was found in water in Virginia after CIPP manufacture for $30 \mathrm{~min}(76 \mathrm{mg} / \mathrm{L}), 14$ days (87 $\mathrm{mg} / \mathrm{L}$ ), 28 days (58 mg/L), $19 \mathrm{mg} / \mathrm{L}$ (60 days), and 90 days (3 mg/L) (Donaldson \& Whelton 2013). During this three month period, this contaminant exceeded the $0.4 \mathrm{mg} / \mathrm{L} 48$ hour LC 50 concentration for golden orfe fish indicating acute toxicity was possible.

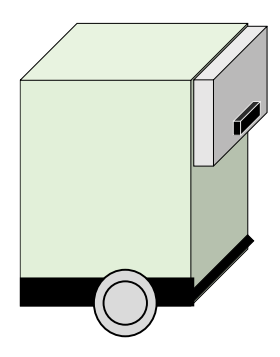

Uncured RESIN tube delivered on a truck

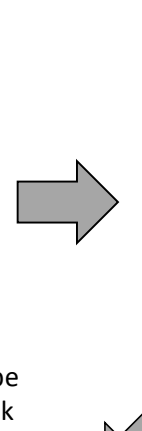

Uncured RESIN tube inserted into damaged pipe (raw chemicals)

Hard ends are cut off

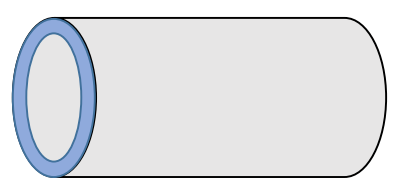

Uncured RESIN tube inflated with air inside host pipe

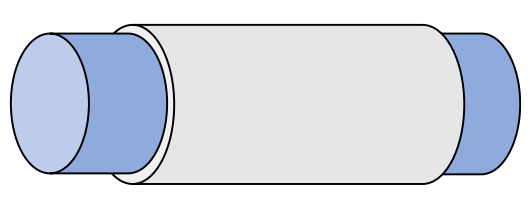

"Curing (Hardening) Method"

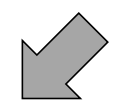

Thermal (Hot Water or Steam) or UV Light

\section{Liner allowed into service}

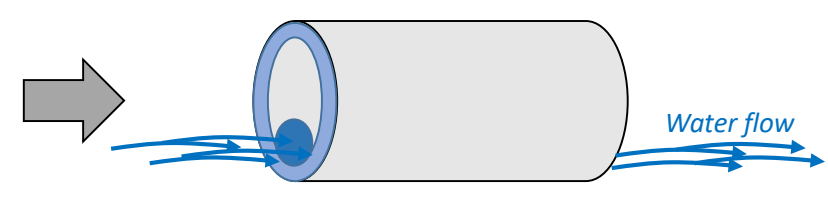

Figure 2. Schematic showing the general steps in manufacture a CIPP for a stormwater culvert 
Table 1. List of water contamination incidents associated with CIPP related to pipe repairs and sanctioned storm sewer field studies not including New York and Virginia field testing results from the present study

\begin{tabular}{|c|c|c|c|}
\hline $\begin{array}{c}\text { Location } \\
\text { (Reference) }\end{array}$ & $\begin{array}{l}\text { Activity } \\
\text { Type }\end{array}$ & Description & $\begin{array}{l}\text { Curing Process; } \\
\text { Resin Type }\end{array}$ \\
\hline $\begin{array}{l}\text { Pennsylvania } \\
\text { (Walmer 2019; PA DEP } \\
\text { 2019a; PA DEP 2019b) }\end{array}$ & Incident & $\begin{array}{l}\text { More than } 300 \text { fish killed (250+ trout) and } 75+\text { other fish; Odor of airplane glue in stream, testing initiated by the Pennsylvania Fish } \\
\text { and Boat Commission and Pennsylvania Department of Environmental Protection, investigation ongoing at the time this report was } \\
\text { complete; A maximum of } 28.7 \text { ug/L styrene was detected for the } 5 \text { samples collected; Sample water temperature approximately } \\
18^{\circ} \mathrm{C} \text {; Time of spill/initial contamination were not reported; A notice of violation (NOV) was issued to the Borough of Carlisle } \\
\text { (infrastructure owner) with pending enforcement action because this pollutant release violated state law. }\end{array}$ & $\begin{array}{l}\text { Hot water; } \\
\text { Styrene resin }\end{array}$ \\
\hline $\begin{array}{c}\text { California } \\
\text { (Currier 2017) }\end{array}$ & $\begin{array}{l}\text { Field } \\
\text { study }\end{array}$ & $\begin{array}{l}\text { Styrene was found leaching from both of styrene and non-styrene CIPPs. A low level of styrene leached from CIPP into simulated } \\
\text { storm water; water flow through the pipe should be delayed at least } 96 \text { hours after CIPP installation. Other leached chemicals such } \\
\text { as acetone, isopropyl benzene, tert-butyl alcohol, n-propyl benzene, toluene, xylenes, 1,2,4-trimethylbenzene, and 1,3,5- } \\
\text { trimethylbenzene were also found. }\end{array}$ & $\begin{array}{l}\text { Steam; } \\
\text { Styrene and non- } \\
\text { styrene resins }\end{array}$ \\
\hline $\begin{array}{l}\text { Georgia } \\
\text { (UGA 2016) }\end{array}$ & Incident & $\begin{array}{l}\text { CIPP contractors released chemicals into a waterway causing odor on university campus; Styrene and a variety of other CIPP } \\
\text { associated compounds were detected in water. }\end{array}$ & $\begin{array}{l}\text { Not reported; } \\
\text { Not reported }\end{array}$ \\
\hline $\begin{array}{c}\text { Alabama } \\
\text { (Tabor et al. 2014) }\end{array}$ & $\begin{array}{l}\text { Field } \\
\text { study }\end{array}$ & $\begin{array}{l}7.4 \mathrm{mg} / \mathrm{L} \text { styrene downstream of culvert; Condensate was from steam- CIPP (at room temperature) dissolved test organisms within } \\
24 \text { hours; A variety of non-styrene compounds were found leaching from the CIPP for } 30 \text { days; D. magna toxicity testing showed } \\
\text { non-styrene compounds were responsible for } 48 \text { hours acute toxicity }\end{array}$ & $\begin{array}{l}\text { Steam; } \\
\text { Styrene resin }\end{array}$ \\
\hline $\begin{array}{l}\text { California } \\
\text { (Renda 2013) }\end{array}$ & Incident & $\begin{array}{l}\text { Styrene leaked during CIPP repair at highway } 49 \text { sinkhole; Odor was first detected by nearby resident; Styrene leak contaminated } \\
\text { the soil and the tributary to Wolf Creek; The stream was diverted to prevent possible contamination to the Creek, and no chemicals } \\
\text { reported to be found in the Creek. }\end{array}$ & $\begin{array}{l}\text { Not reported; } \\
\text { Not reported }\end{array}$ \\
\hline $\begin{array}{c}\text { Vermont } \\
\text { (VTDEC 2013) }\end{array}$ & Incident & $\begin{array}{l}\text { Resident complained about water of Sherman Brook, highest concentration of styrene level of } 5,160 \mathrm{mg} / \mathrm{L} \text { found } 225 \mathrm{ft} \text { below the } \\
\text { culvert on the day of CIPP installation; Styrene level remained up to } 0.08 \mathrm{mg} / \mathrm{L} 70 \text { days after the installation; Acetone, } 1,2,4- \\
\text { trimethylbenzene, 1,3,4-trimethylbenzene, and tert-butanol were also detected. State DOT and Environmental Agencies responded. }\end{array}$ & $\begin{array}{l}\text { Steam; } \\
\text { Styrene resin }\end{array}$ \\
\hline $\begin{array}{c}\text { Oregon } \\
\text { (Fletcher \& Trevis 2013) }\end{array}$ & Incident & CIPP was installed in a storm water culvert using steam curing; $174 \mathrm{mg} / \mathrm{L}$ styrene was reported. & $\begin{array}{l}\text { Not reported; } \\
\text { Not reported }\end{array}$ \\
\hline $\begin{array}{l}\text { Oregon } \\
\text { (CTC 2012) }\end{array}$ & Incident & $\begin{array}{l}\text { Contractor discharged steam cured CIPP waste to the Willamette River; "Styrene levels were so high that the responder had to wear } \\
\text { a respirator to collect samples." }\end{array}$ & $\begin{array}{l}\text { Not reported; } \\
\text { Not reported }\end{array}$ \\
\hline $\begin{array}{l}\text { Colorado } \\
\text { (CDOT 2011) }\end{array}$ & Incident & $\begin{array}{l}\text { Styrene and other organic chemicals released to the Clear Creek Watershed, and passed through a drinking water intake, and } \\
\text { contaminated water was distributed to a community; The maximum styrene level of } 18 \mathrm{mg} / \mathrm{L} \text { in water was found and styrene was } \\
\text { found in soil at } 14 \mathrm{mg} / \mathrm{kg} \text {; Other compounds associated with CIPP installations were also detected. State DOT, Public Health, and } \\
\text { Environmental Agencies responded. }\end{array}$ & $\begin{array}{l}\text { Steam; } \\
\text { Styrene resin }\end{array}$ \\
\hline $\begin{array}{c}\text { Minnesota } \\
\text { (Marohn 2011) }\end{array}$ & Incident & Odor caused by the resin spill prompted building evacuations; Residual remained for five months. No water testing data were found. & $\begin{array}{l}\text { Not reported; } \\
\text { Not reported }\end{array}$ \\
\hline $\begin{array}{l}\text { Canada } \\
\text { (Ministry of Transp. } \\
\text { 2011) }\end{array}$ & Incident & Moratorium instituted; fish kill investigated due to CIPP activity; No water testing data were found. & $\begin{array}{l}\text { Not reported; } \\
\text { Not reported }\end{array}$ \\
\hline
\end{tabular}




\begin{tabular}{|c|c|c|c|}
\hline $\begin{array}{l}\text { Location } \\
\text { (Reference) }\end{array}$ & $\begin{array}{l}\text { Activity } \\
\text { Type }\end{array}$ & Description & $\begin{array}{c}\text { Curing Process; } \\
\text { Resin Type }\end{array}$ \\
\hline $\begin{array}{l}\text { Alabama } \\
\text { (NRC 2010) }\end{array}$ & Incident & $\begin{array}{l}\text { More than 70,000 gallons of CIPP wastewater dumped into creek bed along with concentrated styrene from CIPP storm water culvert } \\
\text { relining. Found } 143 \mathrm{mg} / \mathrm{L} \text { styrene in water; Residents complained drinking water from a local well had odor; Vapors originating from } \\
\text { faucets reportedly made residents ill, } 4 \mathrm{mg} / \mathrm{L} \text { styrene levels were reported at building faucets and the health-based drinking water } \\
\text { limit was } 0.1 \mathrm{mg} / \mathrm{L} \text { (EPA MCL); Incident recorded at the National Response Center; Styrene water testing results were only reported. }\end{array}$ & $\begin{array}{l}\text { Not reported; } \\
\text { Styrene resin }\end{array}$ \\
\hline $\begin{array}{l}\text { Virginia } \\
\text { (Lee 2008) }\end{array}$ & $\begin{array}{l}\text { Field } \\
\text { study }\end{array}$ & $\begin{array}{l}3 \text { CIPPs installed using water inversion, air inversion, pull-in-place and each was manufactured with either hot water, steam, or UV } \\
\text { light; Styrene was tested for and found during liner inversion }(0.004 \mathrm{mg} / \mathrm{L}) \text {, during hot water recirculation (max. } 51 \mathrm{mg} / \mathrm{L}) \text {; When the } \\
\text { new CIPPs were flushed } 19 \mathrm{mg} / \mathrm{L} \text { was found for the hot water-CIPP, } 5.5 \mathrm{mg} / \mathrm{L} \text { was found for the steam-CIPP. No styrene was reported } \\
\text { for the UV CIPP, but the method detection limit wasn't reported. }\end{array}$ & $\begin{array}{l}\text { Steam, hot water, } \\
\text { UV; Styrene resin }\end{array}$ \\
\hline $\begin{array}{c}\text { Virginia } \\
\text { (Donaldson 2009) }\end{array}$ & $\begin{array}{l}\text { Field } \\
\text { study }\end{array}$ & More than $77 \mathrm{mg} / \mathrm{L}$ styrene found in storm water after CIPP installation was completed. & $\begin{array}{c}\text { Steam; } \\
\text { Styrene resin }\end{array}$ \\
\hline $\begin{array}{c}\text { Florida } \\
\text { (Donaldson 2009) }\end{array}$ & Incident & Uncured resin was released into a storm drain during CIPP installation, and a fish kill was found. & $\begin{array}{l}\text { Not reported; } \\
\text { Not reported }\end{array}$ \\
\hline $\begin{array}{c}\text { New York } \\
\text { (O’Reilly 2008) }\end{array}$ & $\begin{array}{l}\text { Field } \\
\text { study }\end{array}$ & $\begin{array}{l}\text { Hot water was discharged into a creek and was associated with a CIPP storm sewer culvert installation; Only styrene data was reported } \\
\text { and styrene }(130 \mathrm{mg} / \mathrm{L}) \text { was detected. }\end{array}$ & $\begin{array}{l}\text { Hot water; } \\
\text { Styrene resin }\end{array}$ \\
\hline $\begin{array}{l}\text { West Virginia } \\
\text { (Spiniello 2008) }\end{array}$ & Incident & $\begin{array}{l}\text { A styrene concentration of } 117 \text { to } 446 \mathrm{mg} / \mathrm{L} \text { in cure water was found at Marmet Locks, WV. The styrene levels found in another CIPP } \\
\text { liner wastewater were } 75 \text { to } 83 \mathrm{mg} / \mathrm{L} \text {; However, "the levels were } 14 \text { hours into the cool down process which used cool water to dilute } \\
\text { the water"; "The styrene molecules present in the resin are smaller than molecules comprising the polyurethane membrane. Therefore, } \\
\text { as the liner is cured the water temperature is raised and the styrene molecules begin to migrate through the polyurethane into the cure } \\
\text { water"; "No controls are expected due to the specifications lacking the appropriate language that the contractor must follow and no } \\
\text { inspections are enforced. Specifications spell out mechanical properties and other standards they must follow but there is a lack of } \\
\text { environmental controls as in other industries using hazardous materials" }\end{array}$ & $\begin{array}{l}\text { Hot water; } \\
\text { Styrene resin }\end{array}$ \\
\hline $\begin{array}{c}\text { Unknown } \\
\text { (Lockheed Martin 2007) }\end{array}$ & Incident & $\begin{array}{l}\text { About } 11.3 \text { to } 15.1 \mathrm{~L} \text { of uncured resin was released into a storm sewer during CIPP installation; More than 5,500 fish were killed. } \\
100 \mathrm{mg} / \mathrm{L} \text { styrene detected downstream. }\end{array}$ & $\begin{array}{l}\text { Not reported; } \\
\text { Not reported }\end{array}$ \\
\hline $\begin{array}{c}\text { Canada } \\
\text { (Gerrits 2007) }\end{array}$ & Incident & $\begin{array}{l}\text { Water was discharged into nearby tributary and a fish kill found; Only styrene data were found and styrene was estimated to be present } \\
\text { in water at } 2 \text { to } 85 \mathrm{mg} / \mathrm{L} \text {. }\end{array}$ & $\begin{array}{l}\text { Not reported; } \\
\text { Not reported }\end{array}$ \\
\hline $\begin{array}{l}\text { Connecticut } \\
\text { (GESI 2004) }\end{array}$ & Incident & $\begin{array}{l}\text { Water and resin from a CIPP installation was released to from the installation site and retention pond; An estimated } 18.1 \text { to } 73.0 \mathrm{~kg} \\
\text { of wastewater was released; } 0.0291 \mathrm{mg} / \mathrm{L} \text { styrene concentration was detected in the water sample which was collected } 12 \text { days after } \\
\text { the installation. }\end{array}$ & $\begin{array}{l}\text { Not reported; } \\
\text { Not reported }\end{array}$ \\
\hline
\end{tabular}


This contaminant did not have a state water quality standard so it would not be routinely monitored or identified by reviewing state water quality code criterion. Though, aquatic toxicity data indicated it could cause environmental harm. Long-term CIPP leaching studies are lacking. Understanding chemical residual loading inside new CIPPs and differences across CIPP could help inform modeling efforts and assess the quality of CIPP manufacture.

\subsubsection{Chemicals and processes used}

Like spray-on linings, for CIPP manufacture, raw chemicals and materials are also transported to the worksite (Figure 2). Vinyl ester and polyester resins often are used for storm sewer and gravity sewer CIPPs, whereas epoxy is used for force mains because of the added strength it provides (NASSCO, Inc. 2011). The uncured resin tubes generally are constructed of felt and/or reinforcing fiber. Sometimes these fabrics have coatings (i.e., polypropylene, polyethylene, polyvinylchloride). Thermally cured materials are also often transported in refrigerated trucks, but UV-cured materials have not had this same transportation requirement. Once onsite, the uncured resin tube is set in place by applying pressurized air inside the resin tube so that it expands and contacts the inner pipe walls. Lubricants such as mineral oil, vegetable oil, and Crisco ${ }^{\circledR}$ are sometimes applied to the resin tube when it is inserted to reduce friction. For some manufacturing processes, the resin is manually inserted into the resin tube on site.

A CIPP is obtained after the tube is hardened by either thermal (hot water or steam) or UV light-curing methods (Doherty et al. 2017). Curing facilitates resin polymerization and chemical cross-linking. Curing time is dependent on the length of the pipe, the liner thickness, the resin composition, and a variety of other factors. A plastic "preliner" can be inserted into the pipe before the uncured resin tube is inserted. This preliner reportedly reduces the amount of resin that exits the tube and reduces the amount of water that enters the tube before beginning the facilitated curing process (Najafi 2010). After the contractor stops the facilitated curing process, the liner is often cooled by forcing hot air or ambient air through the tube, and the liner ends are removed. While the liner is now "solid," the total CIPP “cure time" reportedly can take six months (ATSDR 2005). Styrene-based resins such as polyester and vinyl ester are the most popular due to their low cost, but non-styrene based resins are also used (La Scala et al. 2004, Moore 2011).

Base resins can contain different monomers (i.e., styrene, bisphenol A diglycidyl ether, etc.), stabilizers (i.e., hydroquinone, Interplastic Corporation 2016), and fillers (i.e., talc, AOC 2013; crystalline silica, AOC 2013; silica colloidal amorphous, Ashland 2011; sodium metasilicate, Interflow Pty. Ltd. 2008). Because initiators present in the resin chemically react during the creation of a new CIPP, new VOCs and SVOCs can be created during the curing process (Table 2; Tabor et al. 2014, Teimouri et al. 2017, Ra et al. 2019). Phthalates are also associated with some initiators (Table 2; ICTRD 2007). Much of this information has been obtained by reviewing material SDSs, and prior composition analysis studies of uncured resin tubes or new CIPPs were not found. In the composites industry, styrene oxidation compounds have been reported to include styrene oxide, benzaldehyde, benzoic acid, 2-phenyl acetaldehyde (Noh et al. 2016). Wastewater, condensate, rinse water, and particulate can be generated during certain manufacturing processes.

\subsection{Methods}

A literature review was conducted to identify available bench- and field-scale research studies pertaining to CIPP-associated chemical emissions. Scientific databases, foundation research reports, conference proceedings, trade association literature, AWWA and ASTM standards, trenchless technology textbooks, and state transportation agency research reports were reviewed. One author completed a 1.5day CIPP construction inspector training course in 2017. Thirty-five state transportation agencies were contacted as part of this study and were not randomly selected. Agencies were identified from their prior support, participation in, or conduct of CIPP water quality impact studies. Agencies were also selected on the basis of their prior publication of reports that evaluated the feasibility of CIPP use for culvert repair. Other agencies were contacted in which CIPP-related contamination incidents occurred. Each agency was asked for a copy of its current CIPP construction specifications, and any documented special provisions for pipe rehabilitation. In addition, literature and media reports were reviewed to identify previous surface water contamination incidents associated with CIPP manufacture. The chemicals detected at prior CIPP manufacturing sites were then compared to existing water testing requirements for transportation agencies. This was conducted to determine if existing water testing practices could detect all chemicals associated with CIPP manufacturing.

\subsection{Results and discussion}

\subsubsection{Agencies contacted}

Of the total 35 state transportation agencies that were contacted, 32 responded to the project team' request for CIPP construction documentation. Of these responses, 23 agencies provided construction specifications, special provisions, or other materials related to CIPP technology use (Table 3). Some agencies volunteered addendums, bid summaries, material SDSs, and/or construction maps. 
Table 2. List of degradation products reported for some initiators used for CIPP installations

\begin{tabular}{|c|c|c|c|c|}
\hline Perkadox $^{\circledR}$ & Trigonox $^{\circledR}$ & Butanox $^{\circledR}$ & $N, N$-Dimethylaniline & Norox $^{\circledR}$ \\
\hline $\begin{array}{c}\text { Benzoic acid } \\
\text { 4-tert-Butylcyclohexanone } \\
\text { 4-tert-Butylcyclohexanol } \\
\text { Carbon dioxide } \\
\text { Biphenyl HAP } \\
\text { Phenylbenzoate } \\
\text { Tetradecanol }\end{array}$ & $\begin{array}{c}\text { Acetone } \\
\text { Acetophenone HAP } \\
\text { Benzene CAR, EDC, HAP } \\
\text { Benzoic acid } \\
\text { tert-Amyl alcohol } \\
\text { tert-Butanol } \\
\text { 3-tert-Butoxyheptane } \\
\text { tert-Butylperoxy-3,5,5,-trimethylhexanoate } \\
\text { 2-tert-Butyloxy-2,4,4-trimethylpentane } \\
\text { Carbon dioxide } \\
\text { 3-(1,1,Dimethylpropoxy) heptane } \\
\text { Ethane } \\
\text { 2-Ethylhexanoic acid } \\
\text { Heptane } \\
\text { Methane } \\
\text { 2-Phenylisopropanol } \\
\text { 3.5-Trimethvlcyclohexanone }\end{array}$ & $\begin{array}{c}\text { Acetic acid } \\
\text { Carbon dioxide } \\
\text { Formic acid } \\
\text { Propanoic acid } \\
\text { Methyl ethyl ketone CAR, HAP } \\
\text { Water }\end{array}$ & $\begin{array}{c}\text { Aniline }{ }^{\text {HAP }} \\
\text { Carbon oxide } \\
\text { Nitric oxide }{ }^{\text {HAP }}\end{array}$ & No degradation products listed \\
\hline
\end{tabular}

NOTES: CAR = Suspected or confirmed carcinogen; EDC = Endocrine disrupting compound; HAP = Hazardous air pollutant as defined by EPA; Information provided is based on a review of initiator safety data sheets found for CIPP installations. CIPPs manufactured in ambient conditions has reportedly used benzoyl peroxide initiator systems (ICTRD 2006), but decomposition products for these systems were not found in the literature search. Norox ${ }^{\circledR}$ initiators were also listed but no decomposition products were reported (United Initiators 2017). This table may not account for all initiators used or degradation products of the initiators. Information was obtained from: Akzo Nobel (2005, 2008a, 2008b, 2015, 2016), United Initiators (2015, 2017), Puritan Products (2016). 
Table 3. Comparison of CIPP construction specifications and requirements for state transportation agencies

\begin{tabular}{lc}
\hline Requirement & $\begin{array}{c}\text { Number of } \\
\text { States of } \mathbf{3 5}\end{array}$ \\
\hline No documents provided or no CIPP use & 9 \\
\hline Before construction & 4 \\
Obtain and show POTW permit to the engineer & 4 \\
Install impermeable liner up and downstream & 4 \\
$\quad$ Conduct water testing at the site & 5 \\
\hline Before reinstating flow & 4 \\
$\quad$ Rinse new liner with clean water, capture, and dispose & 2 \\
$\quad$ Prohibit return to service before a minimum unspecified period & \\
$\quad$ Prohibit return to service before a minimum period (2 or 4 days) & 10 \\
\hline General requirements & 4 \\
$\quad$ Capture and dispose of compounds, water, and condensate & 3 \\
Conduct water testing at the site & \\
Contractor is responsible for reporting any water quality alterations & \\
\hline
\end{tabular}

NOTES: POTW—-publicly owned treatment works; Some state agencies provided documents that did not specify CIPP and/or the agency indicated they did not use CIPP; one state agency did not accept CIPP point repairs; one state agency no longer permitted any CIPP technology except for ultraviolet CIPP; two state agencies described plan notes for CIPP because they did not have specifications or special provisions.

A few state agencies indicated that the materials provided to the project team originated from different offices within each state, as there were no statewide guidance documents for CIPP manufacturing activities. One state cited the Greenbook (2015) as its CIPP specification source. During document review, two different degrees of detail were found. California, Colorado, Virginia, and Vermont documents contained the greatest amount of information related to limiting water quality impacts and monitoring.

Before construction, transportation agencies in Colorado, Pennsylvania, Vermont, and Virginia explicitly required contractors to obtain and present a permit to the engineer. This permit was to indicate that a publicly owned treatment works (POTW) permitted the discharge of CIPP waste. Other states varied with regard to their specified waste-handling requirements:

$>$ Eight states did not specify requirements for waste disposal in documents provided.

$>$ Six states required contractors to "...remove and properly dispose of waste.”

$>$ Three states required that "...debris of culvert should be disposed of in accordance with state and local environmental regulations."

$>$ One state required contractors to "...follow the rules and regulations for discharge of waste."
$>$ One state required that “...a compound, process water, or condensate used during the installation or curing operation shall be contained, removed from the site and disposed of in a manner approved by the Engineer."

At the construction site, four states required the use of some type of material (i.e., liner or matting) upstream and downstream of the CIPP installation (California, Nevada, Vermont, Virginia). California had the most explicit requirements and included a plastic coating $20 \mathrm{ft}$ long and 10 mils $(250 \mu \mathrm{m})$ thick to contain resin before liner insertion. The other three states did not describe liner dimensions but required "an impermeable inner and outer plastic film or plastic pre-liner immediately prior to liner installation upstream and downstream of the site." Other states that provided construction documents did not specify the type of material. No studies were found that determined the degree to which these actions limited water quality impacts.

To determine the types of chemicals emitted into the environment from CIPP installations, four of 23 states (Colorado, Nevada, Vermont, Virginia) required water testing (Table 4). One state required the installers to "flush the new pipe until styrene residual levels were below EPA and or wastewater treatment levels," but the specific levels were not mentioned. Because water analysis requires time (typically a 1 to 14-day turnaround) and results are not available in real time, it was unclear how this specification requirement was followed. The water sampling strategies and testing methods varied across these states. A 
comparison of each agency's recommended water testing method is shown in Table 4 . VDOT required styrene testing for all styrene-based CIPP manufacturing sites and diallyl phthalate (DAP) testing for vinyl ester CIPP manufacturing sites. Vermont's Agency of Transportation (VTRANS) also required water testing, and both Vermont and Virginia specifically mentioned styrene and DAP limits that should not be exceeded: for VDOT, $2.5 \mathrm{mg} / \mathrm{L}$ styrene (U.S. EPA Method 8260) and $0.4 \mathrm{mg} / \mathrm{L}$ DAP (U.S. EPA Method 8310M); for VTRANS, $1.0 \mathrm{mg} / \mathrm{L}$ styrene (U.S. EPA Method 8260) and $0.4 \mathrm{mg} / \mathrm{L}$ DAP (method not reported). VDOT styrene and DAP limits were based on the lethal concentration $\left(\mathrm{LC}_{50}\right)$ values for the rainbow trout (Oncorhynchus mykiss) and golden orfe fish (Leuciscus idus), respectively (Donaldson \& Whelton 2012). The VTRANS styrene limit was lower than VDOT's limit because of a recommendation by the Vermont Agency of Natural Resources. The VTRANS DAP limit was adopted from a VDOT study. In addition, NYSDOT did not require water testing, but the state's allowable styrene limit would depend on the class of surface water and groundwater. The strictest maximum allowable concentration of styrene in NY is $0.005 \mathrm{mg} / \mathrm{L}$, which is the water quality standard for groundwater (NYSDEC, 2019). The maximum allowable concentration of styrene for a class A surface water in NY is $0.050 \mathrm{mg} / \mathrm{L}$.

Some compounds known to be released during CIPP manufacture (identified in bench- and field-scale studies) were not covered by the U.S. EPA test methods specified in the state documents (Table 5). As Tables 3 and 4 show, numerous compounds have been associated with CIPP water contamination. However, some compounds would not have been detected by the U.S. EPA test method used, and hence not reported, by the four states that required water testing.

Table 4. Different water testing methods required or used by state transportation agencies for CIPP installations and each method's ability to detect CIPP compounds reported in the literature

\begin{tabular}{|c|c|c|c|}
\hline \multirow{2}{*}{$\begin{array}{l}\text { Name of Compound Previously Detected } \\
\text { at a CIPP Site or Found Leaching From } \\
\text { a CIPP During a Bench-Scale Study }\end{array}$} & \multicolumn{3}{|c|}{$\begin{array}{l}\text { U.S. EPA Water Testing Method Required } \\
\text { or Used by Certain States (State) }\end{array}$} \\
\hline & $\begin{array}{l}524.2 \\
(\mathrm{CO})\end{array}$ & $\begin{array}{c}8260 \\
(\mathrm{CO}, \mathrm{VA}, \mathrm{VT})\end{array}$ & $\begin{array}{l}\text { 8021B } \\
\text { (NV) }\end{array}$ \\
\hline Acetone $^{\theta \ddagger \S \Delta \uparrow \rho}$ & $x$ & $x$ & $\cdot$ \\
\hline Benzene $^{\theta \Delta \uparrow}$ & $\mathrm{x}$ & $\mathrm{x}$ & . \\
\hline 2-Butanone (methyl ethyl ketone) & $\mathrm{x}$ & $\mathrm{x}$ & $\mathrm{x}$ \\
\hline tert-Butyl alcohol $\S$ & . & $\mathrm{x}$ & $\mathrm{x}$ \\
\hline tert-Butyl benzene $^{\rho}$ & $\mathrm{x}$ & $\mathrm{x}$ & $\mathrm{x}$ \\
\hline Chloroform $\backsim \theta \rho$ & $\mathrm{x}$ & $\mathrm{x}$ & $\mathrm{x}$ \\
\hline$o$-Chlorotoluene ${ }^{\theta}$ & $\mathrm{x}$ & $\mathrm{x}$ & $\mathrm{x}$ \\
\hline Diallyl phthalate (DAP) ${ }^{\Phi}$ & $\cdot$ & · & $\cdot$ \\
\hline Ethylbenzene ${ }^{\theta \ddagger}$ & $\mathrm{x}$ & $\mathrm{x}$ & $\mathrm{x}$ \\
\hline Isopropylbenzene $\neq \theta \S \Delta \uparrow \Psi$ & $\mathrm{x}$ & $\mathrm{x}$ & $\mathrm{x}$ \\
\hline$p$-Isopropyltoluene ${ }^{\theta}$ & $\mathrm{x}$ & $\mathrm{x}$ & $\mathrm{x}$ \\
\hline Methylene chloride $₫ \Psi$ & $\mathrm{x}$ & $\mathrm{x}$ & $\mathrm{x}$ \\
\hline$N$-Propylbenzene $\ddagger \S \Delta \uparrow \Psi$ & $\mathrm{x}$ & $\mathrm{x}$ & $\mathrm{x}$ \\
\hline Styrene $¥ \dagger \neq \S \theta q \Delta \rho *$ & $\mathrm{x}$ & $\mathrm{x}$ & $\mathrm{x}$ \\
\hline Toluene ${ }^{\theta \Delta}$ & $\mathrm{x}$ & $\mathrm{x}$ & $\mathrm{x}$ \\
\hline 1,2,4-Trimethylbenzene ${ }^{\theta \neq \S \Delta \uparrow \Psi \rho}$ & $\mathrm{x}$ & $\mathrm{x}$ & $\mathrm{x}$ \\
\hline $1,3,5$-Trimethylbenzene ${ }^{\theta \ddagger \S \Delta \uparrow \Psi \rho}$ & $\mathrm{x}$ & $\mathrm{x}$ & $\mathrm{x}$ \\
\hline Xylene (total) ${ }^{\Delta}$ & $\mathrm{x}$ & $\mathrm{x}$ & $\mathrm{x}$ \\
\hline
\end{tabular}

NOTES: $\mathrm{x}$ —detectable, $[\cdot]$ —not detectable; DAP was detectable using U.S. EPA Method 8310M specified in VDOT (2016); Compounds in table were detected by prior investigators who examined CIPP waste or water sampling; U.S. EPA 524.2 lists purgeable organic compounds, U.S. EPA 8260 lists volatile organic compounds, and U.S. EPA 8021B lists aromatic and halogenated volatiles; symbols correspond to when a compound was detected at an incident during a study: $\Delta$ Currier (2017); * Teimouri et al. (2017); $\rho$ UGA (2016); $\Phi$ VDOT (2016); ๆ Tabor et al. (2014); † Donaldson (2013); $\S$ Spectrum Analytical Inc. (2013a, 2013b, 2013c, 2013d); $\ddagger$ CDOT (2012); $\theta$ Weldon \& Morton (2011); ¥ U.S. NRC (2010); $\Psi$ Tentatively identified compounds in Tabor et al. (2014); Initiator degradation products from material safety data sheets listed in Table 1 were not used to create this table. 
Table 5. Compounds reported in the literature associated with CIPP installations that are not detectable by the U.S. EPA water testing method required or previously used by state transportation agencies

\begin{tabular}{|c|c|}
\hline Acetophenone * & ${\text { Diethyl phthalate }{ }^{\theta} \text { ब }}$ \\
\hline Acrylate monomer (undisclosed) ${ }^{\dagger}$ & Di(2-ethylhexyl) phthalate ${ }^{\theta}$ 甲 \$ \\
\hline Benzaldehyde I* $^{*}$ & 4-(1,1-Dimethyl) cyclohexanol ${ }^{\Psi}$ \\
\hline Benzoic acid ${ }^{\theta *}$ & 4-(1,1-Dimethyl) cyclohexanone ${ }^{\Psi}$ \\
\hline Benzyl alcohol ๆ & 3-Heptanol ๆ \\
\hline Butylated hydroxytoluene * & Phenol $\|^{*}$ \\
\hline 4-tert-Butylcyclohexanol * & 1-Tetradecanol * \\
\hline 4-tert-Butylcyclohexanone * & Tripropylene glycol diacrylate * \\
\hline Dibutyl phthalate ๆ \$* & Vinylic monomer (undisclosed) $^{\dagger}$ \\
\hline
\end{tabular}

NOTES: Symbols correspond to when a compound was detected at an incident during a study. Multiple monomers can be present. Initiator degradation products from material safety data sheets listed in Table 2 were not used to create this table. $\Delta$ Currier (2017); * Teimouri et al. (2017); I Tabor et al. (2014); \$ Whelton et al. (2014); † Donaldson (2013); $\theta$ Weldon and Morton (2011); § Spectrum Analytical Inc. (2013a, 2013b, 2013c, 2013d); $\Psi$ Tentatively identified compounds in Tabor et al. (2014).

Therefore, the single U.S. EPA method required or suggested for use by these four states will not result in a complete understanding of potential environmental impacts from CIPP sites. Chemicals released from CIPP installations are likely influenced by the resin composition, the applied CIPP curing and cool-down process, and possibly other parameters (i.e., environmental conditions, preliners, cutting pieces after curing, air emissions, etc.).

Some construction documents specified that the contractor must capture and dispose of CIPP wastes. Ten states explicitly mentioned the requirement to capture and dispose of wastewater. NYSDOT (2016) required contractors to utilize "a preliner bag and excavate a temporary resin control pit at the outlet 4-5 $\mathrm{m}$ long, twice the culvert diameter wide and $300 \mathrm{~mm}$ deep." The pit's purpose was to collect the 'styrene' and allow the wastewater to cool. Five states required contractors to rinse the newly installed CIPP with clean water, and then capture and dispose of the rinse water. None of the construction documents indicated from where the clean water should originate or what kind of the water to use (i.e., chlorinated drinking water, creek water, etc.). Discharge of chlorinated water to surface waters may require approval from the state or federal environmental agency in accordance with the Clean Water Act.
Some states required a certain time period before the repaired pipe was allowed to be returned to service: California (four days) and Maine (two days). Four states required that the pipe be returned to service after "a length of time to complete the cure," but the characteristics used to determine when the "cure" was complete were not defined. Unique to NYSDOT was that when the contractor uses/specifies a non-styrene resin, the non-styrene resin must contain less than $5 \%$ VOCs with less than $0.1 \%$ hazardous air pollutants (NYSDOT 2016). Also, "the resulting cured liner shall contain less than $0.1 \%$ of the water quality pollutants" listed in state code. In terms of compliance, NYSDOT approves product use if the installer and manufacturer claim their product meets these requirements. NYSDOT has not conducted independent chemical confirmation to determine if these requirements are being or have been met. NYSDOT is currently seeking the data contractors have used to certify their past claims. It is unclear whether contractors are meeting or can meet these requirements. 


\subsubsection{Standards, textbooks, and guideline documents}

Because several construction specifications cited standards related to CIPP, these standards and other related literature were reviewed. The purpose of reviewing this information was to determine whether the standards, texts, and guideline documents contained information regarding CIPP water quality impacts and waste disposal. Several ASTM documents were mentioned in construction specifications (ASTM 2017, 2016, 2012, 2011), but none contained information about water quality impacts or waste disposal. The AWWA (2014) manual for water main cleaning and lining was mentioned in ASTM sewer-related documents, but this manual did not mention water quality impacts or waste disposal. Two trenchless technology textbooks were also reviewed. These books mentioned that hazards can exist with steam condensate and with water used during the curing process, but chemical analysis data and studies were not cited (Najafi 2010, Najafi \& Gokhale 2005).

A culvert repair construction and best practices study prepared for the Minnesota Department of Transportation and two trade association documents regarding CIPP use were reviewed. Trade association documents were examined because they were cited in transportation agency reports. In the 2014 best practices document, the capture and disposal of CIPP (waste) water was recommended, but other actions implemented by some states such as upstream/downstream protection, delay in return to service, or water testing were not mentioned (Wagener \& Leagjeld 2014). Wagener and Leagjeld (2014) also recommended that states hire "NASSCO-trained construction inspectors to monitor installation and curing." According to training materials issued to CIPP construction inspector trainees in 2017 (NASSCO, Inc. 2011) and participation of one of the study authors in that course, construction inspectors were not trained on past water quality impacts, methods to detect them, or evidence-based construction practices to help avoid them. Two trade documents were also evaluated because they were referenced in reports prepared for state agencies about CIPP. The first document published by the North American Society of Trenchless Technology (NASTT) mentioned human health concerns about CIPP technology, but recommendations lacked citations necessary to understand the justification for these concerns (Doherty et al. 2017). For example, the document stated "use styrene-free resins where public waterway contamination is a concern" but did not cite evidence that indicated "styrene-free resins" would not contaminate a public waterway. A prior study found that a styrene-free resin system can contaminate water (Donaldson 2013).

A NASSCO, Inc. (2009) resin handling document cited in the NASTT document was reviewed also. This resin handling document also was issued to CIPP construction inspector trainees in 2017. It contained information about styrene levels in process water and the disposal of process water and condensate into ditches and/or waterways. Specifically, the document indicated that condensate discharge into receiving waters was acceptable if the waste contained $30 \mathrm{mg} / \mathrm{L}$ styrene or less (p. 11, paragraph 2). These statements lacked citations to chemical analysis and related toxicity data. Some questions about the representativeness of information contained in this document were previously identified by O'Reilly (2008). Table 1 of the present study shows numerous water contamination incidents have been associated with CIPP manufacture including waste discharge to waterways, the presence of multiple chemicals, and aquatic toxicity. Other than styrene, no other compounds present in CIPP wastewater or condensate were described in the NASSCO, Inc. (2009) guidance document. As mentioned previously, many VOCs and SVOCs can be present and cause aquatic toxicity. A study conducted for the Wisconsin Department of Transportation cited this document, but added that "styrene and other chemicals leach into cure water" and "wastewater should not be discharged to the environment" (Salem et al. 2008). None of the standards, textbooks, or guideline documents indicated that approval of state environmental protection officials may be required before CIPP associated chemicals could be discharged to a surface water.

The project team also reviewed a styrene resin handling document released in late 2017 that mentioned water quality impacts associated with CIPP manufacture (NASSCO, Inc. 2017). Like the NASSCO, Inc. (2009) resin handling document, content in the more recent NASSCO, Inc. (2017) document focused solely on styrene. Similar to the 2009 document, some claims about styrene levels in CIPP wastewater (i.e., $20-25 \mathrm{mg} / \mathrm{L}$ ) lacked supporting data, and publicly available data indicated styrene levels were orders of magnitude greater than 20-25 $\mathrm{mg} / \mathrm{L}$ (Table 1). For example, a CIPP company reported up to $446 \mathrm{mg} / \mathrm{L}$ styrene was in CIPP generated wastewater (Spiniello 2008). NYSDOT reported $130 \mathrm{mg} / \mathrm{L}$ styrene in a CIPP wastewater (O'Reilly 2008). One recommendation in the NASSCO, Inc. (2017) document was that steam-CIPP airflow should be maximized to minimize the amount of condensate waste generated. As hypothesized by 
Currier (2017), this practice may remove chemicals from the CIPP that may otherwise leach into water after the CIPP is placed into service. It is unknown whether this practice increases the chemical exposure risk to workers and the nearby public. General recommendations for improved worksite safety were provided, but details and/or references to support statements were not provided. Another recommendation put forward was that a permit or permission should be obtained from a local regulatory agency before CIPP wastewater is discharged to the environment. Though, clarification from state environmental agencies about organizations that permit and monitor waste discharges from CIPP manufacturing sites is needed. The authority of permitted pollutant discharges under the National Pollutant Discharge Elimination System has been delegated by the U.S. EPA to 46 states and one territory, not to local authorities (U.S. EPA 2018). The NASSCO, Inc. (2017) document did not reference all available independent peer-reviewed research pertaining to CIPP emissions.

\subsection{Conclusion}

Water contamination incidents (16) were identified that were associated with CIPP pipe rehabilitation activities in 13 states and Canada. Reported incidents generally involved the discharge of uncured resin, chemicals, or other wastes (e.g., CIPP wastewater by curing) into the local surface water. Reported incidents involved fish kills, odors, and/or drinking water supply contamination. Respiratory protection was worn to collect water samples following one incident. Water testing methods differed across incidents, and some of the analytical methods used were unable to detect the presence of some compounds known to be released during CIPP manufacture. Sometimes styrene was detected in water for weeks to several months. To better design water testing strategies, more independent testing data are needed about the chemicals that are used, created, and released during and after CIPP manufacture.

When this literature review was conducted, there was no master list of chemicals of concern for water testing because little was known about the array of chemicals used, created, and emitted during CIPP manufacture. Some state transportation agencies had identified a few compounds (Tables 3 and 4). Water testing challenges arose because of the high variability in CIPP manufacturing conditions (i.e., a CIPP installation at one site may cause different chemical releases than another installation, even when the same methods are used). As found on material SDSs and in prior field testing, new chemicals can be created during CIPP manufacture that are not listed as ingredients on safety data sheets. While waters can be analyzed for monomers like styrene, a prior study showed other non-styrene compounds (from a styrenebased CIPP) can be responsible for the observed aquatic toxicity.

CIPP construction specifications differed greatly among 32 states and nearly always water testing was not a required activity. To limit chemical release from CIPP installations into the environment, four states required the temporary installation of materials (i.e., streambed liners) upstream and downstream of the CIPP manufacturing site. However, the type and characteristics of the specific materials varied. Some states required that the pipe not be returned to service for multiple days after CIPP manufacture. Water testing before and after CIPP manufacture was required by four states. No federal or state standards, literature texts, or industry documents were found that described evidence-based practices for limiting CIPP water quality impacts, or for capturing and disposing of the waste generated as a result of CIPP manufacture. 


\section{CIPP LINING: WATER QUALITY IMPACTS IN MULTIPLE STATES}

\subsection{Introduction}

CIPP manufacturing sites in California, New York, and Virginia were visited by the project team where testing was conducted. Testing practices were developed based on the literature review and a review of construction submittals. A description of actions carried-out at each site can be found in Table 6 .

The first field effort involved contractor manufacture of CIPPs at a staged storm water culvert research site established by California State University at Sacramento (CSUS) with assistance from CALTRANS. Air monitoring was conducted at that site, and samples of the CIPPs were exhumed and characterized. CSUS evaluated storm water chemical impacts. The CIPPs that were installed included styrene- and non-styrene based resin using the steam process only. The second field effort involved traveling to storm water culvert repair sites in Syracuse, New York. Three CIPPs were installed underneath an active roadway using the UV process. The third field activity involved monitoring the manufacture of a single UV CIPP installed near Interstate-65 outside Washington, D.C. In Virginia, upstream and downstream CIPP specimens were collected from the single CIPP after manufacture.

Table 6. Comparison of project team actions at each CIPP site

\begin{tabular}{|c|c|c|c|}
\hline \multirow{2}{*}{ Site Characteristic } & \multicolumn{3}{|c|}{ Site Location } \\
\hline & California & New York & Virginia \\
\hline Number, Resin Type as described by contractor & $\begin{array}{c}4 \text { styrene / } \\
1 \text { non-styrene }\end{array}$ & 3 styrene & 1 styrene \\
\hline Process & Steam & UV & UV \\
\hline Location & $\begin{array}{l}\text { Research } \\
\text { site }\end{array}$ & $\begin{array}{l}\text { Active } \\
\text { roadway }\end{array}$ & $\begin{array}{l}\text { Active } \\
\text { roadway }\end{array}$ \\
\hline \multicolumn{4}{|l|}{ Project Team Actions } \\
\hline Obtained uncured resin tube for lab tests & Yes & Yes & No \\
\hline Water testing & ${ }^{1}$ CSUS & Yes & ${ }^{2}$ Yes \\
\hline Air testing & Yes & ${ }^{3}$ No & Yes \\
\hline $\begin{array}{l}\text { Removed upstream CIPP sample(s) and } \\
\text { characterized chemical characteristics }\end{array}$ & No & No & Yes \\
\hline $\begin{array}{l}\text { Removed downstream CIPP sample(s) and } \\
\text { characterized chemical characteristics }\end{array}$ & Yes & Yes & Yes \\
\hline $\begin{array}{l}\text { Characterized CIPP physical and/or } \\
\text { mechanical characteristics }\end{array}$ & Yes & Yes & Yes \\
\hline
\end{tabular}

NOTES: CSUS conducted water testing as part of a project funded by CALTRANS; 2 . The project team and CIPP contractor separately collected rinse water samples for analysis; 3. Air testing was not conducted in New York because the UV CIPP contractor told the project team UV CIPP did not release chemicals into the air. Credible studies about UV CIPP chemical emissions into air also were not found at the time. Once the project team was onsite, it became apparent that UV CIPP manufacture did release chemicals into the air and caused one of the team members to experience self-reported health symptoms. Air testing was conducted at the Virginia UV CIPP manufacturing site. 


\subsection{Methods}

The field- and bench-scale methods are described in the following subsections. For brevity, additional methods can be found in the peer-reviewed publications listed in the Foreword section of this report.

\subsubsection{Analytical standards}

Analytical standards for VOC and SVOC confirmation and quantification GC/MS were obtained. Additional methods information can be found in Teimouri et al. (2017), Li et al. (2019), and Ra et al. (2019).

\subsubsection{California steam CIPP installations}

\subsubsection{Conditions and sampling}

In August 2016, five CIPPs were installed in corrugated steel pipes (CSP) [pipes 1, 3, 4, 5] and a reinforced concrete pipe (RCP) [pipe 2] in Sacramento, California. The manufacturing conditions were predetermined by CSUS (Currier 2017) (Table 7). Each CIPP was manufactured using the steam curing process by the same contractor. According to contractor submittals, each CIPP was manufactured using one of two resins, and was designed with an inner layer of felt, and outer layer of $0.4318 \mathrm{~mm}$ thick thermoplastic polyurethane coating on the felt's interior (SAK 2016), as well as a polymer sealing tape on top of the outer layer. The felt contained polyethylene terephthalate polyester staple fiber. Preliners (Griffolyn ${ }^{\circledR}$ TX-1200, a 3-ply laminate, two layers of low-density polyethylene and a high-strength cord grid) were inserted into pipes 1,3 , and 4 before the uncured resin tubes were inserted. The styrenebased resin [AOC L713-LTA-12] was used for pipes $1,3,4$, and 5 . Submittal product data sheets indicated this resin contained Vipel ${ }^{\circledR}$ isophthalic based polyester resin with $0.5 \%$ Trigonox ${ }^{\circledR}$ KSM, 1\% di-(4-tert-butylcyclohexyl) peroxydicarbonate, $32.0 \%$ wt of styrene, and $20-30 \%$ wt of talc. Though, the submittal also indicated that $1 \%$ Perkadox $^{\circledR} 16$ and $0.5 \%$ Trigonox $^{\circledR}$ $C$ could be used (SAK 2016). For pipe 2, a "low VOC” non-styrene vinyl ester resin [EcoTek ${ }^{\mathrm{TM}}$ L040TNVG-33] was used and its composition was not disclosed. The uncured resin tubes had a contractor reported nominal thickness of $9 \mathrm{~mm}$, and a desired final CIPP design wall thickness of $7.62 \mathrm{~mm}$.

For both resins, a $104.4{ }^{\circ} \mathrm{C}$ minimum post cure steam temperature was recommended. The styrenebased resin product sheet recommended a 1.5 hour post cure (steam hold) time at a $54{ }^{\circ} \mathrm{C}$ minimum interface temperature or a 1 hour duration hold time at a $65{ }^{\circ} \mathrm{C}$ minimum interface temperature (AOC 2010). For the non-styrene resin, a 2.5 hour post cure time at a minimum of $54{ }^{\circ} \mathrm{C}$ was needed or a 2 hour duration at a minimum of $65^{\circ} \mathrm{C}$ (AOC 2008). Contractors designed all the CIPPs with a 1 hour recommended cure time (steam exposure), $104.4{ }^{\circ} \mathrm{C}$ post cure temperature, and $232.2{ }^{\circ} \mathrm{C}$ maximum exotherm temperature (SAK 2016). The maximum temperature capability of the felt coating was $203.9{ }^{\circ} \mathrm{C}$ (SAK 2016). The contractor recommended resin tube expansion pressure was 5.8 psi but was recorded in the field at the end of the CIPP as 5 psi for all pipes.

Samples of uncured resin tubes and CIPPs were obtained while the project team was in California. Contractors cut uncured resin tube samples to approximately $20 \mathrm{~cm} \mathrm{x} 30 \mathrm{~cm}$ panels. The project team further cut these specimens to approximately $2.54 \mathrm{~cm}^{2}$, immersed them in dichloromethane (DCM) and hexane solutions, and stored them at $4{ }^{\circ} \mathrm{C}$ until analysis. After each CIPP was installed, contractors cut CIPP pieces from the end of each pipe. Specimens were stored in bags at $4{ }^{\circ} \mathrm{C}$ until analysis.

Table 7. Manufacturing conditions

\begin{tabular}{cccccc}
\hline Pipe & $\begin{array}{c}\text { Host pipe } \\
(\mathbf{L} / \mathbf{D}-\mathbf{m} / \mathbf{c m})\end{array}$ & $\begin{array}{c}\text { Pre-liners } \\
\text { Used }\end{array}$ & $\begin{array}{c}\text { Resin } \\
\text { Type }\end{array}$ & $\begin{array}{c}\text { Steam Exposure } \\
\text { Duration, min }\end{array}$ & $\begin{array}{c}\text { Cool down Method, } \\
\text { Duration in min }\end{array}$ \\
\hline 1 & CSP (6/ 45.7) & Yes, 1 & L713 (styrene) & 92 & Ambient Air, 35 ** \\
2 & CSP (6/ 48.2) & No, 0 & $\begin{array}{c}\text { EcoTek } \\
\text { (non-styrene) }\end{array}$ & 111 & None \\
3 & CSP (6/ 45.7) & Yes, 2 & L713 (styrene) & 107 & Hot Air, $60 * *$ \\
4 & RCP (6/ 45.7) & Yes, 1 & L713 (styrene) & 100 & None \\
5 & CSP (6/ 45.7) & No, 0 & L713 (styrene) & 104 & None \\
\hline
\end{tabular}

NOTES: According to the contractor's submittal all L713-LTA (styrene-based resin) and EcoTek (non-styrene based resin); **An asterix corresponds to the contractor's reported cool down time. 


\subsubsection{New York and Virginia UV CIPP installations}

\subsubsection{Conditions and sampling}

In August 2017 workers installed CIPPs at three corrugated metal culvert sites in New York. In December 2017, a single CIPP was installed for a reinforced concrete pipe in Virginia. Before the preliner was inserted at each location, water at the culvert inlet and outlet was drained if present, and plywood was placed at the culvert inlet and outlet. This was followed by the placement of a plastic sheet to cover the plywood and the area around the culvert. When workers were handling the uncured resin tube, gloves were used. Curing was conducted by passing a UV light train through the uncured resin tube. During curing, the resin tube was physically constricted at each end, minimizing air exchange with the external environment.

At New York sites, curing time was about 12 hour and duration was not specified in the construction submittal. A $4 \times 1000 \mathrm{~W}$ light bulb UV light train was used. The wavelengths of highest intensity were between 400 and $450 \mathrm{~nm}$ and the full reported spectrum for the bulbs is presented in $\mathrm{Li}$ et al. (2019). The liner tube manufacturer recommended a light source for different diameter pipes: either a $4 \times 1000 \mathrm{~W}$ light train or $8 \times 1000 \mathrm{~W}$ double core train for a $600-800 \mathrm{~mm}$ pipe (SMG, 2012). At the VA site, the contractor stated a UV light train that contained $4 \times 2000 \mathrm{~W}$ light bulbs was used, and the UV exposure time was $76 \mathrm{~min}$. After UV exposure, the ends of the new CIPP were cut and a thin translucent film was pulled out from the inside of the pipe. Contractors wore a respirator and gloves during cutting, and sometimes disposable Tyvek ${ }^{\circledR}$ coveralls. After each CIPP was installed, a plastic hose was then used to flush chlorinated drinking water down the pipe bottom. Both contractors reported that their rinse water originated from nearby drinking water utilities that utilized free chlorine as a disinfectant residual. Additional liner tube information and CIPP measurement methods can be found in the Supplementary Material file of Li et al. (2019).

In California, water samples were collected by the CSUS. In New York, water samples were collected by the project team and a trained NYSDOT representative in New York. In Virginia, water samples were collected by the project team and separately by a CIPP contractor. Water samples from New York were analyzed at Purdue University. CIPP contractor water samples were analyzed by a commercial laboratory chosen by that contractor.

\subsubsection{Characterization methods}

\subsubsection{Dimensions, imaging, and thermogravimetry} analysis

CIPP wall thickness was measured using a Mitutoyo absolute digital caliper. The bulk density mean and standard deviation for each CIPP was calculated by using the sample mass of three replicate cubes (6 mm x 7 mm x $8 \mathrm{~mm}$ ). CIPP thermal stability, volatile content, and residue content was determined using a Q-500 from TA Instruments, Inc. (New Castle, DE). Platinum pans were used and sample weight was 10-15 mg. Samples were heated at $10{ }^{\circ} \mathrm{C} / \mathrm{min}$ to $160{ }^{\circ} \mathrm{C}$ under $\mathrm{N}_{2}$ atmosphere and held for $120 \mathrm{~min}$ to facilitate the evaporation of VOCs (i.e., styrene) and other materials. Next, samples were further heated at $10{ }^{\circ} \mathrm{C} / \mathrm{min}$ to $900{ }^{\circ} \mathrm{C}$ in air to determine thermal stability and residue content of the composite. The gas purge flow was $60 \mathrm{~mL} / \mathrm{min}$.

\subsubsection{Differential scanning calorimetry}

The degree CIPPs were cured, as indicated in this study by heat release during thermal analysis, was investigated. A Q-2000 differential scanning calorimeter (DSC) (TA Instruments Inc., DE, USA) was used along with aluminum pans. Sample weight was approximately $10 \mathrm{mg}$. Scans were performed at $10^{\circ} \mathrm{C} / \mathrm{min}$ from $-25^{\circ} \mathrm{C}$ to $200^{\circ} \mathrm{C}$. If no exotherm peak was detected, it was assumed that the samples were cured.

\subsubsection{GC/MS analysis of CIPP extracts}

To obtain specimens for DCM and hexane extraction, all CIPP samples were drilled into small curly-Q shapes. This approach enabled increased wettable surface area in contact with each solvent. Approximately $3 \mathrm{~g}$ of CIPP was added to each $20 \mathrm{~mL}$ amber glass vial with PTFE caps and stored at room temperature in the dark. After three days of soaking CIPP specimens in DCM and hexane, visual differences were observed. The DCM solution ( $\rho=$ $1.33 \mathrm{~g} / \mathrm{mL}$ ) was cloudy and had suspended particles throughout the solvent while the hexane solution ( $\rho=$ $0.655 \mathrm{~g} / \mathrm{mL}$ ) was visibly clear. To prevent solids from entering the GC/MS, before extractant dilution, solvents were filtered through a $0.2 \mu \mathrm{m}$ PTFE filter. Solvents without CIPP (controls) were also filtered through PTFE filters and analyzed by GC/MS. Three replicates were removed from each batch during each sampling period up to 28 days. Extractant was analyzed using a GC/MS-TQ8040 (Shimadzu). Control vials (solvents without CIPP) were also used. Each extract was diluted by a factor of 10 and $1.5 \mathrm{~mL}$ of sample with $1 \mathrm{mg} / \mathrm{L}$ of internal standard $(1,4-$ dichlorobenzene-d4) was added. Helium was the 
carrier gas in purge and column flow at $3.0 \mathrm{~mL} / \mathrm{min}$ and $1.5 \mathrm{~mL} / \mathrm{min}$, respectively. Samples were injected in split mode with the ratio of $1: 10$ at $280{ }^{\circ} \mathrm{C}$, and cut time for DCM was $1.8 \mathrm{~min}$ to $27.5 \mathrm{~min}$ and cut time for hexane was $2.5 \mathrm{~min}$ to $27.5 \mathrm{~min}$. Syringes were thrice rinsed with methanol between injections. Based on the GC/MS scan, compound confirmation and quantification was conducted for some compounds that had high peak area or were known or suspected to be toxic to aquatic organisms or humans. Details on methods can be found in Teimouri et al. (2017), Ra et al. (2019), and Li et al. (2019).

\subsection{Results and discussion}

\subsubsection{Chemical composition of uncured resin tubes}

Extraction of uncured resin tubes revealed multiple analytical methods were needed to identify resin components and material SDSs should not be solely relied upon for predicting chemical release as they do not list all contaminants of concern. A variety of chemicals that were not listed on the material SDS and chemicals detected were sometimes specific to the extraction solvent used. Table 8 lists chemical loading found in five felt uncured resin tubes from California (two styrene-based resins, 1 non-styrene based resin) and Table 9 describes the composition of a styrenebased resin tube from the New York site. A similarity is that styrene was detected in the styrene-based resins for both sites. For the resin tube results from California, the DCM extraction and GC/MS method identified BHT and benzaldehyde present when hexane extraction of the same resin tube did not. BHT is an antioxidant common to resins and plastics. Benzaldehyde is suspected to be a styrene degradation product based on composite industry studies (Noh et al 2016). Hexane extraction revealed that the nonstyrene based resin contained TPGDA, a monomer.

Uncured resin tubes for UV CIPP manufacturing did not contain felt, but consisted of six layers and the grey outer layer (Layer 1) was polyvinyl chloride (PVC) (Figure 3). Layer 2 was used as a bleeder, which is a porous layer used to absorb excess resin. The bleeder layer was a polyethylene terephthalate (PET) fiber cloth coated with polyethylene (PE) and polypropylene (PP). Layers 3 and 4 contained glass fiber with vinyl ester resin. Layer 5 was a PET fiber cloth also used as a bleeder, while layer 6 , the material closest to the UV light train, was PE laminated with polyamide (PA). The uncured resin tube contained more than 70 compounds. Nineteen chemicals were confirmed and quantified in dichloromethane extracts (Table 9), and 11 of those were also found in hexane extracts. Four compounds were only detected in dichloromethane extracts: 1-Dodecanol, maleic anhydride, phthalic anhydride and 1-tetradecanol. 1Dodecanol and 1-tetradecanol were only found in the PVC layer. Styrene was present in the greatest loading within layers $2-5(112,400$ to $144,400 \mathrm{mg} / \mathrm{kg})$, and in the PVC outer layer at more than 10-fold less loading $(22,200 \pm 4,500 \mathrm{mg} / \mathrm{kg})$. Results indicated that styrene had adsorbed to and/or absorbed into the PVC layer before CIPP manufacture. Dibutyl phthalate (DBP)

Table 8. Mass loading of confirmed compounds present in each uncured resin tube from California

\begin{tabular}{|c|c|c|c|c|c|}
\hline \multirow{2}{*}{$\begin{array}{l}\text { Extraction } \\
\text { Solvent, } \\
\text { Compound }\end{array}$} & \multicolumn{5}{|c|}{$\begin{array}{l}\text { CIPP Installation Site Number (resin type) } \\
\text { Compound loading (mg compound / kg resin tube) }\end{array}$} \\
\hline & $\begin{array}{c}1 \\
\text { (styrene) }\end{array}$ & $\begin{array}{c}2 \\
\text { (non-styrene) }\end{array}$ & $\begin{array}{c}3 \\
\text { (styrene) }\end{array}$ & $\begin{array}{c}4 \\
\text { (styrene) }\end{array}$ & $\begin{array}{c}5 \\
\text { (styrene) }\end{array}$ \\
\hline \multicolumn{6}{|l|}{ DCM extracts } \\
\hline Styrene & $52,850 \pm 6,720^{\mathrm{II}}$ & - & $\underset{\text { III }}{72,910 \pm 4,390}$ & $\underset{\text { III }}{66,230 \pm 7,530}$ & $\begin{array}{l}45,270 \pm 9,470 \\
\text { III }\end{array}$ \\
\hline BHT & $5,330^{I}$ & $>\mathrm{HCL}$ & $7,300^{I}$ & - & - \\
\hline $\begin{array}{l}\text { Benzaldehyde } \\
\text { Hexane extracts }\end{array}$ & $1,650^{\mathrm{I}}$ & - & $1,690 \pm 680^{\mathrm{III}}$ & - & $1,410^{\mathrm{I}}$ \\
\hline Styrene & $44,510 \pm 6,690 \mathrm{II}$ & $<\mathrm{MRL}^{\mathrm{II}}$ & $\underset{\text { III }}{61,350 \pm 5,250}$ & $\begin{array}{c}53,720 \pm 3,630 \\
\text { III }\end{array}$ & $\begin{array}{c}49,260 \pm 2,800 \\
\text { III }\end{array}$ \\
\hline TPGDA & - & $319,630 \pm 24,290^{I I I}$ & - & - & - \\
\hline
\end{tabular}

NOTES: Three replicate extractions were conducted for each uncured resin tube. Sometimes compounds were detected in some, but not all, replicates. The number of replicates where compounds were detected are denoted by the use of roman numerals: I: 1 replicate; II: 2 replicates; III: 3 replicates. Lowest concentration minimum reporting level (MRL) on calibration curve: styrene (in hexane): 1.208 ppm, styrene (in DCM): 0.241 ppm, Benzaldehyde: 20.88 ppb, BHT: 43.52 ppb, Highest concentration maximum reporting level (HCL) on calibration curve: Styrene (DCM) $=2.47$ ppm, BHT: 195.8 ppb. For the installation 1 hexane extraction, one replicate resulted in zero compounds detected. 


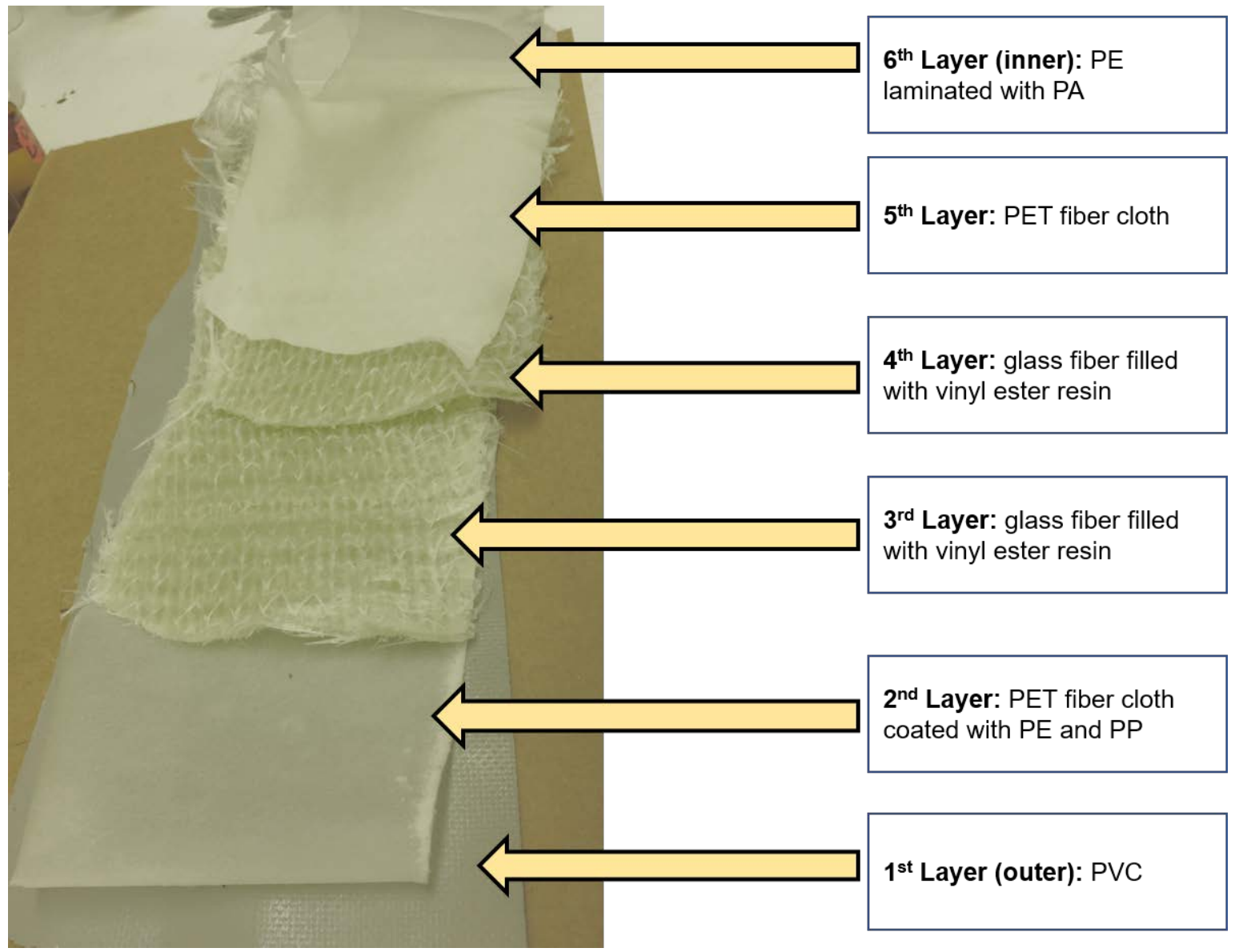

Figure 3. The uncured resin tube in New York contained six components. PA: polyamide, PE: polyethylene, PET: polyethylene terephthalate, PP: polypropylene, PVC: polyvinyl chloride.

was in greatest abundance at the PVC layer 1 but was also present at a much lower loading towards the center of the uncured resin tube. DBP is a common plasticizer, HAP, and suspected endocrine disruptor. Layer 6, the layer closest to the UV light train, generally had the lowest contaminant loading. It is unclear if chemicals penetrated through the PVC layer as this was not the intent of the testing. It is wellknown that PVC can be permeated by organic contaminants like those used in CIPP resins, but this would depend on temperature, concentration, thickness of the PVC, among other factors. When the uncured resin tube was inserted and underwent curing, some of the outer layer extended out of the host pipe and was exposed to the air.
4.3.2 Chemicals extracted from the CIPPs after they were installed

\subsubsection{CIPPs manufactured in California}

A variety of chemicals were extracted from the five CIPPs manufactured in California, but the extraction method influenced which chemicals were found. The new CIPPs contained a significant amount of volatile material, roughly $1.02-2.21 \mathrm{wt} \%$. Additional material identification details and images can be found in $\mathrm{Li}$ et al. (2019). If this result is representative of the entire $45 \mathrm{~cm}$ [18 in] diameter CIPP, a $6.1 \mathrm{~m}[20 \mathrm{ft}]$ liner could potentially contain 5$10 \mathrm{~kg}$ [11-22 lbs] of residual chemical.

${ }^{1} \mathrm{H}$ NMR spectroscopy indicated that several compounds extracted from CIPPs were also found in the uncured resin tubes (Ra et al. 2019). ${ }^{1} \mathrm{H}$ NMR spectroscopy found that styrene was extracted from pipes 1, 3, 4 and 5. These CIPPs were manufactured with an isophthalic polyester styrene resin. Styrene 
was not extracted from CIPP pipe 2; this CIPP was manufactured with a non-styrene vinyl ester resin. Instead, TPGDA was found in CIPP pipe 2 and was suspected to be an active monomer. Styrene oxidation products such as benzaldehyde and 2-phenyl acetaldehyde were also detected by ${ }^{1} \mathrm{H}$ NMR. 4-tertButylcyclohexanol, a known degradation product of the initiator Perkadox ${ }^{\circledR}$, was extracted from all CIPPs. Also, acetophenone was only found in pipe 2, the nonstyrene resin CIPP, and is a known degradation product of Trigonox ${ }^{\circledR}$. Phenol and benzaldehyde were found in all styrene-based CIPPs. Acetone, bis(tertbutylcyclohexyl) peroxydicarbonate, 1-tetradecanol, and tert-butyl peroxy-2-ethylhexanoate (initiators) were also detected in CIPPs. Similar to a styrene-based CIPP installed in an Indiana sanitary sewer, analyses in the present study also revealed the presence of styrene dimer and trimer compounds in styrene-based CIPPs, but not styrene oxide (Nuruddin et al. 2019). A multitude of chemicals were present in the CIPPs to include, but are not limited to, initiator degradation products (i.e., acetophenone, 4-tertbutylcyclohexanone, 1-tetradecanol, benzoic acid), monomers (i.e., styrene, TPDGA), an oxidation product (i.e., benzaldehyde), plasticizer (i.e., dibutyl phthalate), and a compound previously associated with CIPP water contamination incidents (i.e., phenol) (Table 10). Though, different compounds were large amount of chemical remains unidentified ( $\mathrm{Ra}$ et al. 2019).extracted from the same CIPP by different solvents and the quantity of compounds detected varied across CIPPs. Also notable was that most of the chemical mass extracted from CIPPs was not identified (69-94\%) indicating a large amount of chemical remains unidentified (Ra et al. 2019).

\subsubsection{CIPPs manufactured in New York and Virginia}

Partially cured resin, particulate, and other materials were found in the water at the manufacturing sites and had been released during the construction activity (Figure 4). In addition, dust created during CIPP cutting was found to contain significant amounts of chemical residual (Figure 5). A "pinch" of CIPP dust (100 mg) leached $16 \mathrm{mg} / \mathrm{L}$ styrene into $40 \mathrm{~mL}$ laboratory prepared water within 48 hours. It is unknown if greater levels would have occurred if the static leaching experiment was not halted after 24 hours. Particulate is a common byproduct generated at steam, hot water, and UV CIPP manufacturing sites. CIPP dust also contained other chemicals subsequently identified in CIPPs (next paragraph). When CIPP dust was placed into laboratory prepared water, some of the particulate settled and others particulate remained suspended. These results indicated CIPP dust is likely a significant contributor of pollution. Because these materials could settle in waterways, they may also be a source of continued chemical release into the environment away from the CIPP itself.

Both NY CIPPs (1.0-1.7 wt\%) and VA CIPPs (5.5-6.8 wt\%) lost a significant amount of weight due to volatile compound emission at $120^{\circ} \mathrm{C}$, and even a greater amount at $160^{\circ} \mathrm{C}(9.2 \mathrm{wt} \%)$. The variation in volatile compound emission may be due to manufacturing protocols and differences in the starting material vendor specific formulations. For NY CIPPs, chemical extractions revealed more than 30 compounds. Dichloromethane extraction results showed that 14 of 19 compounds in the NY uncured resin tube were also present in the NY CIPPs (Table 11). Similar chemical loading was found for $\mathrm{NY}$ CIPPs during 49-day extractions using dichloromethane and hexane extractions. Five compounds in the NY uncured resin tube that were not found in the CIPPs included BADGE, DBP, 1dodecanol, maleic anhydride, and 1-tetradecanol. For dichloromethane extracts, generally, the chemical mass loading in the order of higher loading to lower loading includes: Styrene $>$ Irgacure $^{\circledR} \quad 184>$ benzaldehyde $>$ styrene oxide $>1,2,4$ TMB $>$ decane $>$ phthalic $\quad$ anhydride $>N-$ propylbenzene $\quad>\quad 1,3,5-$ TMB $>$ isopropylbenzene $\sim$ xylenes $>$ BHT $>1,2,3-$ TMB $>$ ethylbenzene. DBP, 1-dodecanol, and 1tetradecanol were not found in the CIPP extracts, but CIPP samples provided to the project team did not include the PVC layer. Styrene and Irgacure ${ }^{\circledR} 184$ were the most abundant compounds in CIPPs, but the CIPPs contained less styrene (94-98\%), Irgacure ${ }^{\circledR} 184$ (81-83\%), phthalic anhydride (67-100\%), and BHT (80-82\%). The mass loading of some chemicals was unchanged (e.g., decane, ethylbenzene, isopropylbenzene, $N$-propylbenzene and xylenes). A greater styrene oxide loading was found in New York site 2 and 3 CIPPs (59\% and 71\%, respectively) compared to the uncured resin tube. Reasons for the chemical loading variations in the exhumed CIPPs were not determined as this was not the intent of the effort. This may be due to different resin loadings in the CIPPs, different curing conditions, among other factors. 
Table 9. Mass loading of confirmed compounds for an uncured resin tube obtained at the New York Site 2

\begin{tabular}{|c|c|c|c|c|c|c|c|}
\hline \multirow{2}{*}{ Compound } & \multicolumn{7}{|c|}{ Compound loading (mg compound / kg uncured resin tube layer) } \\
\hline & Whole & $1^{\text {st }}(\mathrm{PVC})$ & $2^{\text {nd }}$ & $3^{\text {rd }}$ & 4th & $5^{\text {th }}$ & 6th \\
\hline BADGE $^{\circ}$ & $1,110 \pm 40$ & - & $1,730 \pm 175$ & $1,010 \pm 70$ & $1,010 \pm 60$ & $2,610 \pm 30$ & - \\
\hline Benzaldehyde & $130 \pm 11.0$ & - & $295 \pm 28.0$ & $195 \pm 11$ & $89 \pm 6.0$ & $253 \pm 12$ & - \\
\hline BHT & $86 \pm 4.0$ & - & $162 \pm 4.0$ & $69 \pm 2.0$ & $92 \pm 3.0$ & $237 \pm 6.0$ & $44 \pm 2.0$ \\
\hline DBP EDC, HAP & $388 \pm 60$ & $7,700 \pm 380$ & $62 \pm 17.0$ & $30 \pm 3.0$ & - & $18 \pm 2.0$ & $41 \pm 4.0$ \\
\hline Decane & $60 \pm 5.0$ & - & $109 \pm 6.0$ & $62 \pm 2.0$ & $68 \pm 5.0$ & $74 \pm 4.0$ & $34 \pm 3.0$ \\
\hline 1-Dodecanol & $156 \pm 15$ & $743 \pm 96$ & - & - & - & - & - \\
\hline Ethylbenzene HAP & $5.0 \pm 0.0$ & - & $8.0 \pm 1.0$ & $8.0 \pm 1.0$ & $7.0 \pm 1.0$ & $8.0 \pm 2.0$ & $3.0 \pm 5.0$ \\
\hline Irgacure $^{\circledR} 184^{\text {PI }}$ & $2,270 \pm 80$ & - & $4,330 \pm 150$ & $2,290 \pm 30$ & $2,160 \pm 120$ & $6,090 \pm 96$ & $936 \pm 72$ \\
\hline Isopropylbenzene CAR, HAP & $21 \pm 1.0$ & - & $31 \pm 2.0$ & $24 \pm 1.0$ & $26 \pm 2.0$ & $33 \pm 1.0$ & - \\
\hline Melaic anhydride HAP, M & $280 \pm 2.0$ & - & $550 \pm 40$ & $273 \pm 40$ & $314 \pm 13$ & $811 \pm 42$ & $94 \pm 3.0$ \\
\hline Phthalic anhydride HAP, M & $124 \pm 12$ & - & $274 \pm 36$ & $175 \pm 21$ & $176 \pm 17$ & $402 \pm 0.0$ & - \\
\hline$N$-Propylbenzene & $40 \pm 2.0$ & - & $58 \pm 3.0$ & $42 \pm 1.0$ & $46 \pm 4.0$ & $57 \pm 3.0$ & $6.0 \pm 2.0$ \\
\hline Styrene oxide ${ }^{\text {CAR, HAP }}$ & $56 \pm 6.0$ & - & $60 \pm 1.0$ & $138 \pm 10$ & $47 \pm 3.0$ & $63 \pm 5.0$ & - \\
\hline Styrene CAR, HAP, M & $107,900 \pm 12,400$ & $22,240 \pm 4,500$ & $144,362 \pm 10,135$ & $112,400 \pm 4,250$ & $134,000 \pm 8,900$ & $124,970 \pm 2,600$ & $10,400 \pm 3,310$ \\
\hline 1-Tetradecanol & $98 \pm 12$ & $988 \pm 180$ & - & - & - & - & - \\
\hline 1,2,3-TMB & $19 \pm 1.0$ & - & $32 \pm 1.0$ & $18 \pm 0.0$ & $19 \pm 0.0$ & $38 \pm 2.0$ & $1.0 \pm 2.0$ \\
\hline 1,2,4-TMB & $113 \pm 3.0$ & - & $175 \pm 9.0$ & $105 \pm 3.0$ & $115 \pm 4.0$ & $186 \pm 5.0$ & $11 \pm 5.0$ \\
\hline 1,3,5-TMB & $36 \pm 1.0$ & - & $52 \pm 2.0$ & $53 \pm 3.0$ & $38 \pm 1.0$ & $56 \pm 2.0$ & $4.0 \pm 1.0$ \\
\hline Xylenes HAP & $15 \pm 1.0$ & - & $22 \pm 1.0$ & $20 \pm 0.0$ & $21 \pm 2.0$ & $22 \pm 1.0$ & $7.0 \pm 10$ \\
\hline 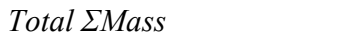 & 112,907 & 31,671 & 152,312 & 116,912 & 138,228 & 135,928 & 1 \\
\hline
\end{tabular}

NOTES: Results shown represent dichloromethane extraction. Hexane extraction results can be found in Li et al. (2019). The resin tube sample was obtained after the resin tube for CIPP installation was inserted at NY site 2. More than 70 compounds were present in the uncured resin tube, and 19 compounds were confirmed in the present study. Three replicates were used for each extraction, mean and standard deviation values shown; Compounds that were not found above the calibration limit were considered as zero in calculation; CAR = suspected or confirmed carcinogen; EDC = suspected or confirmed endocrine disrupting compound; HAP= hazardous air pollutant; $\mathrm{M}=$ suspected monomer; $\mathrm{O}=$ suspected oligomer; PI = photoinitiator; Xylenes represents $m$ - and $p$ - xylenes because these two compounds were not separated in the chromatogram, and the existence of $o$-xylene was not confirmed due to the high response of styrene. 


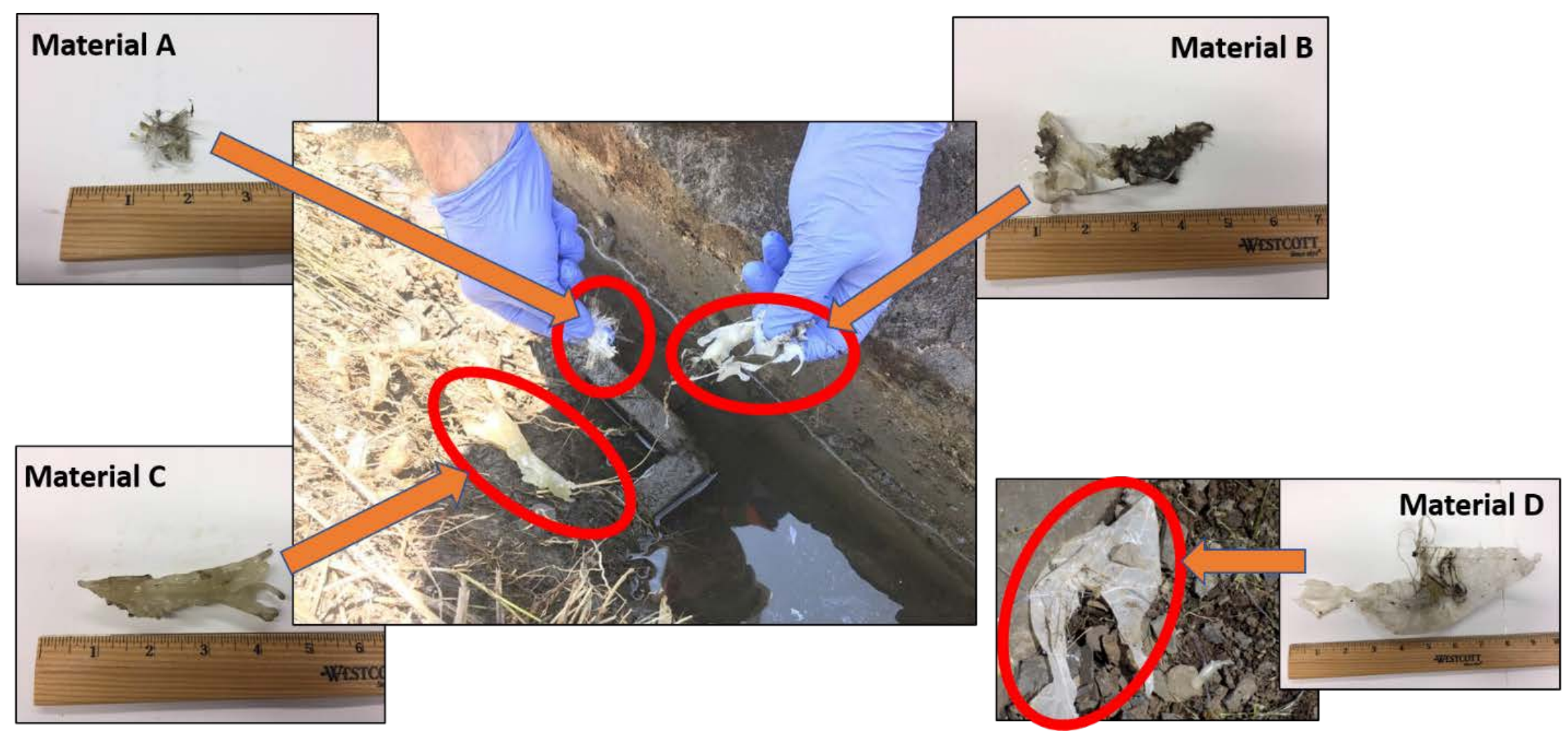

Figure 4. Materials found at NY site 2 CIPP installation were identified using optical microscopy, FTIR, and TGA. Fiber glass reinforced vinyl ester resin (material A); partially cured vinyl ester resin (materials B and C); PE laminated with PP (material D). Materials A-C were found on the culvert inlet standing water, Material $D$ was found at the culvert outlet on top of rip rap. 
Table 10. Mass loading of confirmed compounds for CIPPs from California

\begin{tabular}{|c|c|c|c|c|c|}
\hline \multirow{2}{*}{$\begin{array}{l}\text { Compound } \\
\text { Detected }\end{array}$} & \multicolumn{5}{|c|}{$\begin{array}{c}\text { Pipe [Resin Type, \# of Pre-liners Used] } \\
\text { Compound loading (mg compound/kg CIPP sample) }\end{array}$} \\
\hline & $\begin{array}{c}\text { Pipe } 1 \\
{[1]}\end{array}$ & $\begin{array}{c}\text { Pipe } 2 \\
{[0]} \\
\end{array}$ & $\begin{array}{c}\text { Pipe } 3 \\
\text { [2] } \\
\end{array}$ & $\begin{array}{c}\text { Pipe } 4 \\
\text { [1] } \\
\end{array}$ & $\begin{array}{c}\text { Pipe } 5 \\
{[0]} \\
\end{array}$ \\
\hline \multicolumn{6}{|l|}{ DCM extracts } \\
\hline Styrene ${ }^{\dagger \neq \uparrow}$ & $86 \pm 22$ & $124 \pm 165$ & $322 \pm 21$ & $562 \pm 44$ & $235 \pm 62$ \\
\hline 1-Tetradecanol & $2,140 \pm 193$ & $394 \pm 77$ & $2,200 \pm 91$ & $2,360 \pm 69$ & $2,650 \pm 133$ \\
\hline Benzaldehyde & $55 \pm 14$ & $72 \pm 60$ & $92 \pm 18$ & $242 \pm 13$ & $364 \pm 20$ \\
\hline 4-TBCH & - & $786 \pm 440$ & - & - & - \\
\hline Acetophenone ^ & - & $1,090 \pm 10$ & - & - & - \\
\hline Phenol ^ & $37 \pm 23$ & - & $37 \pm 1$ & $39 \pm 1$ & $33 \pm 3$ \\
\hline Benzoic acid & $491 \pm 113$ & $1,800 \pm 284$ & $470 \pm 80$ & $590 \pm 16$ & $828 \pm 66$ \\
\hline Total इMass & 2,809 & 4,266 & 3,121 & 3,793 & 4,110 \\
\hline \multicolumn{6}{|l|}{ Hexane extracts } \\
\hline Styrene ${ }^{\dagger \ddagger \rrbracket}$ & $75 \pm 6$ & $32 \pm 15$ & $93 \pm 5$ & $52 \pm 23$ & $62 \pm 11$ \\
\hline 1-Tetradecanol & $749 \pm 48$ & $433 \pm 285$ & $719 \pm 71$ & $817 \pm 101$ & $872 \pm 183$ \\
\hline Benzaldehyde & $14 \pm 2$ & $14 \pm 1$ & $25 \pm 2$ & $28 \pm 7$ & $94 \pm 11$ \\
\hline 4-ТВСH & - & $220 \pm 661$ & - & - & - \\
\hline Acetophenone & - & $305 \pm 7$ & - & - & - \\
\hline TPGDA & - & $565 \pm 15$ & - & - & - \\
\hline Total इMass & 838 & 1,569 & 837 & 897 & 1,028 \\
\hline
\end{tabular}

NOTES: Mass loading is reported as the mass of chemical detected per mass of CIPP sample that was analyzed. Mean and standard deviation shown; (-): compound not detected; ${ }^{\dagger}$ carcinogenic compound (US CDC 2018), ${ }^{\ddagger}$ endocrine disruptors (DEPA 2018), " HAP (US EPA 2017). Najafi et al. (2018) reported a prior study had identified different allowable styrene loadings in new CIPPs [400, 500, and $1,000 \mathrm{mg} / \mathrm{kg}$ ], but the source document could not be obtained or reviewed by the project team.

\subsubsection{Chemicals found in water after CIPPs were installed}

\subsubsection{California rinse water}

Water testing after CIPP manufacture in California was conducted by CSUS. This activity was not scoped for the pooled fund project and was conducted under separate contract funded by and managed by CALTRANS. First flush and subsequent flush samples were collected by CSUS. Chemicals that were tested for were determined by CSUS, and not all chemicals previously found released from CIPP manufacturing sites were included. Further, the steam injection and cool down processes applied by the contractor were much longer than conditions proposed in the submittal. This was documented by $\mathrm{Ra}$ et al. (2019). As a result, contractor actions may have stripped out residual chemicals so that Currier (2017) underestimated chemical release into water for typical CIPP installations. CIPP extraction results of the present study may also underestimate chemical residual in these CIPPs because of these extended steam and cool down periods.
Styrene was found in the rinse water that was exposed to the styrene-based CIPPs (1, 3, 4, and 5). Also discovered however was that styrene was found in rinse water exposed to CIPP 2, which was created with a non-styrene-based resin (Currier 2017). Further examination revealed that styrene was extracted from this CIPP 2 after installation, but was not found in the non-styrene-based uncured resin tube before installation (Teimouri et al. 2017). Therefore, the contractors likely contaminated CIPP 2 with styrene during installation. No standard equipment cleaning practices were found in the literature for CIPP contractors who use styrene and non-styrene resins that would prevent cross-contamination at different manufacturing sites. Phenol was not detected in the uncured resin tube, but was found being emitted into the air during CIPP installation and was detected in rinse water from the same CIPPs (Teimouri et al. 2017; Ra et al. 2019).

4.3.3.2 New York and Virginia rinse water, standing water, water exiting the culvert once the newly manufactured plastic was placed into service

Water samples were collected from different locations for CIPP manufacture during both New York 
and Virginia projects. In New York, water samples were collected (a) in standing water that was present at the culvert inlet and outlet, (b) rinse water added to the newly manufactured CIPP, and (c) periodic water samples collected over a 22-day period after CIPP manufacture. Rainfall was recorded by a rain gage on 9 of the 22 days after CIPP installation as described in $\mathrm{Li}$ et al. (2019). In Virginia, water samples were only collected from rinse water. The reason for the dissimilar approaches is because of differences in site characteristics and requests made by the individual transportation agencies. For example, in Virginia, there was no standing water present, so it could not be sampled. The culvert rehabilitated was dry when the contractors arrived and dry after the CIPP was manufactured. The temporal sampling conducted in New York was conducted because NYSDOT specifically asked for this approach while the project team was onsite.

All three New York installations released organic compounds into the standing water at the culvert inlet and outlet (Table 12) and had a wide range of physical chemical properties and aquatic toxicity thresholds (Table 13). Some chemicals were found in standing water before CIPPs were installed (i.e., tetrachloroethane, 1-methoxybutan-2-ol, etc.), but none were associated with CIPPs. Nine compounds found in the resin tube and CIPPs were found in water after CIPPs were installed: Benzaldehyde, DBP, Irgacure $^{\circledR}$ 184, phthalic anhydride, styrene, 1,2,3TMB, 1,2,4-TMB, 1,3,5-TMB, and xylenes. Two new compounds (acetophenone and phenol) were discovered in the water and were not detected in resin tube and CIPP. Acetophenone is a HAP and decomposition product of the photoinitiator Irgacure ${ }^{\circledR}$ 651, which was declared on the resin SDS (DSM, 2011). Another resin SDS provided by the contractors suggested the addition of a small amount of peroxide (e.g., Trigonox ${ }^{\circledR} 178$ and Trigonox $^{\circledR}$ 239) for achieving low styrene residual (Aliancys, 2015), and acetophenone is a decomposition product of these thermal initiators (Akzo Nobel, 2009, 2015g). Acetophenone was detected at one prior thermal cure CIPP site where non-styrene based resin was used, and phenol was found at two prior thermal cure CIPP sites where styrene based resins were used (Teimouri Sendesi et al. 2017). Phenol is also a HAP, but its exact source is unclear. Phthalic anhydride was only found in NY site 3 standing water, and phenol, 1,2,3-TMB, 1,2,4-TMB, 1,3,5-TMB and xylenes were only found in site 2 standing water after the CIPP was installed. The highest styrene concentration $(2.32 \mathrm{mg} / \mathrm{L})$ was found in site 2 standing water and was about 30- to 40fold higher than at the other two sites. These levels exceed some surface water quality standards for some states for some types of waters (not all), and are similar to levels found by others in nearby waters after CIPP manufacture (Tabor et al. 2014; Donaldson and Whelton 2013; Donaldson and Baker 2008). For the specific site in NY however, the CIPP discharged into a class $C$ waterway, which did not have a styrene water quality standard, unlike NY class A and NY class GA waters. The contamination discovered may be due to the partially cured resin, CIPP cutting dust, CIPP leaching, and/or cross-contamination by resin contaminated worker clothing with the water during the install (Figures 4 and 5).

VOCs and SVOCs were released from CIPPs into NY and VA rinse waters (Table 12). The truck water used for rinsing NY sites contained DBP (4.8$6.5 \mu \mathrm{g} / \mathrm{L}$ ) but did not contain any other compounds that were confirmed in either the NY uncured resin tube or in NY CIPPs. Since the truck water contained DBP, it is unclear whether CIPP leached DBP into rinse water (6.3-12.5 $\mu \mathrm{g} / \mathrm{L})$. The rinse water contained three other compounds that were also found inside the uncured resin tube (by chemical extraction) and inside the CIPPs (by chemical extraction): Benzaldehyde (12.5$68 \mu \mathrm{g} / \mathrm{L})$, Irgacure ${ }^{\circledR} 184(0-55.2 \mu \mathrm{g} / \mathrm{L})$, and styrene (3.2-446 $\mu \mathrm{g} / \mathrm{L})$. Acetophenone (3.4-10.0 $\mu \mathrm{g} / \mathrm{L})$, not present in the resin tube, was found in water after CIPP installations. Compound concentration differed across sites. Water exiting NY site 1 CIPP contained CIPP associated compounds for 22 days; the greatest styrene concentration was found 7 days after installation $(381.6 \pm 13.5 \mu \mathrm{g} / \mathrm{L})$, greater than the initial rinse water. Styrene levels also seemed to decrease with time (14 days: $68.7 \mu \mathrm{g} / \mathrm{L} ; 22$ days: $46.7 \mu \mathrm{g} / \mathrm{L})$. Benzaldehyde $(1.0-9.2 \mu \mathrm{g} / \mathrm{L})$ and DBP $(4.3-9.2 \mu \mathrm{g} / \mathrm{L})$ were also found in water exiting the culvert during the 22-day post-installation period. Few precipitation events occurred during this 22-day period, and CIPP discoloration at the outlet was observed ( $\mathrm{Li}$ et al. 2019). Chemical contamination has also been reported elsewhere at other CIPP manufacturing sites for weeks to months in sanctioned field studies (Tabor et al. 2014; Donaldson and Whelton 2013; Donaldson and Baker 2008).

In VA, the truck water did not contain any organic compounds that were extracted from the VA CIPP, and no standing water was present at either the culvert inlet or outlet. Because the CIPP contractors immersed their sampling container in the first flush rinse water, that water had to be discarded. Using new rinse water that the authors collected, the subsequent rinse water samples revealed the presence of acetophenone (1.4-2.9 $\mu \mathrm{g} / \mathrm{L})$, benzaldehyde (2.7$8.1 \mu \mathrm{g} / \mathrm{L})$, phenol $(0.5-0.6 \mu \mathrm{g} / \mathrm{L})$, and styrene $(9.5-$ $53.9 \mu \mathrm{g} / \mathrm{L})($ Table 12). 
These compounds were also found exiting NY CIPPs. CIPP contractors self-collected rinse water from the same bucket used by the project team. A copy of third party laboratory results for those waters declared that the water sample was "properly preserved and where required, on ice” and U.S. EPA method 8260C was applied (Test America, 2017). Truck water was chlorinated, and the project team do not know if the contractor added appropriate preservatives and dechlorination agents. Contractor sampling containers were immersed in the water during sample collection. The contactor's laboratory results indicated that rinse water contained acetone (5.9-6.4 $\mu \mathrm{g} / \mathrm{L})$ and 2butanone (3.2-4.3 $\mu \mathrm{g} / \mathrm{L})$ and neither compound was detected in the truck water (Test America, 2017). Neither compound was found by the project team in the truck water or rinse water, likely because the project team's GC/MS program was not designed to detect them. The contractor's styrene MRL was $5 \mu \mathrm{g} / \mathrm{L}$, but styrene was not detected. Differences between the project team results and the third-party report may be attributed to sample collection, preservation, shipping, and/or analytical methods.

Table 11. Mass loading of confirmed compounds for CIPPs from New York and Virginia sites

\begin{tabular}{|c|c|c|c|c|c|}
\hline \multirow{2}{*}{ Compound } & \multicolumn{5}{|c|}{ Compound loading (mg compound / kg CIPP sample) } \\
\hline & NY Site 1 & NY Site 2 & NY Site 3 & VA Inlet & VA Outlet \\
\hline Benzaldehyde & $67 \pm 6.0$ & $149 \pm 1.0$ & $125 \pm 21$ & $33 \pm 1.0$ & $27 \pm 1.0$ \\
\hline $\mathrm{BHT}$ & $16 \pm 1.0$ & $16 \pm 0.0$ & $15 \pm 1.0$ & $41 \pm 3.0$ & $44 \pm 1.0$ \\
\hline Decane & $50 \pm 1.0$ & $46 \pm 0.0$ & $51 \pm 3.0$ & - & - \\
\hline Ethylbenzene HAP & $6.0 \pm 0.0$ & $6.0 \pm 0.0$ & $6.0 \pm 0.0$ & $8.0 \pm 1.0$ & $8.0 \pm 0.0$ \\
\hline Irgacure $^{\circledR} 184^{\text {PI }}$ & $369 \pm 29$ & $417 \pm 16$ & $365 \pm 10$ & - & - \\
\hline Isopropylbenzene CAR, HAP & $22 \pm 1.0$ & $21 \pm 1.0$ & $23 \pm 1.0$ & $25 \pm 1.0$ & $29 \pm 1.0$ \\
\hline Phthalic anhydride ${ }^{\mathrm{HAP}, \mathrm{M}}$ & $40 \pm 4.0$ & $41 \pm 3.0$ & - & $483 \pm 99$ & $135 \pm 16$ \\
\hline$N$-Propylbenzene & $36 \pm 1.0$ & $34 \pm 0.0$ & $38 \pm 1.0$ & $15 \pm 1.0$ & $17 \pm 1.0$ \\
\hline Styrene CAR, HAP, M & $5,270 \pm 380$ & $1,310 \pm 40$ & $4,680 \pm 300$ & $16,700 \pm 700$ & $7,040 \pm 370$ \\
\hline Styrene oxide ${ }^{\text {CAR, HAP }}$ & $48 \pm 3.0$ & $95 \pm 19$ & $88 \pm 19$ & $21 \pm 1.0$ & $19 \pm 1.0$ \\
\hline 1,2,3-TMB & $12 \pm 0.0$ & $12 \pm 0.0$ & $14 \pm 1.0$ & - & - \\
\hline 1,2,4-TMB & $77 \pm 1.0$ & $75 \pm 2.0$ & $86 \pm 4.0$ & - & - \\
\hline 1,3,5-TMB & $23 \pm 0.0$ & $22 \pm 1.0$ & $26 \pm 1.0$ & $1.0 \pm 0.0$ & $1.0 \pm 0.0$ \\
\hline Xylenes HAP & $22 \pm 1.0$ & $20 \pm 1.0$ & $21 \pm 0.0$ & $17 \pm 2.0$ & $18 \pm 1.0$ \\
\hline Total $\Sigma$ Mass & 6,058 & 2,264 & 5,538 & 17,344 & 7,338 \\
\hline
\end{tabular}

NOTES: Results shown represent dichloromethane extraction. Hexane extraction results can be found in Li et al. (2019). All contaminants were found in the NY uncured resin tube; Three replicates were used for each extraction, mean and standard deviation values shown, a compound that was detected, but present at a level below MRL was considered at a concentration half of MRL; Compounds that were not found above the calibration limit were considered as zero in calculation; $\mathrm{CAR}=$ suspected or confirmed carcinogen; EDC = suspected or confirmed endocrine disrupting compound; $\mathrm{HAP}=$ hazardous air pollutant; $\mathrm{M}$ = suspected monomer; $\mathrm{PI}$ = photoinitiator; Xylenes represents $\mathrm{m}$ - and p- xylenes, because these two compounds were not separated in GC/MS chromatograph, and the existence of o-xylene was not confirmed due to the high styrene response. 
Table 12. Maximum levels of organic contaminants found in sampled waters $(\mu \mathrm{g} / \mathrm{L})$ in New York and Virginia CIPP manufacturing sites compared to the most stringent six state water quality standard

\begin{tabular}{|c|c|c|c|c|c|c|c|c|c|}
\hline \multirow[b]{2}{*}{ Compound } & \multirow{2}{*}{$\begin{array}{c}\text { Most stringent } \\
6 \text { state water } \\
\text { quality } \\
\text { standard } \\
(\mu \mathrm{g} / \mathrm{L}) \\
\end{array}$} & \multicolumn{3}{|c|}{ New York Site 1} & \multicolumn{2}{|c|}{ New York Site 2} & \multicolumn{2}{|c|}{ New York Site 3} & \multirow{2}{*}{$\begin{array}{c}\text { Virginia } \\
2^{\text {nd }} \text { Flush } \\
\text { Rinse } \\
\text { Water }\end{array}$} \\
\hline & & $\begin{array}{l}\text { Standing } \\
\text { Water }\end{array}$ & $\begin{array}{c}\mathbf{1}^{\text {st }} \text { Flush } \\
\text { Rinse } \\
\text { Water }\end{array}$ & $\begin{array}{c}22 \text { days } \\
\text { post } \\
\text { install }\end{array}$ & $\begin{array}{c}\text { Standing } \\
\text { Water }\end{array}$ & $\begin{array}{c}\mathbf{1}^{\text {st }} \text { Flush } \\
\text { Rinse } \\
\text { Water }\end{array}$ & $\begin{array}{l}\text { Standing } \\
\text { Water }\end{array}$ & $\begin{array}{c}\mathbf{1}^{\text {st }} \text { Flush } \\
\text { Rinse } \\
\text { Water }\end{array}$ & \\
\hline Acetophenone ${ }^{\mathrm{HAP}}$ & 3,500 & $7.7 \pm 1.0$ & $4.1 \pm 0.2$ & - & 3.4 & $10.0 \pm 0.2$ & $3.2 \pm 0.0$ & $3.4 \pm 0.0$ & $2.9 \pm 0.3$ \\
\hline Benzaldehyde & - & $27.0 \pm 6.7$ & $12.5 \pm 0.4$ & $\begin{array}{c}9.2 \pm \\
0.2\end{array}$ & 14.1 & $51.2 \pm 0.5$ & $\begin{array}{c}20.1 \pm \\
2.3\end{array}$ & $68.0 \pm 4.9$ & $8.1 \pm 1.0$ \\
\hline DBP EDC, HAP & 3 & $9.6 \pm 1.0$ & $6.3 \pm 0.2$ & $\begin{array}{c}9.2 \pm \\
0.2\end{array}$ & 4.8 & $7.0 \pm 0.2$ & $8.8 \pm 0.7$ & $12.5 \pm 0.0$ & - \\
\hline Irgacure $^{\circledR} 184^{\text {PI }}$ & - & - & - & - & 220.1 & $55.2 \pm 0.2$ & $\begin{array}{c}13.6 \pm \\
1.9\end{array}$ & $21.3 \pm 0.6$ & - \\
\hline Phenol HAP & 1 & - & - & - & 16.7 & - & - & - & $0.6 \pm 0.0$ \\
\hline Phthalic anhydride HAP, M & - & - & - & - & - & - & $9.5 \pm 0.1$ & - & - \\
\hline Styrene CAR, HAP, M & 5 & $50.6 \pm 0.9$ & $3.2 \pm 1.1$ & $\begin{array}{c}382 \pm \\
14\end{array}$ & $\begin{array}{c}x_{2,320} \pm \\
60\end{array}$ & $446 \pm 11.9$ & $\begin{array}{c}79.7 \pm \\
2.9\end{array}$ & $154.6 \pm 30.6$ & $53.9 \pm 9.2$ \\
\hline 1,2,3-TMB & 5 & - & - & - & $<\mathrm{MRL}$ & - & - & - & - \\
\hline 1,2,4-TMB & 5 & - & - & - & 1.3 & - & - & - & - \\
\hline 1,2,4-TMB & 5 & - & - & - & $<$ MRL & - & - & - & - \\
\hline Xylenes HAP & 5 & - & - & - & 3.1 & - & - & - & - \\
\hline
\end{tabular}

NOTES: Standing water was present under the NY culvert inlets and outlets where workers manufactured CIPPs. Rinse water was the water that rinsed through the bottom of the newly installed CIPPs from one end and exited the other end of CIPP. Before truck water was discharged into CIPPs (and it became 'rinse water'), truck water was sampled. None of the chemicals shown in the table for NY truck water were present except DBP. DBP was present in truck water at NY site $1(6.5 \pm 0.6 \mu \mathrm{g} / \mathrm{L})$, NY site $2(4.9 \pm 0.0 \mu \mathrm{g} / \mathrm{L})$ and $\mathrm{NY}$ site $3(4.8 \mu \mathrm{g} / \mathrm{L})$ and was not found in Virginia truck water. With the exception of acetophenone and phenol, all contaminants found in water were present in the NY uncured resin tube and CIPPs. CAR = suspected or confirmed carcinogen; EDC = suspected or confirmed endocrine disrupting compound; HAP= hazardous air pollutant, $\mathrm{M}=$ suspected monomer, $\mathrm{PI}=$ photoinitiator. Bold text denotes that a NY styrene surface water quality standard exceeded for a NY class A water (drinking water sources, 0.050 mg/L) and NY class GA water (groundwater, $0.005 \mathrm{mg} / \mathrm{L}$ ). These CIPPs discharged into a NY class C water, which did not have specific styrene limit. X = 48 hour LC50 aquatic toxicity threshold exceeded for algae. Toxicity thresholds for rainbow trout, fathead minnow, and D. magna were not exceeded. The most stringent surface water quality standards were from North Carolina (acetophenone), Kansas (DBP) and New York (phenol, styrene, 1,2,3-TMB and 1,2,4-TMB, xylenes). Styrene was confirmed and quantified by HS GC/MS. Other compounds were confirmed and quantified using LLE GC/MS. The results without standard deviation value indicates only one replicate was analyzed due to limited water sample available. For Virginia, rinse water represented a second rinse of the newly installed CIPP, not the first rinse because the contractors improperly handled that first flush rinse water which the authors had to discard. 
Table 13. Physiochemical properties of confirmed organic compounds found in the New York and Virginia resin tube, CIPP, particulate and water

\begin{tabular}{|c|c|c|c|c|c|c|c|c|c|c|}
\hline \multirow[b]{2}{*}{ Compounds } & \multirow[b]{2}{*}{ CAS \# } & \multicolumn{5}{|c|}{ Physical and Chemical Properties } & \multicolumn{4}{|c|}{ Aquatic Toxicity Thresholds, mg/L } \\
\hline & & MW, g/mol & $\begin{array}{c}\text { Water Sol, } \\
\mathrm{mg} / \mathrm{L} \\
\text { at } 25^{\circ} \mathrm{C} \\
\end{array}$ & $\begin{array}{c}\text { Vapor Pr, } \\
\text { mmHg } \\
\text { at } 25^{\circ} \mathrm{C} \\
\end{array}$ & $\log K_{\text {ow }}$ & $\log K_{o c}$ & $\begin{array}{l}\text { D. magna, } \\
48 \text { hr LC }\end{array}$ & $\begin{array}{c}\text { Algae, } \\
48 \mathrm{hr} \mathrm{LC}_{50}\end{array}$ & $\begin{array}{c}\text { Fathead } \\
\text { minnow, } \\
48 \text { hr LC } 50\end{array}$ & $\begin{array}{l}\text { Rainbow } \\
\text { trout, } \\
48 \text { hr LC50 }\end{array}$ \\
\hline Acetophenone & $98-86-2$ & 120.15 & 6,130 & 0.397 & 1.58 & 1.71 & $528.7^{*}$ & - & $163^{* *}$ & - \\
\hline Benzaldehyde & $100-52-7$ & 106.13 & 6,950 & 1.27 & 1.48 & 1.04 & $50^{\mathrm{a},+}$ & - & $15.8^{€}$ & $12.6^{€}$ \\
\hline BADGE & $1675-54-3$ & 340.42 & 0.7 & $1.1 \mathrm{E}-07$ & 3.84 & 3.81 & - & - & - & - \\
\hline BHT & $128-37-0$ & 220.36 & 0.6 & $5.2 \mathrm{E}-03$ & 5.10 & 4.17 & $1.44^{\mathrm{d}, \beta}$ & - & - & - \\
\hline Decane & $124-18-5$ & 142.29 & 0.052 & 1.43 & 5.01 & 3.16 & $18^{\mathrm{Z}}$ & - & - & $>1000^{\mathrm{b}, \Phi}$ \\
\hline DBP & $84-74-2$ & 278.35 & 11.2 & $2.0 \mathrm{E}-05$ & 4.50 & 3.06 & $2.99^{\mathrm{d}, \mathbb{z}}$ & $3.5^{\mathrm{d}, \#}$ & $1.49^{\S}$ & $1.60^{\mathrm{b}, ¥}$ \\
\hline 1-Dodecanol & $112-53-8$ & 186.34 & 4 & 8.5E-04 & 5.13 & 2.63 & $0.765^{\mathrm{e}, £}$ & - & $1.01^{\mathrm{b}, \Theta}$ & - \\
\hline Ethylbenzene & $100-41-4$ & 106.17 & 169 & 9.6 & 3.15 & 2.65 & $2.12^{\mathrm{T}}$ & $4.6^{\mathrm{e}, \delta}$ & - & - \\
\hline Irgacure $^{\circledR} 184$ & $947-19-3$ & 204.27 & - & - & 2.81 & 1.92 & $59.3^{\mathrm{d}, \Delta}$ & $14.4^{\mathrm{e}, \Delta}$ & - & - \\
\hline Maleic anhydride & $108-31-6$ & 98.06 & 3,700 & 0.25 & 1.62 & 1.36 & $330^{\mathrm{d}, \Pi}$ & $>150^{\mathrm{e}, \Pi}$ & & $75^{\mathrm{b}, \Pi}$ \\
\hline Isopropylbenzene & $98-82-8$ & 120.20 & 61.3 & 4.50 & 3.66 & 2.84 & $0.6^{\mathrm{T}}$ & $2.6^{\mathrm{e}, \delta}$ & - & $5.8^{\Psi}$ \\
\hline Phenol & $108-95-2$ & 94.11 & 82,800 & 0.35 & 1.46 & 2.27 & $12^{\mathrm{Z}}$ & - & $28^{\mathrm{b}, \Sigma}$ & $5.8^{2}$ \\
\hline Phthalic anhydride & $85-44-9$ & 148.12 & 6,000 & $5.2 \mathrm{E}-04$ & 1.60 & 1.00 & $>640^{\mathrm{d}, \mathrm{W}}$ & $60-350^{f, \underline{U}}$ & - & - \\
\hline$N$-Propylbenzene & $103-65-1$ & 120.20 & 52.2 & 3.42 & 3.69 & 2.91 & $2.21^{\mathrm{c}, Q}$ & $1.8^{\mathrm{e}, \delta}$ & - & - \\
\hline Styrene & $100-42-5$ & 104.15 & 300 & 6.40 & 2.95 & 2.65 & $23^{Z}$ & $0.56^{\mathrm{d}, \chi}$ & $12^{x}$ & $6.6^{\mathrm{b}, \sigma}$ \\
\hline Styrene oxide & $96-09-3$ & 120.15 & 3,000 & 0.30 & 1.61 & 2.06 & $21.6^{\rho}$ & $32^{\mathrm{f}, \lambda}$ & $4.54^{\mathrm{b}, \rho}$ & - \\
\hline 1-Tetradecanol & $112-72-1$ & 214.39 & 0.191 & $1.1 \mathrm{E}-04$ & 6.03 & 3.15 & $3.2^{\mathrm{d}, \Omega}$ & - & - & - \\
\hline 1,2,3-TMB & 526-73-8 & 120.20 & 75.2 & 1.69 & 3.66 & 2.80 & - & - & - & - \\
\hline 1,2,4-ТMB & $95-63-6$ & 120.20 & 57 & 2.10 & 3.63 & 2.79 & $3.6^{\mathrm{T}}$ & - & $7.72^{\mathrm{b}, \Gamma}$ & - \\
\hline 1,3,5-TMB & $108-67-8$ & 120.20 & 48.2 & 2.48 & 3.42 & 2.78 & $6^{\mathrm{T}}$ & $25^{\mathrm{d}, \#}$ & - & - \\
\hline m-Xylene & $108-38-3$ & 106.17 & 161 & 8.29 & 3.20 & 2.57 & $9.56^{\mathrm{T}}$ & $4.9^{\mathrm{e}, \delta}$ & - & $8.4^{\mathrm{b}, \delta}$ \\
\hline p-Xylene & $106-42-3$ & 106.17 & 162 & 8.84 & 3.15 & 2.57 & $8.49^{\mathrm{T}}$ & $3.2^{\mathrm{b}, \delta}$ & - & $2.6^{\mathrm{b}, \delta}$ \\
\hline
\end{tabular}

NOTES: a indicates 24 hour LC50, b indicates 96 hour LC50, c indicates 24 hour EC50, d indicates 48 hour EC50, e indicates 72 hour EC50, f indicates 96 hour EC50. Information was obtained from the Estimation Programs Interface (EPI) Suite ${ }^{\mathrm{TM}}$. ${ }^{*}$ Pawlisz and Peters (1995), ${ }^{* *}$ Mattson et al. (1976), ${ }^{+}$Bringmann and Kühn (1977), ${ }^{€}$ Phipps and Holcombe (1985), ${ }^{\beta}$ Passino and Smith (1987), ${ }^{\mathrm{Z}}$ Leblanc (1980), ${ }^{\Phi}$ Sigma Aldrich (2017), ${ }^{\ddagger}$ Adams et al. (1995), ${ }^{\#}$ Kühn and Pattard (1990), ${ }^{\S}$ Mayer Jr and Sanders (1973), ${ }^{£}$ Sigma Aldrich (2015), ${ }^{\ominus}$ Veith et al. (1983), ${ }^{\mathrm{T}}$ Bobra et al. (1983), ${ }^{\delta}$ Galasst et al. (1988), ${ }^{\Delta}$ Sigma Aldrich (2014), ${ }^{\Pi}$ Sigma Aldrich (2018), ${ }^{\Psi}$ Glickman et al. (1995), ${ }^{\Sigma}$ Phipps et al. (1981), ${ }^{2}$ Brown (1968), ${ }^{\prime}$ Sigma Aldrich (2017), ${ }^{Q}$ Tosato et al. (1993), $\chi$ Cushman et al. (1997), ${ }^{\sigma}$ Castaño et al. (1996), ${ }^{\rho}$ Brooke (1991), ${ }^{\lambda}$ Geyer (1985), ${ }^{\Omega}$ Sigma Aldrich (2014), ${ }^{\Gamma}$ Sigma Aldrich (2018). 
(a)

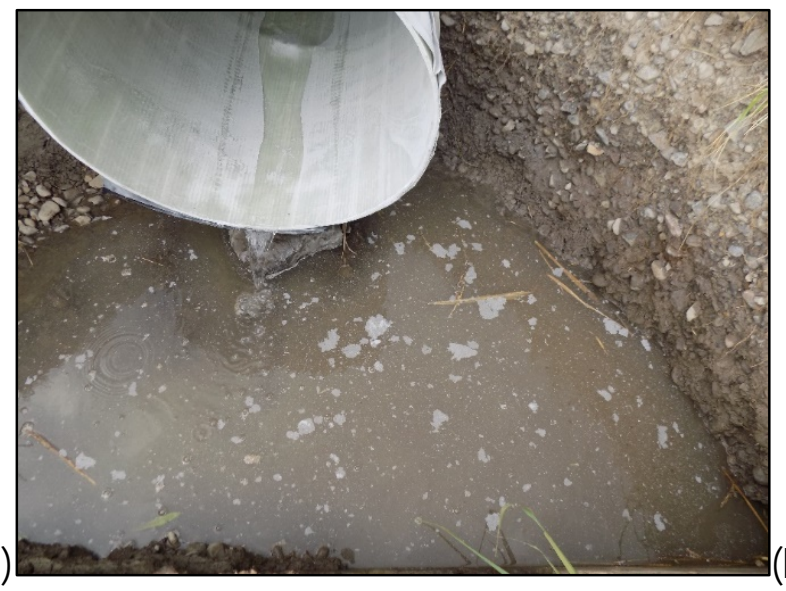

(c)
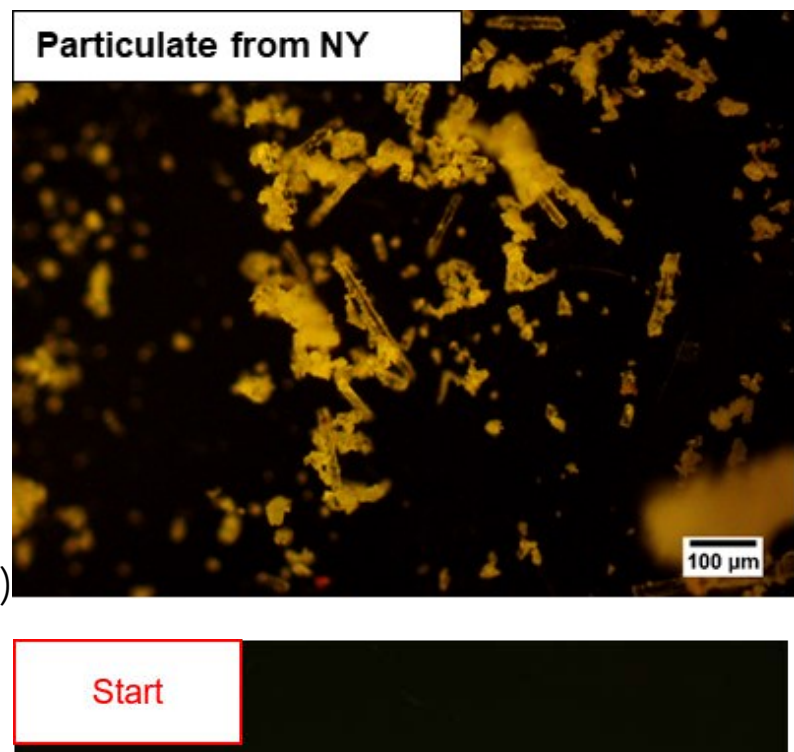

(d)

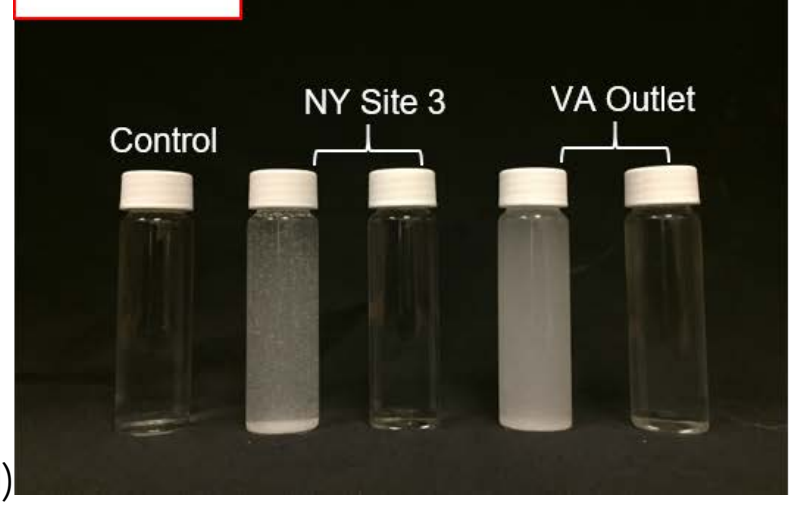

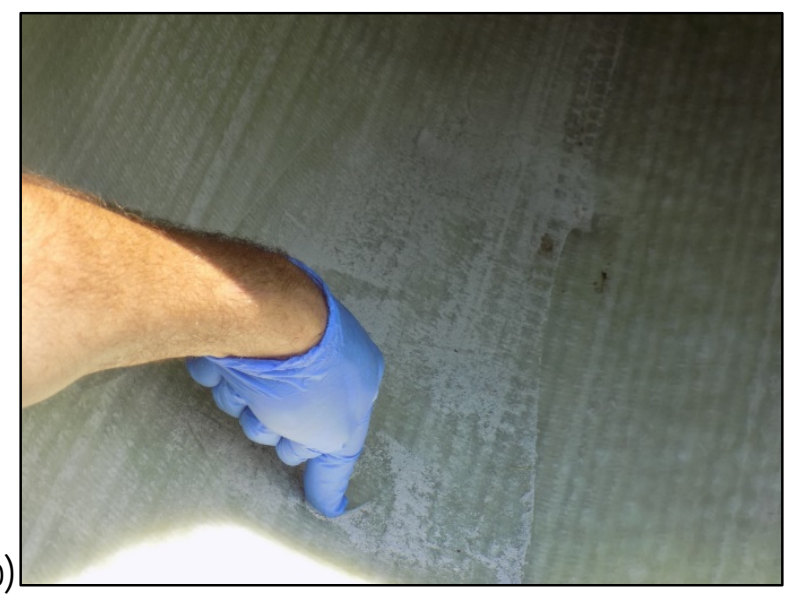

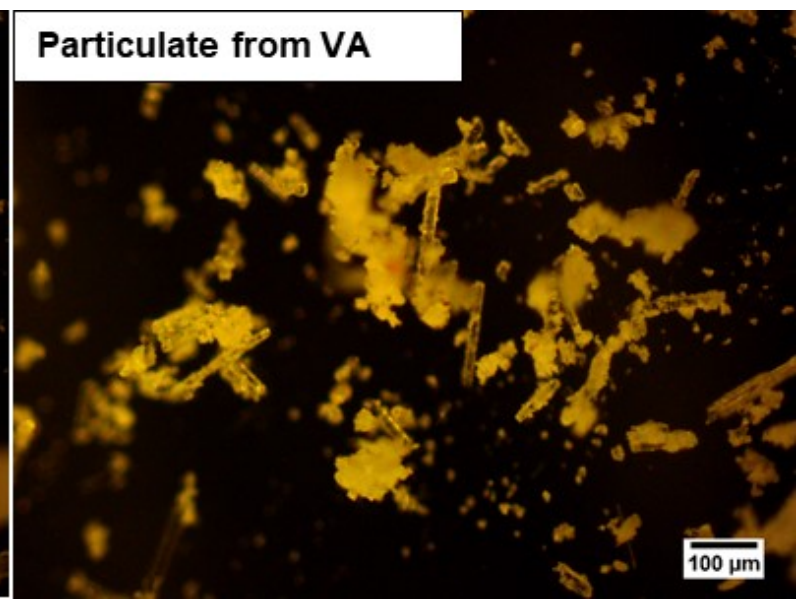

After $48 \mathrm{hr}$

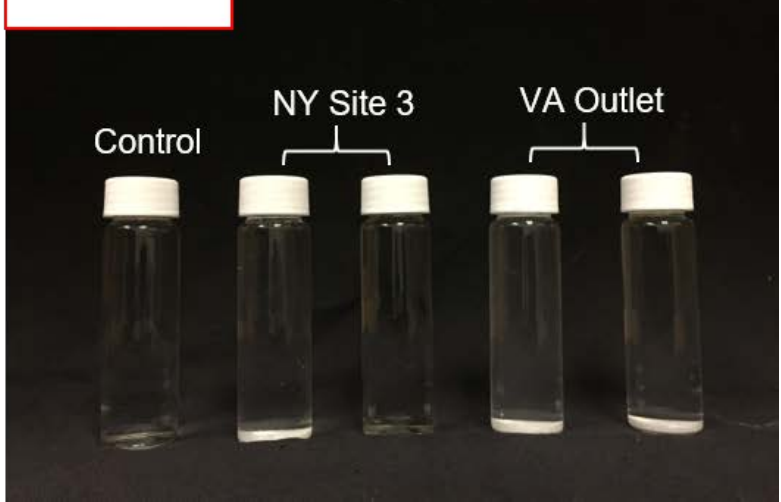

Figure 5. (a) Visual observation of cutting material left in water at the culvert outlet, (b) Visual observation of cutting materials staying on the CIPP inner surface, (c) Optical microscopy images of cutting particulates from NY and VA CIPPs, (d) Particulate behavior in water. 


\section{LABORATORY ACCELERATED AGING AND MATERIAL INTEGRITY TESTS FOR LONGEVITY OF THERMALLY- CURED AND UV-CURED CIPPS}

\subsection{Introduction}

The goal of this experiment was to better understand properties of newly installed CIPPs. Specific objectives were to: (1) to identify the physical, thermal and mechanical properties across the thickness of the onsite installed CIPP, (2) to compare the physical and thermal properties of the onsite-cured CIPP with laboratory, oven-cured CIPP (3) to identify the composition of organic chemicals which can be extracted from onsite-cured CIPP and compared with oven-cured CIPP, and (4) to determine the effects of water conditioning on the physical and mechanical properties of CIPP.

\subsection{Methods}

In July 2016, CIPPs were installed using the steam curing process inside $45.7 \mathrm{~cm}$ diameter vitrified clay sanitary sewer pipes in Indiana. According to contractor provided materials, the resin-impregnated felt consisted of ITI 191024 CTD Felt 15 mil 69 (1129 wt\%), high molecular weight isophthalic unsaturated polyester 102T/TA resin, (38-47 wt\%), amorphous fumed silica (0-2 wt\%), styrene (15-31 $w t \%)$, various organic peroxides (0.5-0.7 wt\%), fiberglass (0-20 wt\%), and proprietary filler(s) (0-22 wt\%). The resin impregnated tube liner consisted of two layers of flexible PET felt which helped obtain the desired CIPP thickness (Insituform 2005).

While onsite, the project team collected uncured resin tube samples, and the contractors cut samples of newly installed CIPP (7-8 mm thick) from the end of the newly installed CIPP. Fabric was also obtained that had not been impregnated with resin. Resin containing materials were stored at $0{ }^{\circ} \mathrm{C}$ until analysis. The fabric (without resin) was stored at room temperature.

\subsubsection{Curing of uncured resin tube in the laboratory}

The maximum curing temperature of the uncured resin tube was determined by DSC analysis (Nuruddin et al. 2019). The collected uncured resin tube was cut into $10^{\prime \prime} \times 10^{\prime \prime}$ squares and heated in the oven at $110^{\circ} \mathrm{C}$ for 2 hours. No pressure was applied.

\subsubsection{Aging of onsite-cured CIPP samples}

Onsite-cured CIPP samples were cut using a water jet cutting machine to $120 \mathrm{~mm}$ (length) $\times 12.5$ $\mathrm{mm}$ (width) $\times 7.5 \mathrm{~mm}$ (thickness). The samples were polished to achieve a smooth surface using 2000 and 320 grit micro-fine sandpaper. Sample immersion tests in distilled water were conducted according to the ASTM D543-14 standard. Ten samples were immersed in $500 \mathrm{ml}$ solution in a $500 \mathrm{ml}$ glass bottle with PTFE lined caps and kept in the oven at $40^{\circ} \mathrm{C}$ for 7 days. At the end of test, the samples were taken out of the solution and kept at $23{ }^{\circ} \mathrm{C}$ and $50 \%$ relative humidity for 48 hours, according to the ASTM D61813 standard.

\subsubsection{Thermogravimetric analysis (TGA)}

The thermal stability, and the volatile content of the onsite-cured CIPP (inner and outer layers), the uncured and oven-cured CIPP liner were studied using a Q-500 thermogravimetric analyzer and platinum pans, both from TA Instruments Inc. (Delaware, USA). Sample weight was maintained between 10-15 $\mathrm{mg}$ and a gas purge flow rate of $60 \mathrm{~mL} / \mathrm{min}$ was used. Samples were heated at $10{ }^{\circ} \mathrm{C} / \mathrm{min}$ to $160{ }^{\circ} \mathrm{C}$ in a nitrogen atmosphere and held for 120 min to examine the volatilization of organic compounds and the evaporation of styrene. Samples were further heated at $10{ }^{\circ} \mathrm{C} / \mathrm{min}$ to $900^{\circ} \mathrm{C}$ in air to examine the degradation of the composite material.

\subsubsection{Differential scanning calorimetry (DSC)}

Curing behavior and thermal analysis of the inner and outer layers of the onsite-cured CIPP, the uncured resin tube and the oven-cured resin tube were performed using a Q-2000 differential scanning calorimeter (TA Instruments Inc., Delaware, USA). Aluminum sealed pans were used with sample weight of approximately $10 \mathrm{mg}$ and scans were performed at $20{ }^{\circ} \mathrm{C} / \mathrm{min}$ from -25 to $200{ }^{\circ} \mathrm{C}$. A heat-cool-heat cycle was used during the experiment to understand residual curing behavior and the emission of volatile chemicals.

\subsubsection{Flexural test}

Flexural test (Three-point bending) of the as received and water aged CIPP specimens was performed according to modified ASTM D790-17 standard, using an MTS 810 instrument (MTS Systems Corporation, MN, USA) with a 22 Kip load cell. The apparent flexural strength and modulus of the CIPP specimens were determined from the test results. 


\subsection{Results and discussion}

5.3.1 Physical and mechanical properties of the exhumed CIPP

Visual differences in the CIPP inner and outer layer led the project team to investigate each individual layer. The newly created CIPP removed from the field (onsite-cured) consisted of two resinimpregnated PET felt layers (Table 14). Notably, the CIPP thickness and the physical properties differed between the CIPP's inner and outer layer. The thickness of inner and outer layers were $2.65 \mathrm{~mm}$ and $5.26 \mathrm{~mm}$, respectively. Porosity of the inner layer (3.4\%) was less than that of outer layer (8.1\%). Interestingly, the CIPP bulk densities were not different. Allouche et al. (2014) reported the density and porosity of five different installations sites in Denver, Colorado and Columbus, Ohio. The range of density and porosity of CIPPs of those sites were $1.0731-1.174 \%$ and $8.16-17.75 \%$, respectively.

During steam curing, there is likely a temperature difference between the inner layer (in contact with steam) and the outer layer (in contact with the cold host pipe) as depicted in Table 14 (Young 1995). Therefore, the outer layer of the CIPP liner likely experienced a slower temperature increase than the inner layer because resin saturated fiber felts have low thermal conductivity. The complete consolidation of the outer layer could not be achieved prior to the resin viscosity rising beyond the processable range, which resulted in a non-uniform and poor consolidation region in the outer layer of the liner (Young 1995).
Thus, the thickness of the outer layer is higher than that of the inner layer because of this consolidation effect.

Porosity can be formed due to entrapped air during resin impregnation, the insertion of impregnated uncured resin liner into the culvert, and the liberation of volatiles formed during the curing cycle. The observed porosity difference between the inner and outer layer may have been caused by several phenomena. During CIPP manufacture, high pressure steam was applied to expand the liner, and this pressure may have forced entrapped air bubbles towards the edge of the CIPP. In addition, the porosity of the inner layer of the CIPP is smaller and spherical in shape, while large cylindrical pores were observed at the CIPP edges. The consolidation pressure (curing pressure) may vary across the thickness of the fiber reinforced composite laminate (Young 1995, Mackenzie 1993) The consolidation pressure was applied from the inner layer during steam curing, and then the pressure was distributed across the thickness of the liners. When consolidation pressure was applied from the inner layer (comparatively high-pressure region), resin started to flow towards the edge of the liner (low pressure region). The voids (formed due to entrapped air or volatiles) may have migrated from the inner layer to the edge and coalesced to form large cylindrical pores. Liu and Chen (2016) reported that voids were small and spherical at a higher pressure while larger and elongated voids could be observed in lower pressure regions. Another explanation of this behavior could be that the CIPP reached a cured state

Table 14. Physical properties of the inner and outer layers of the exhumed CIPP

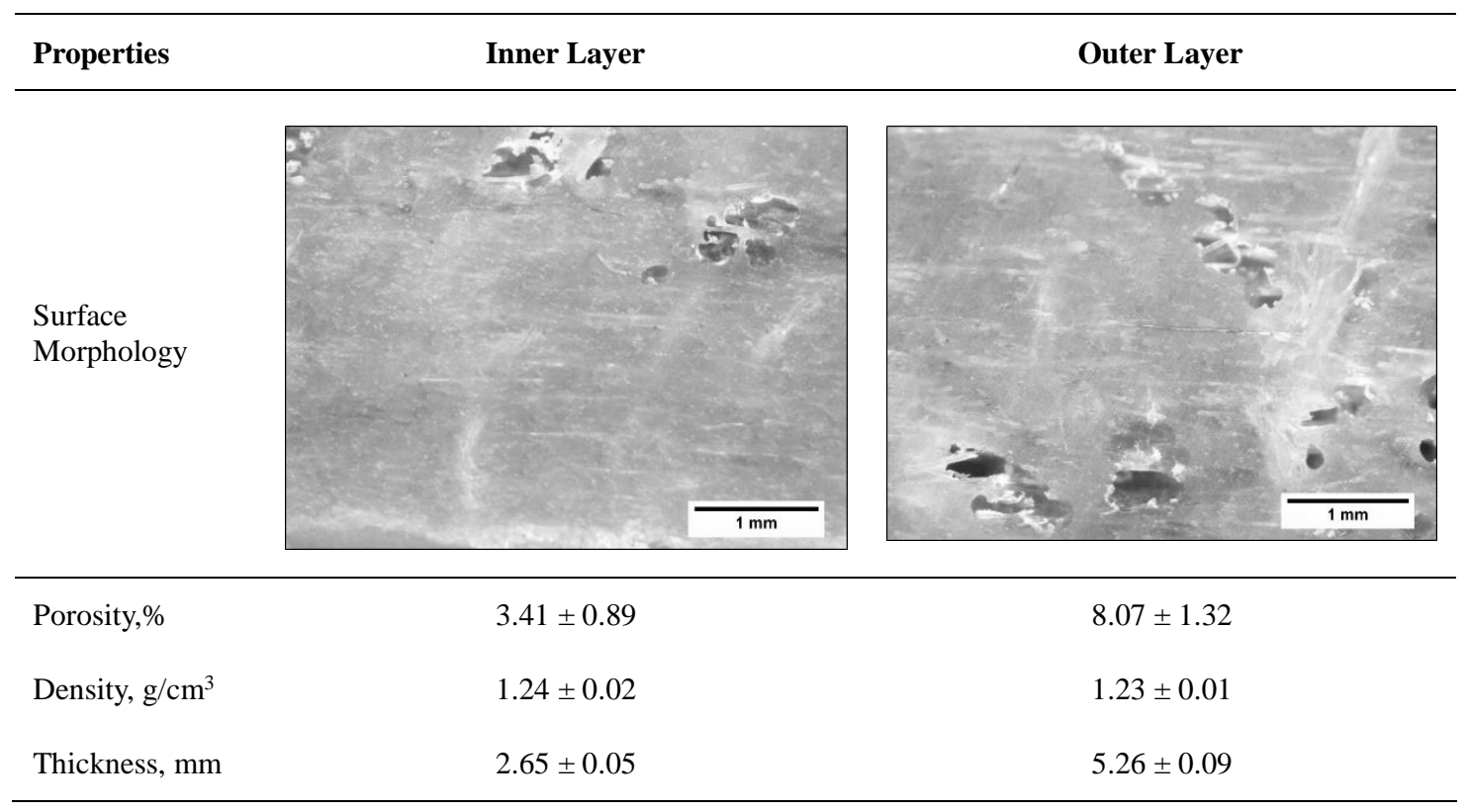


Table 15. Thermal behavior of uncured, onsite-cured, and oven-cured CIPP liners

\begin{tabular}{|c|c|c|c|c|c|c|}
\hline \multirow{2}{*}{ Sample Type } & \multirow{2}{*}{$\begin{array}{l}\text { Weight loss } \\
\text { at } \\
120^{\circ} \mathrm{C}(\mathrm{wt} \%)\end{array}$} & \multirow{2}{*}{$\begin{array}{c}\text { Weight loss } \\
\text { at } \\
160^{\circ} \mathrm{C}(\mathrm{wt} \%)\end{array}$} & \multicolumn{3}{|c|}{ Decomposition Steps, Temp $\left({ }^{\circ} \mathrm{C}\right)$} & \multirow{2}{*}{$\begin{array}{c}\text { Residue } \\
\text { Content at } \\
900{ }^{\circ} \mathrm{C} \\
(\mathrm{wt} \%) \\
\end{array}$} \\
\hline & & & 1st step & 2nd step & 3rd step & \\
\hline Uncured liner & $7.73 \pm 0.18$ & $9.16 \pm 0.33$ & $373.6 \pm 0.8$ & $412.44 \pm 0.30$ & $528.30 \pm 0.56$ & $24.74 \pm 0.75$ \\
\hline Oven-cured liner & $0.42 \pm 0.11$ & $1.41 \pm 0.29$ & $381.8 \pm 0.48$ & $410.21 \pm 2.52$ & $532.29 \pm 0.51$ & $25.44 \pm 0.82$ \\
\hline $\begin{array}{l}\text { Onsite-cured } \\
\text { (Inner layer) }\end{array}$ & $0.47 \pm 0.03$ & $0.80 \pm 0.06$ & $379.95 \pm 0.47$ & $403.11 \pm 8.51$ & $528.83 \pm 3.78$ & $15.95 \pm 1.27$ \\
\hline $\begin{array}{l}\text { Onsite-cured } \\
\text { (Outer Layer) }\end{array}$ & $0.53 \pm 0.03$ & $1.63 \pm 0.21$ & $381.84 \pm 0.48$ & $420.6 \pm 0.48$ & $530.25 \pm 1.42$ & $26.40 \pm 0.82$ \\
\hline
\end{tabular}

or sufficiently high viscosity prior to entrapped air or porosity completely diffusing out of the CIPP, leaving large regions of porosity near the edge. Rubin \& Jerina (1994) reported that insufficient curing pressure would form porosity in a composite laminate.

Mechanical properties could only be measured for the entire exhumed CIPP sample, not the individual layers. The flexural strength and modulus of the exhumed CIPP were $43.25 \pm 2.13 \mathrm{MPa}$ and 1,437 \pm 93.99 MPa, respectively. Minimum standards for the flexural strength and flexural modulus of the approved polyester-saturated felt CIPP liners are $31 \mathrm{MPa}$ and $1,720 \mathrm{MPa}$, respectively according to contractor records (Miller Pipeline 2016) and in some cases

\subsubsection{Thermal behavior: Exhumed CIPPs vs. oven cured CIPP material}

Calorimetry and thermogravimetry measurements identified differences between the uncured resin tube, inner and outer layers of onsite-cured CIPP, and oven cured CIPP material. The uncured resin shows a pronounced exotherm between $80^{\circ} \mathrm{C}$ and $120^{\circ} \mathrm{C}$ with a maximum peak temperature around $100{ }^{\circ} \mathrm{C}$ due to the thermal curing of the resin. In both the first and second heating scan of the uncured resin tube, two endothermic peaks were observed at around $120{ }^{\circ} \mathrm{C}$ and $160^{\circ} \mathrm{C}$, indicating the melting temperature $\left(\mathrm{T}_{\mathrm{m}}\right)$ of polyethylene/polypropylene bilayer coating (Nurrudin et al. 2019). In contrast, the onsite cured CIPP exhibited much different thermal behavior, even compared to the inner and outer layers. Neither the first or second heating scan revealed the presence of an exothermic response associated with curing, indicating no residual reactivity and that the resin was essentially "fully cured". Both inner and outer layers had small endotherms between $25^{\circ} \mathrm{C}$ and $120^{\circ} \mathrm{C}$ on meeting a minimum mechanical performance threshold is used to determine if a CIPP installation has been "fully-cured". The types of resin (polyester or vinyl ester), reinforcing materials (flexible felts or equivalent woven or non-woven materials) and most importantly, the curing condition (pressure and temperature) play a vital role to control the mechanical strength of the cured CIPP liners. The minimum and maximum flexural strength and flexural modulus of CIPP reported in the literature are 34.7-50.1 MPa and 1,259-3,379 MPa, respectively (Allouche 2014). As the project team could not separate the two layers, it is unknown whether the extra porosity in the outer layer weakened it or the final composite, although this cannot be discounted.

the first heating scan only, which may be indicative of volatilization. This lack of an endotherm on the second scan indicates that lack of detectable amount of volatile contents. Oven-cured CIPPs exhibited very similar thermal characteristics to onsite-cured CIPP, even though oven cured CIPP was not exposed to pressurized steam. Like onsite-cured CIPP, an endotherm was detected for the first heating scan, but not the second scan, and the thermoplastic bilayer coating melting response was also found.

Thermogravimetric analysis was applied using air and nitrogen atmospheres to further examine the thermal behavior of the uncured resin tube, onsitecured CIPP (inner, middle and outer layers), and ovencured resin tube (Table 15, Figure 6). The initial weight loss around $120{ }^{\circ} \mathrm{C}$ and was due to the evaporation of the residual volatile compounds, water and unreacted styrene. Since the boiling point of styrene is around $145^{\circ} \mathrm{C}$, the residual entrapped and unreacted styrene evaporated by around $160{ }^{\circ} \mathrm{C}$ (U.S. NTP 2016). As expected, the uncured resin tube 

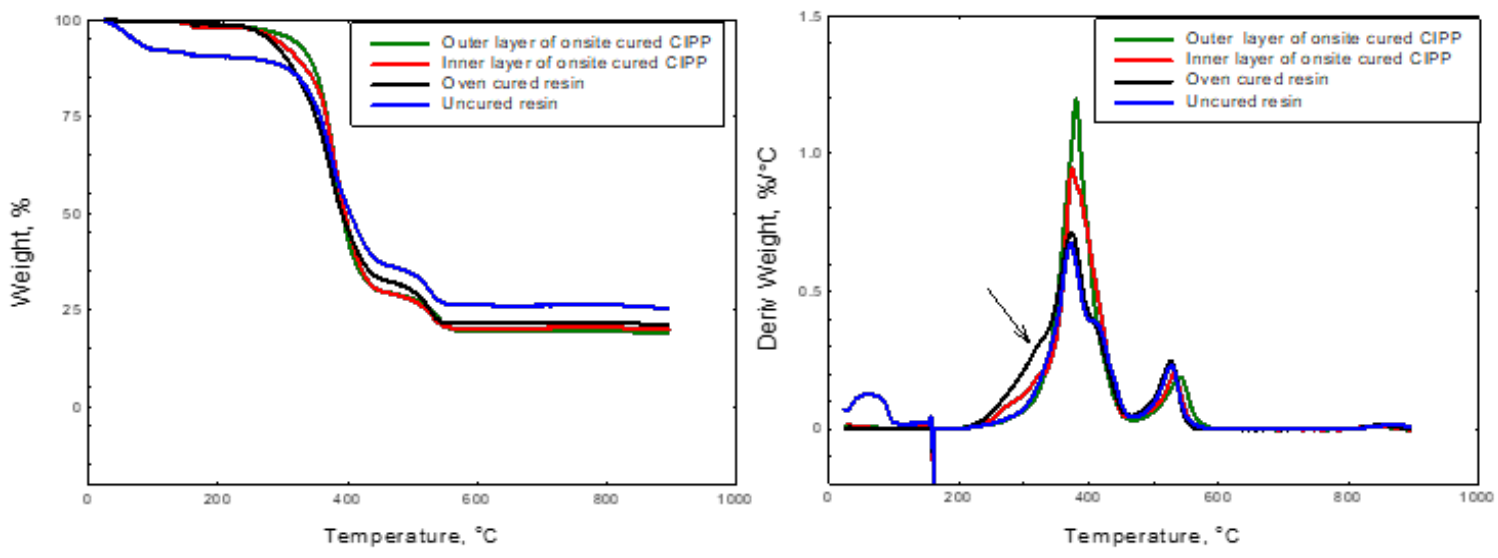

Figure 6. (a) Thermogravimetric (TG) and (b) Derivative thermogravimetric (DTG) curves of uncured, onsite-cured, and oven-cured CIPP liners

contained the most volatile material (7.73 and 9.16 wt\% at $120 \quad{ }^{\circ} \mathrm{C}$ and $160{ }^{\circ} \mathrm{C}$, respectively). Interestingly, the oven-cured CIPP liner exhibited substantially less weight loss than onsite-cured CIPP samples, indicating that the onsite-cured samples may not have the same level of process optimization which can be met under laboratory conditions. Furthermore, the volatile and styrene contents of the outer layer ( 0.53 and $1.63 \mathrm{wt} \%$ ) of onsite-cured CIPP were higher than in the inner layer (0.40 and $0.80 \mathrm{wt} \%)$. During installation, the air pressure may have induced most of

\subsection{Conclusion}

The goal of these experiments were to investigate the CIPP liner in terms of physical properties, presence of unreacted volatile compounds and mechanical properties. The porosity and density of the inner layer differed from the outer layer as the inner layer may have been influenced by higher pressure and temperature during installation. Installation pressure and temperature also likely influenced the presence of unreacted volatile content. Volatile organic compounds present in the CIPPs included styrene, its oxidation products, and other possible carcinogens of varying amounts. Thermogravimetric analysis showed that the volatile content, of inner layers was lower than outer layer. Unique to this study was that styrene dimer and trimers were found in the onsite cured CIPP liner but were not detected when the same uncured resin tube was oven cured in the laboratory. The inner and outer layer exhibited response differently to water conditioning, showing different porosities and uptake. Furthermore, water conditioning did not change strength of the liner significantly, although conditioning did show onset of cracks and debonding indicating that long-term mechanical performance the residual volatiles and unreacted active styrene monomers to migrate from the inner layer to the outer layer. These volatile compounds entrapped in outer layer because of curing of the resin tube. Another possible explanation could be that the inner layer has a higher/longer temperature and so is more fully cured which reduced the volatile content. The absence of prior studies that examined CIPPs at this detail inhibited a more fundamental explanation of the factors that influenced result.

may be compromised to some degree. For the shortterm aging test, liner structural integrity and longevity was not compromised by chemical leaching. Additional work should be conducted to examine the role of aging duration, chemical leaching, and aging environment on long-term liner structural integrity and longevity. Additional work is also needed to document the characteristics of CIPPs being installed, elucidate the role of the temperature gradient down the length of the liner and through the pipe wall, and sensitivity of final properties to pressure, curing temperature, and exposure duration. 


\section{CIPP SAFETY OBSERVATIONS AND RECOMMENDATIONS}

\subsection{Observations during the present study}

During this study the project team encountered previously unreported safety hazards associated with CIPP lining projects. This included the discovery that a variety of materials were emitted into air from steam CIPP worksites which included particulates, uncured resin, multiple VOCs and SVOCs, and other materials. Also observed was that some contractors handled uncured resin tubes with their bare hands and stood in the chemical emission plumes without respiratory or complete dermal protection. Some members of the project team also had self-reported eye irritation at a UV CIPP site as air was being blown through the uncured resin tube during UV curing. These symptoms went away when the persons removed themselves from the location. Some of the safety observations are documented in video evidence and also the peerreviewed papers cited below. A complete list of available studies and additional information can be obtained in Ra et al. (2019).

\subsection{Select safety related events}

In recent years, transportation agencies, municipalities, consultants, utilities, regulators, and health officials have raised concerns regarding chemical emission occurring during and after CIPP installation. Below is a brief summary of events:

> 2019: More than 100 air contamination incidents associated with CIPP use have been documented in the U.S. (Teimouri et al. 2017; Ra et al. 2019). Some storm sewer and sanitary sewer lining projects involved complaints of odors, whereas others involved health symptoms, including incidents in which people were administered medical assistance at schools, day care centers, offices, or residences.

$>$ 2019: In the U.S., an inhalation toxicology study of materials emitted from four steam CIPP manufacturing sites indicated potential health risks as well as variations between worksites regarding emissions and toxicity. The evaluation identified biological pathways that require future evaluation and also demonstrated that exposure assessment of CIPP worksites should examine multiple chemical components beyond styrene, as many cellular responses were styrene-independent (Kobos et al. 2019).
2019: Chemical air testing conducted at multiple CIPP worksites in the U.S. revealed a multitude of materials discharged to the air such as uncured resin, particulates, organic vapors, and water vapor. Chemicals (more than styrene) were confirmed to be emitted. Results indicated the need for air monitoring at all worksites and further study. Photoionization detectors (PID) calibrated for styrene did not accurately represent styrene air concentration differing sometimes by 10 s- to 1,000 s-fold. This was likely due to the fact that multiple VOCs emitted from the CIPP process were found in air samples (Teimouri et al. 2017; Ra et al. 2019). Because PID signals have been shown to be significantly affected by local environmental conditions and other VOCs present in the air (Coffey et al. 2012; LeBouf et al. 2013; LeBouf \& Coffey 2015), they should not be solely relied upon at CIPP worksites to identify safe/unsafe conditions.

> 2019: The U.S. National Institute for Occupational Safety and Health (NIOSH) found $140 \mathrm{ppm}_{\mathrm{v}}$ styrene at a CIPP manufacturing site exceeded the 15 min shortterm exposure limit of $100 \mathrm{ppm}_{\mathrm{v}}$ (U.S. NIOSH 2019). Another chemical, divinylbenzene was also detected in air. The federal agency recommended that workers ventilate manholes, bag excess liner immediately, and change gloves regularly when they contact resin.

2018: U.S. researchers published a review of safety data sheets and chemical test results available for current and prior CIPP sewer products. As found on material safety data sheets and in prior field testing, new chemicals can be created during CIPP manufacture that are not listed as ingredients on safety data sheets ( $\mathrm{Ra}$ et al. 2018). These compounds included endocrine disrupting compounds, carcinogens, hazardous air pollutants and compounds with limited toxicological data. Some compounds had state water quality standards.

2018: The U.S. Occupational Safety and Health Administration (OSHA) issued a citation to a CIPP contractor associated with a CIPP worker fatality that occurred in October 2017. Chemical exposure contributed to a worker fatality where blood styrene levels indicated a 220-270 ppm $_{\mathrm{v}}$ exposure (U.S. OSHA 2018).

2018: Researchers in France monitored CIPP worker urine and found their styrene exposures 
were punctually high and recommended additional monitoring and testing (Persoons et al. 2018).

> 2017: A worksite fatality during an Illinois, U.S. sanitary sewer CIPP installation triggered a federal investigation (Peterson 2017).

> 2017: The California Department of Public Health (CDPH) issued a second statement about CIPP that included "Persons who detect an odor and experience health symptoms...should contact their medical provider and local health department; utilities, engineering firms, and contractors should not tell residents the exposures are safe. There is no credible testing data for all CIPP installation scenarios” (CDPH 2017b).

> 2017: The CDPH issued a statewide safety alert on the basis of their own investigation of residential building chemical contamination caused by a CIPP sanitary sewer installation (CDPH 2017a).

> 2017: U.S. researchers, invited by U.S. NIOSH, published a summary at the NIOSH blog about potential inhalation and dermal exposure risks associated with CIPP manufacturing sites (Whelton et al. 2017).

$>$ 2016: U.S. researchers reported that at three steam CIPP sanitary sewer worksites in Los Angeles, CA styrene air concentrations of 2501,070 $\mathrm{ppm}_{\mathrm{v}}$ and 3.62-76.7 $\mathrm{ppm}_{\mathrm{v}}$ were detected during curing and cooldown processes, respectively (Adjari 2016).

> 2012: CIPP chemicals traveled "kilometers from the worksite” aboveground (Bauer 2012). [1 kilometer $=0.62$ mile $]$

$>$ 2012: Sweden's Institute of Environmental Medicine found that contact dermatitis is associated with epoxy lining CIPP and some workers left the trade because of their allergic reactions (Berglind et al. 2012).

2006: In the Netherlands, several emission control and monitoring recommendations implied (1) styrene was the only compound of concern, (2) monitoring should include a photoionization detector (PID), and (3) a fan should be installed on manholes that can move thousands of $\mathrm{m}^{3}$ air/hour during and for at least 24 hours after CIPP installation (RIVM 2006).
2005: In the Netherlands, styrene concentration remained unchanged 1 kilometer [0.62 mi] down a sanitary sewer (RIVM 2005).

2005: The U.S. Agency for Toxic Substances and Disease Registry (ATSDR) (2005) investigated a building chemical contamination incident and declared that a CIPP installation caused an indoor air pollution 'public health hazard'.

\subsection{Recommendations}

The project team recommends that agencies that conduct CIPP manufacture or oversee projects take two actions simultaneously. First, it is recommended that agencies request a free health hazard evaluation from U.S. NIOSH with a set of representative CIPP projects, not every CIPP project. This activity enables NIOSH to conduct confidential worksite monitoring to determine if any upgrades in practices are needed to protect workers; those conducting the installation and those observing the installation. At the time this project was completed, one UV CIPP company had completed a health hazard evaluation (HHE) with NIOSH. Two state transportation agencies had also initiated HHE support. Two common questions the project team received are shown below.

Second, simultaneously agencies should also upgrade existing outdoor CIPP manufacture construction practices, require emission capture and require confirmation they were captured, and provide more oversight that includes well-trained environmental monitoring and industrial hygiene professionals to CIPP worksites. The outdoor CIPP manufacturing process requires engineering and administrative controls as well as safety upgrades to protect the health of CIPP workers as well as transportation agency, and other workers (i.e., consultants, construction inspectors) nearby as well as the environment and public from harm. This can include (1) minimizing dermal and inhalation exposures, (2) capturing emissions and confirming this by chemical monitoring, and (3) using appropriate personal protective equipment even for site observers. More specific recommendations are provided in the construction specifications at the end of this report.

6.3.1 What is a health hazard evaluation and how do I request one?

The NIOSH has a list of frequently asked questions about their program and this information can be found at the website below. Agencies, agency employees, their consultants, and CIPP contractors are encouraged to contact NIOSH for information and 
assistance. NIOSH is already working to assist some other state agencies with worksite safety evaluations. The employee who contact's NIOSH for help can have their identity kept confidential when that choice is marked on the request form. NIOSH also protects individually identifiable medical information according to federal law. If you have concerns or questions about confidentiality, call 1-513-841-4382 to speak with a member of NIOSH's staff.

6.3.2 When a CIPP worker, consulting engineer, or municipal employee who visits a worksite has a health concern or safety questions, whom should they contact?

Questions and concerns about the safety of CIPP workers and others who visit CIPP manufacturing sites in the conduct of their duties were raised during the conduct of this study. A worksite safety plan should be created to describe the type and location of hazards (i.e., inhalation, dermal, eye, hearing) associated with the construction activity, including engineering controls (i.e., emission capture), administrative controls (i.e., setback distances), and recommended personal protective equipment (i.e., inhalation, eye, hearing protection). If an employee has a health concern or safety question, they should consider seeking information from their employer, but are also covered by a state agency for safety/health hazard reporting purposes. The specific agency varies from state to state. If a person wishes to file a complaint alleging unsafe work conditions, they can do so with a regulatory agency. For example, in Illinois, local government employees (city, village, state, county) may file complaints alleging unsafe working conditions with the Illinois Department of Labor. The OSHA website below provides a web link to each state organization with contact details.

All private sector employees may file complaints with federal OSHA where this agency has jurisdiction. There are a number of states that have the legal authority to enforce the OSHA standards and have complaint processes similar to the federal OSHA states. Complaints may be filed electronically, by contacting the OSHA Hotline (1-800-321-OSHA) or by contacting the local OSHA field office.

\section{NIOSH Website}

The NIOSH Health Hazard Evaluation (HHE) Program

https://www.cdc.gov/niosh/hhe/default.html

Telephone: 1-513-841-4382

The NIOSH health hazard evaluation program helps employees, union officials, and employers learn whether health hazards are present at their workplace and recommends ways to reduce hazards and prevent workrelated illness. Our evaluations are done at no cost to the employees, union official, or employers.

The NIOSH will keep the requester's information confidential.

\section{OSHA Website}

How to file a safety and health complaint

\section{https://www.osha.gov/workers/file_complaint.html}

The U.S. Occupational Safety and Health Act of 1970 gives employees and their representatives the right to file a complaint and request an OSHA inspection of their workplace if they believe there is a serious hazard or their employer is not following OSHA standards. Workers do not have to know whether a specific OSHA standard has been violated in order to file a complaint. The complaint should be filed as soon as possible after noticing the hazard or lack of compliance because OSHA citations may only be issued for violations that currently exist or existed in the past 6 months.

OSHA will keep the filer’s information confidential. 


\section{CONSTRUCTION SPECIFICATION AND SPECIAL PROVISION RECOMMENDATIONS}

\subsection{Spray-on lining}

\subsubsection{Minimize environmental impacts}

1. Solid and hazardous wastes should only be disposed of in accordance with local, state, and federal regulations. This includes compliance with the Clean Water Act, Land Disposal Rule, air quality regulations, as well as other applicable regulations.

2. Before construction is permitted, contractors should obtain and present a publicly owned treatment works (POTW) permit to the Engineer that describes their permission to dispose of any liquid waste generated onsite. If disposal at the POTW may not be the feasible option, liquid waste may need to go to a permitted Resources Conservation and Recovery Act (RCRA) or industrial wastewater treatment plant that is permitted to accept non-hazardous industrial wastewaters. Alternatively, contractors could be required to submit their wastewater/waste management plan which outlines where they will dispose of or otherwise treat wastewaters/wastes generated on the project.

3. To prevent overspray, a temporary curtain at the pipe inlet and outlet is recommended.

4. Air monitoring should be conducted to determine if pollutants were released into the environment. The type of monitoring recommended to detect the pollutants emitted can be provided to the CIPP Contractor, Engineer, or Consultant by requesting a free National Institute for Occupational Safety and Health (NIOSH) health hazard evaluation. As previously found, particulates, partially cured resin, a multitude of organic vapors, and water vapor have been found to be emitted at prior worksites where they were not captured.

5. Water testing before and after the installation is recommended. Sampling at the pipe inlet and outlet immediately before and after the liner is placed in service should constitute temporal (and spatial) sampling events (estimated to be 4 samples). Specific water tests to be conducted will depend on the type of liner installed.

a. Water collected at cementitious liner sites should be examined for $\mathrm{pH}$ and alkalinity at a minimum, and results should be compared to state water quality standards and aquatic toxicity thresholds where present.

b. Water samples from polyurea and polyurethane liner sites should be analyzed for $\mathrm{pH}$, COD, TOC, TN, MDI, MDA, VOCs, and SVOCs. Also, any ingredients or decomposition products reported on product data sheets should also be considered for monitoring (i.e., bisphenol A) and compared against water quality standards.

6. Upon installation, the liner should be rinsed before return to service. Rinse water should be collected and properly disposed.

7. No water should be allowed to pass through the newly lined pipe for at least 24 hours, unless representative chemical testing data specific to that site indicates the construction activity did not release materials (i.e., cutting dust, resin, etc.) and the liner does not contain or leach compounds that exceed aquatic organism toxicity thresholds for chemicals of concern or state water quality standards.

8. If water testing after installation reveals exceedance of any prescribed limit, remediation actions should be initiated, and the pipe should be removed from service until it no longer poses an environmental or human health risk.

\subsubsection{Worksite safety}

1. No observations were made during this study for this category 
7.1.3 Determine product quality

1. No observations were made during this study for this category 


\subsection{CIPP lining}

\subsubsection{Before the contractor begins work}

1. The Engineer shall review Appendix B of the six state lining study report to identify potential opportunities for chemical release into the environment due to the CIPP manufacturing activity.

2. The Engineer shall consider the following considerations when deciding the suitability of and necessary controls for the CIPP manufacturing site location. These include, but are not limited to, the site's proximity to drinking water wells and water bodies, nearby surface and ground water quality, state and federal water quality standards, nearby land uses, the watershed area, environmental conditions, and proximity to sensitive populations (i.e., schools, residences) and environmental areas.

3. A Worksite Safety and Sampling plan shall be provided to the Engineer. The plan should include, at the minimum, the following:

a. A description of chemical exposure hazards during setup, installation, and cleanup, as well as a list of chemicals for the liner and resin mixture that are used or generated before, during and after the onsite curing process.

b. A map denoting the location of equipment, including exhaust or fugitive emission points, location of setback distances from public ways, private property, buildings nearby to include schools, health care facilities, if any, expected heights of any emission discharge points, chemical fallout areas, and waste capture systems.

c. A description of personal protective equipment (PPE) CIPP workers shall wear at the plastic manufacturing site as recommended by industrial hygienists, to protect workers from worksite and installation hazards, including chemical exposure through inhalation, dermal exposure, or eye exposure. This should be listed by job duty. The type of PPE recommended can be determined by the CIPP Contractor, Engineer, or Consultant requesting a free National Institute for Occupational Safety and Health (NIOSH) health hazard evaluation.

d. Provide the Engineer a copy of the written approval for the disposal of wastes to be generated during the setup, installation, and cleanup process. This includes both solid and hazardous wastes as applicable.

a. Contractor shall report any accidental discharge, small or large, to the Engineer and environmental regulatory officials immediately, so that downstream water supplies, the environment, and surrounding populations can be protected.

4. The Engineer will provide a list of the contaminants of concern to the Contractor based on information from state and federal water quality standards, and by any other additional available information. Chemicals listed in Appendix $\mathrm{C}$ of the six state lining study report as well as on material safety data sheets, product sheets, and additional information as it comes available should be considered. Material safety data sheets should not be solely relied upon to identify chemicals of concern as they have shown not to list all chemicals of environmental concern that are present. Chemicals detected shall not exceed state water quality limits or specific aquatic species toxicity thresholds for chemicals deemed a concern by the Engineer and other agencies as noted. These chemicals and/or their concentrations may vary between and within states, depending upon which waterways are near the installation site and other factors as deemed important by the Engineer and regulatory agencies. It is recommended the Engineer consult with state environmental and public health agencies about the type of monitoring CIPP lining sites should be conducted. Different requirements may exist for or be required by different states.

\subsubsection{Minimize environmental impacts}

1. A transportation agency construction inspector who is trained to recognize environmental emissions and pollution during plastic manufacture shall be assigned to each worksite.

2. Waste should only be disposed of in accordance with local, state, and federal regulations. This includes compliance with the Clean Water Act, Land Disposal Rule, air quality regulations, as well as other applicable regulations. 
3. Contractor shall capture particles and shavings created during any CIPP cutting activities and not permit their entry into the environment. This capture activity may include, but is not limited to, a portable device to capture emitted particulate dust as generated with negative pressure.

4. Contractor shall not permit floating materials to enter the surface water or nearby vegetation.

5. Contractor shall use sufficiently thick plastic sheets (i.e., greater than 10 mils thick) immediately upstream and downstream of the pipe to help prevent chemicals from entering the environment. The protected area's size may depend on the pipe size and area morphology. Water flow should be diverted from the pipe until a complete cure has been established. A barrier material shall be placed in the inlet and outlet work area to prevent the uncured resin tube from contacting the ground.

6. Materials deposited on the mat or barrier material shall be collected and disposed.

7. The entire newly manufactured CIPP's inner surface area shall be rinsed, and the rinse water shall be collected and disposed in accordance with Clean Water Act, and other applicable federal and state laws.

8. Water or steam condensate used for curing or rinse water shall not enter the environment (waterways, soil) and should be collected. These materials should be properly discharged to a publicly owned treatment works (POTW), with preapproval of the POTW, or other approved facility. For example, if disposal at a POTW is not a feasible option, liquid waste may need to go to a permitted Resources Conservation and Recovery Act (RCRA) or industrial wastewater treatment plant that is permitted to accept non-hazardous industrial liquid waste.

9. In the absence of waste collection, any discharge to the environment should have preapproval by the state or federal agency responsible for pollutant discharge. The Contractor shall present this discharge authorization to the Engineer before the project begins. This approval may not be permitted in all states, but the state and federal agency responsible should be contacted for clarification.

10. Any accidental discharge or release, small or large, should be reported to state officials immediately, including the state environmental protection agency, so actions can be taken to protect downstream water supplies, the environment, and nearby population. Some raw materials and wastes generated during CIPP manufacture are highly concentrated and small amounts can cause environmental damage (i.e., dissolve fresh water organisms).

11. Water testing shall be conducted to determine if applicable water quality standards have been exceeded.

a. Chemical testing shall not be solely based on the material safety data sheet because chemicals of concern and those generated by the liner manufacturing process are not all reported on safety data sheets (See 7.2.1).

b. Water testing methods selected shall be capable of detecting all contaminants of concern. Testing procedures, analytical methods, locations, number of samples, and temporal extent (i.e., to include preand post-installation) need to be clearly defined. Independent organizations, properly trained on environmental sampling, sample preservation, and analysis, shall conduct testing. Results shall be rapidly obtained and compared against state and federal water quality limits for allowable pollutant discharge, limits in construction specifications, and to acute and chronic toxicity limits for native aquatic species. It is recommended that prior to the project beginning the Engineer consult with state environmental and public health agencies about the type of monitoring CIPP lining sites should be conducted. Different requirements may exist for different states, areas, and sites.

c. Sampling at the pipe inlet and outlet immediately before and after the CIPP is placed in service shall constitute temporal (and spatial) sampling events (estimated to be 4 samples).

d. Any discharges to receiving waters that exceed state water quality standards and limits set forth in specifications or defined by environmental and public health agencies should trigger additional water testing for that CIPP site/location as well as state environmental and public health agency notification. The Contractor is responsible for immediately alerting the responsible agencies. As known contamination incidents and existing studies have indicated, follow-up testing for days to months may be necessary if contamination is suspected or discovered. This testing will be the financial and logistical 
responsibility of the Contractor. This follow-up testing will be conducted at the direction of the state environmental and public health agencies and is not the financial responsibility of the Engineer. Remediation actions, if determined necessary by either state environmental or public health agencies, would also be the responsibility of the Contractor not the Engineer.

e. If rinse water is used, a sample of that water before entry into the new CIPP (control sample) and a water sample collected as the first water exits the CIPP shall be collected. This sampling is to be conducted even if the rinse water is planned for disposal, and can help document the immediate CIPP impact on the water. If drinking water is used for CIPP rinsing, appropriate methods must be used to neutralize drinking water disinfectant onsite to preserve the integrity of the collected water sample.

12. The Contractor's staff and its subcontracted organizations shall not conduct water sampling or analysis. Instead, a third-party organization with proper environmental monitoring expertise shall conduct and be responsible for water sampling, analysis, and reporting to the Engineer.

13. New CIPPs shall not be placed in service until testing of receiving water indicates no water quality limit exceedances unless representative chemical testing data specific to that site indicates the construction activity did not release materials (i.e., cutting dust, resin, etc.) and the liner does not contain or leach compounds that exceed aquatic organism toxicity thresholds for chemicals of concern or state water quality standards.

14. Chemicals identified in the six state pooled fund study and others, should be considered for water testing.

15. Because partially cured resin, particulates, and contaminated water, are emitted into the air during steam CIPP manufacture, pollution emissions into air should be captured and monitored to confirm complete capture for processes that involve water, and on a case by case basis for UV and ambient cure applications. This capture activity may include, but is not limited to, a portable device to capture emitted materials as generated.

\subsubsection{Worksite safety}

1. Contractors shall have provided worksite safety information according to Section 7.2.1. Additional requirements are below.

2. Contractors shall establish a clear physical perimeter and setback distance to prevent persons from approaching pollution emission points and chemical fallout areas. The perimeter and setback distance may vary depending on manufacturing practices and site conditions. It is recommended the determination of what perimeter and setback distances are recommended for different CIPP technologies and environmental/site conditions be made by a free National Institute for Occupational Safety and Health (NIOSH) health hazard evaluation.

3. Persons who inspect, monitor, visit, or conduct water or air sampling at CIPP manufacturing sites shall wear appropriate personal protective equipment (PPE). This could include respirators and chemically resistant gloves, depending on the potential exposure routes (inhalation, dermal) as determined appropriate by industrial hygienists and the National Institute for Occupational Safety and Health (NIOSH), or other occupational health and public health regulatory agencies.

4. As previously required, Contractors shall capture pollution emissions and confirm this by monitoring. Contractors shall record the amount and type of pollutant captured, and describe the waste generated (i.e., condensate, rinse water, plastic cutting dust, recirculation water, uncured resin tube). Contractors shall report and submit this information to the Engineer, in addition to identifying the waste's disposal location.

\subsubsection{Determine product quality}

1. A sample of upstream and downstream sections of the installed liner should be removed and physically and chemically characterized. This may be facilitated by the use of an external sleeve or collar with similar thermal/chemical resistance characteristics as the host pipe being repaired. This material can then be removed without damaging the new CIPP and should be characterized to determine:

a. The presence of unreacted chemicals in the liner by differential scanning calorimetry (DSC). The method is listed in Appendix A of the six state lining study report. 
b. The amount of volatile material (reported as percent weight) remaining in the new liner by thermogravimetric analysis (TGA). The method is listed in Appendix A of the six state lining study report.

c. The amount of hazardous air pollutant (reported as percent weight) and water quality pollutants listed in state code (reported as percent weight) by liquid-solid extraction (LSE) gas chromatograph / mass spectrometry (GC/MS). The method is listed in Appendix A of the six-state lining study report. 


\section{RECOMMENDATIONS FOR FUTURE WORK}

\subsection{Spray-on lining}

1. Agencies should seek clarification from their respective state or federal environmental agencies who permit pollutant discharges under the National Pollutant Discharge Elimination System about what requirements to minimize water quality impacts are recommended. These agencies, with the assistance of this report and other information, can provide more informed guidance to the agency about the use of spray-on lining technology and whether or not any specific practices must be added to construction specifications.

2. Additional testing is needed to understand what compounds are used and can be released into the environment at spray-on lining sites. In future studies, water samples should be screened for a wider range of compounds. Samples of the uncured resin and recently installed lining should also be chemically extracted and analyzed.

\subsection{CIPP lining}

1. Agencies should seek clarification from their respective state or federal environmental agencies who permit pollutant discharges under the National Pollutant Discharge Elimination System about what water quality impacts and requirements are recommended. These agencies, with the assistance of this report and other information, can provide more informed guidance to the agency about the use of CIPP technology and whether or not any specific practices should be added to construction specifications.

2. Chemical extraction of new liners according to NYSDOT's requirement that "the resulting cured liner shall contain less than $0.1 \%$ of the water quality pollutants" listed in state code should be considered nationwide. This approach could help other transportation, state, and federal agencies understand what chemicals are used, created, and remain in the CIPP after installation.

3. Additional studies should

a. Document a more complete list of chemicals used, generated, and released during CIPP installation and their toxicities.

b. Determine evidence-based waste handling practices and identification of the necessary time required before placing the CIPP into service to limit chemical leaching.

c. Document chemical leaching from CIPPs over time, after facilitated curing (UV, steam, hot water, ambient cure) has occurred, with the rate of leaching examined as a function of facilitated curing and post-curing time (with temperature and air flowrate, etc. where appropriate).

d. Determine the necessary time required before returning each pipe to service to minimize contaminant release from the worksite and the CIPP. Additional work is needed to determine the time required for CIPP leaching to decrease below accepted chemical concentrations, and limits for some chemicals may differ between states.

e. Elucidate the relationship between water quality impacts caused by the CIPP after installation and chemical emission into the air during CIPP manufacture.

f. Clarify the role of the temperature gradient down the length of the liner and through the pipe wall, and sensitivity of final properties to pressure, curing temperature, and exposure duration.

g. Develop sampling methods and approaches to better characterize chemical air emissions, chemical air mixture exposures, and short- and long-term health impacts. To understand worker chemical exposures and the types and masses of chemicals emitted, their phases and exposure duration and the mixture's toxicological impacts should be investigated. 
4. Organizations that contract for CIPP technology use need to be aware of the human health and environmental risks associated with the manufacturing process and product use. Organizations also need to require and implement evidenced-based practices to mitigate health risks to their employees, the public, and the environment. 


\section{REFERENCES}

Adjari, E.B. 2016. Volatile Organic Compound (VOC) Emission during Cured-in-Place-Pipe (CIPP) Sewer Pipe Rehabilitation. Dissertation. University of New Orleans, LA.

AirZone Inc., 2001. A Report on the Monitoring of Styrene in Toronto Homes During the Cured in Place Pipe (CIPP) Process for Sewer Pipe Rehabilitation by Insituform. Project 041-6742. AirZone, Inc., Toronto, Ont., Canada.

Ajdari, E.B., 2016. Volatile Organic Compound (VOC) Emission During Cured-In-Place-Pipe (CIPP) Sewer Pipe Rehabilitation. Doctoral dissertation, University of New Orleans, New Orleans, LA.

Akzo Nobel, 2016a. Product Data Sheet: Butanox ${ }^{\circledR}$ M-50, Amsterdam, Netherlands.

Akzo Nobel, 2016b. Product Data Sheet: Trigonox ${ }^{\circledR}$ C, Amsterdam, Netherlands.

Akzo Nobel, 2015a. Product Data Sheet: Perkadox ${ }^{\circledR}$ 16, Amsterdam, Netherlands.

Akzo Nobel, 2015b. Product Data Sheet: Perkadox ${ }^{\circledR} 26$, Amsterdam, Netherlands.

Akzo Nobel, 2015c. Product Data Sheet: Perkadox ${ }^{\circledR}$ CH-50, Amsterdam, Netherlands.

Akzo Nobel, 2015d. Product Data Sheet: Trigonox ${ }^{\circledR} 21-C 50$, Amsterdam, Netherlands.

Akzo Nobel, 2015e. Product Data Sheet: Trigonox ${ }^{\circledR} 21 S$, Amsterdam, Netherlands.

Akzo Nobel, 2015f. Product Data Sheet: Trigonox ${ }^{\circledR} 42 S$, Amsterdam, Netherlands.

Akzo Nobel, 2015. Product Data Sheet: Trigonox ${ }^{\circledR}$ 178, Amsterdam, Netherlands.

Akzo Nobel, 2009. Product Data Sheet: Trigonox ${ }^{\circledR} 239$, Amsterdam, Netherlands.

Akzo Nobel, 2008a. Product Data Sheet: Perkadox ${ }^{\circledR}$ BTW-50, Amsterdam, Netherlands.

Akzo Nobel, 2008b. Product Data Sheet: Trigonox ${ }^{\circledR}$ 121-BB75, Amsterdam, Netherlands.

Akzo Nobel, 2008c. Product Data Sheet: Trigonox ${ }^{\circledR} 21-O P 50$, Amsterdam, Netherlands.

Akzo Nobel, 2008d. Product Data Sheet: Trigonox ${ }^{\circledR}$ K90, Amsterdam, Netherlands.

Aliancys, 2015. Product Data Sheet: ATLAC ${ }^{\circledR}$ E-NOVA RE 3475. Schaffhausen, Switzerland.

Allouche, E., Alam, S., Simicevic, J., Sterling, R., Condit, W., Matthews, J. Selvakumar, A. 2014. A pilot study for retrospective evaluation of cured-in-place pipe (CIPP) rehabilitation of municipal gravity sewers. Tunneling and Underground Space Technology. 39, 82-93. https://doi.org/10.1016/j.tust.2012.02.002.

AOC, LLC, 2013. Material Safety Data Sheet: L721-LTI-12. Collierville, TN.

AOC, LLC, 2010. Production Information Sheet: Cure procedure of L040-TNVG-33. Collierville, TN.

AOC, LLC, 2008. Production Information Sheet: Vipel ${ }^{\circledR}$ L713-LTA Series Polyester Resin. Collierville, TN.

Ashland, 2011. Material Safety Data Sheet: Aropol MR 12018. Covington, KY.

ASTM, 2017. Standard Practice for Rehabilitation of Existing Pipelines and Conduits by Pulled-In-Place Installation of Cured-In-Place Thermosetting Resin Pipe (CIPP). F1743-17, ASTM, West Conshohocken, PA.

ASTM, 2016. Standard Practice for Rehabilitation of Existing Pipelines and Conduits by the Inversion and Curing of a Resin-Impregnated Tube. F1216-16, ASTM, West Conshohocken, PA.

ASTM, 2012. Standard Specification for Cured-In-Place Thermosetting Resin Sewer Piping Systems. D5813-12, ASTM, West Conshohocken, PA. 
ASTM, 2011. Standard Practice for Rehabilitation of Existing Pipelines and Conduits by the Pulled in Place Installation of Glass Reinforced Plastic (GRP) Cured-In-Place Thermosetting Resin Pipe (CIPP). F2019-11, ASTM, West Conshohocken, PA.

AWWA, 2014. Manual of Water Supply Practices, M28. Rehabilitation of Water Mains, $3^{\text {rd }}$ ed. Denver, CO.

Bauer, G. 2012. Styrene: an overview, an awareness. Presentation for the Underground Infrastructure Research Int. Conf. and Trenchless Technology Road Show Center for Advancing Trenchless Technology. British Columbia, Canada.

Berglind, I.A., Lind, M.L., \& Lidén, C. 2012. Epoxy pipe relining—an emerging contact allergy risk for workers. Contact Dermatitis. 67 (2), 59-65. https://doi.org/10.1111/j.1600-0536.2011.02028.x

BWSC (Boston Water and Sewer Commission), 2019. Section F1, Sewer and Drain Pipe Lining (Non-Man Entry). Boston, MA.

CDOT (Colorado Department of Transportation), 2012. Joint Budget Committee Hearing Agenda. FY 2012-13, Department of Transportation, Denver, CO.

Coffey, C.C., LeBouf, R., Lee, L., \& Slaven, J.E. 2015. Effect of calibration and environmental condition on the performance of direct-reading organic vapor monitors. Journal of Occupational and Environmental Hygiene. 9 (11), 670-680. https://doi.org/10.1080/15459624.2012.725015.

Commonwealth of Pennsylvania Department of Environmental Protection (PA DEP). Notice of Violation: Sewage3A, Carlisle STP, NPDES Permit No. PA0026077. August 19, 2019b. Carlisle, PA.

Commonwealth of Pennsylvania Department of Environmental Protection (PA DEP). Sewage Compliance Inspection Report: Carlisle Regional Water Pollution Control Facility, NPDES Permit No. PA0026077. July 31, 2019a. Carlisle, PA

CTC \& Associates, LLC, 2012. Preliminary Investigation: Environmental Effects of Cured In Place Pipe Repairs. Caltrans Division of Research and Investigation, Sacramento, CA.

Currier, B., 2017. Water Quality of Flow Through Cured-In-Place Pipe (CIPP). Final Report, Office of Water Programs, California State University Sacramento, Sacramento, Calif. Prepared for California Department of Transportation, Sacramento, CA. http://trid.trb.org/view.aspx?id=1467684.

DEPA (The Danish Environmental Protection Agency), 2018. The EU List of Potential Endocrine Disruptors. København, Denmark. http://eng.mst.dk/chemicals/chemicals-in-products/endocrine-disruptors/the-eu-list-ofpotential-endocrine-disruptors/

Doherty, I., Downey, D., Macey, C., Rahaim, K., \& Sarrami, K., 2017 (1st ed.). NASTT's Cured-In-Place-Pipe (CIPP) Good Practices Guidelines. North American Society for Trenchless Technology, Cleveland, OH.

Donaldson, B. \& Whelton, A.J., 2013. Impact of Stormwater Pipe Lining Materials on Water Quality: Field Study and Resulting Specifications. Journal of the Transportation Research Board. 2362 (1), 49-56. https://doi.org/10.3141/2362-07.

Donaldson, B.M., 2013. Water Quality Implications of Culvert Repair Options: Vinyl Ester Based and Ultraviolet Cured-In-Place Pipe Liners. Final Report VCTIR 13-R2, Virginia Transportation Research Council, Charlottesville, VA. https://trid.trb.org/view/1225679.

Donaldson, B.M., Whelton, A. J. Water quality implications of culvert repair options: cementitious and polyurea spray-on liners (No. FHWA/VCTIR 13-R3). Virginia Center for Transportation Innovation and Research. 2012. https://trid.trb.org/view.aspx?id=1243674.

DSM, 2011. ATLAC ${ }^{\circledR}$ Material Safety Data Sheet: E-Nova RE 3475. Schaffhausen, Switzerland.

Ellison, D., Sever, F., Oram, P., Lovins, W., Romer, A., Duranceau, S.J., \& Bell, G. Global review of spray-on structural lining technologies. Water Research Foundation, Denver, CO. 2010.

http://www.waterrf.org/PublicReportLibrary/4095.pdf 
Greenbook, 2015. Standard Specifications for Public Works Construction. BNI Building News, Vista, CA.

Griffin, J., 2008. Virginia DOT Lifts CIPP Ban. Underground Construction, 63 (6), 44.

Henry, C., 2007. Discharges From Cured In Place Pipe (CIPP) Installations, Central Contra Costa Sanitary District Experience. Presentation at the California Water Environment Association Conf., April 19, Ontario, CN.

Miller Pipeline, Inc. Harrison Street Sewer Line Repair - 2016. Section 335500 - Sewer Pipe Lining (Cured-InPlace Pipe). 2016.

Horzmann, K., Perre, C., Whelton, A.J., \& Freeman, J.L., 2017. Comparative Analytical and Toxicological Assessment of Methylcyclohexanemethanol (MCHM) Mixtures Associated with the Elk River Chemical Spill. Chemosphere. 188, 599-607. https://doi.org/10.1016/j.chemosphere.2017.09.026.

Huang, X., Whelton, A.J., Andry, S., Yapturi, J., Kelly, D., \& Ladner, D.A., 2017. Interaction of Fracking and Crude Oil Contaminants with Water Distribution Pipes. Final Report 4579. Water Research Foundation, Denver, CO.

ICTRD, 2006. Cured-In-Place Pipe Resins: An Endless Flow of Experience and Innovation. ICTRD, St. Paul, MN. www.interplastic.com/UserFiles/File/M_CIPP bro.pdf.

ICTRD (Interplastic Corporation Thermoset Resins Division), 2007. Technical Research: Optimizing Initiator Systems for Cured-In-Place Pipe Infrastructure Repair. ICTRD, St. Paul, MN. www.interplastic.com/UserFiles/File/T_OptInitiatorSys7_07.pdf.

Insituform Technologies. 2005. Material safety data sheet: Impregnated Insitutube ${ }^{\circledR}$. Chesterfield, MO.

Interflow Pty Ltd, 2008. Interfit Resin Part A \& B. MSDS ID NC317TCP Version No. 2.0. Girraween, Australia. http://gulfcoastunderground.com/wp-content/uploads/2014/04/MSDS-Resin-B-Interfit.pdf and http://gulfcoastunderground.com/wp-content/uploads/2014/04/MSDS-Resin-A-Interfit.pdf.

Interplastic Corporation, 2016. CIPP COR78-AT-579 Resin. Interplastic Corporation, St. Paul, MN.

Kobos, L., Teimouri Sendesi, S.M., Whelton, A.J. Boor, B.E., Howarter, J.A., \& Shannahan, J. 2019. In vitro toxicity assessment of emitted materials collected during the manufacture of water pipe plastic linings. Inhalation Toxicology. 31 (4), 131-146. https://doi.org/10.1080/08958378.2019.1621966.

La Scala, J., Sands, J.M., Orlicki, J.A., Robinette, E.J., \& Palmese, G.R. 2004. Fatty acid-based monomers as styrene replacements for liquid molding resins. Polymer. 45 (22), 7729-7737. https://doi.org/10.1016/j.polymer.2004.08.056.

LeBouf, R.F., Slaven, J.E., \& Coffey, C.C. 2015. Effect of calibration environment on the performance of directreading organic vapor monitors. Journal of the Air Waste Management Association. 63 (5), 528-533. https://doi.org/10.1080/10962247.2013.772926.

LeBouf, R.F., \& Coffey, C.C. 2015. Effect of interferents on the performance of direct-reading organic vapor monitors. Journal of the Air Waste Management Association. 65 (3), 261-269. https://doi.org/10.1080/10962247.2014.986308.

Lee, R. 2008. Risks associated with CIPP lining of storm water pipes and the release of styrene. Proceedings of the North American Society of Trenchless Technology No Dig Conference, April 27-May 2. Paper E-1-05-1. 10 pp.

Li, X., Nuruddin, Md., Ra, K., Sendesi, S.M.T., Howarter, J.A., Jafvert, C.T., Youngblood, J.P., \& Whelton, A.J. 2018. Outdoor Manufacture of UV-Cured Plastic Linings for Storm Water Culvert Repairs: Chemical Emission and Residual. Environmental Pollution. 245, 1031-1040. https://doi.org/10.1016/j.envpol.2018.10.080.

Liu, X., \& Chen, F. 2016. A review of void formation and its effects on the mechanical performance of carbon fiber reinforced plastic. Engineering Transactions. 64: 33-51. 
Loendorf, T., \& Waters, D., 2009. Styrene Removal Adds to the Challenges of Rehabilitating Sewer Pipeline in Reno, Nevada. Proceedings of the North American Society for Trenchless Technology (NASTT) NO-DIG Conf., NASTT, Liverpool, NY.

Mackenzie, K.A. Measurement of resin pressure in composite laminates during cure, Canada: University of British Columbia, 1993.

MENP (Ministry of Environment and Natural Protection), 2004. Agriculture and Consumer Protection (MUNLV) of the North Country Rhine-Westphalia in Bielefeld: Bielefeld, Germany. Final Report: Untersuchungenzu Styrol emission enbeimgro $\beta$ technischen Ein-satz von Schlauchlining verfahrenbei Kanalsanierungen, Vereinheitlichung der Probenahme und Analysemethoden, Festsetzung von Grenzwerten und Optimierung der SanierungsverfahrensowieallgemeingültigenAusschreibungsempfehlungen (in German), p. 104.

Moore, W. 2011. Non-Styrene Options for Cured in Place Pipe. AOC, LLC, Ft. Lauderdale, FL.

Morrison, R., Sangster, T., Downey, D., Matthews, J., Condit, W., Sinha, S., \& Sterling, R., 2013. State of Technology for Rehabilitation of Water Distribution Systems. EPA/600/R-13/036. Prepared for Environmental Protection Agency, Office of Research and Development, National Risk Management Laboratory, Water Supply and Water Resources Division. Washington, DC.

Najafi, M., Sattler, M., Schug, K., Kaushal, V., Korky, S., Iyer, G., Kakkera, S., Habibzeh, S., Nayak, S., \& Farazifard, R. Evaluation of Potential Rerelease of Organic Chemicals in the Steam Exhaust and Other Release Points during Pipe Rehabilitation Using the Trenchless Cured-In-Place-Pipe (CIPP) Method, Final Report, April 30, 2018. Publicly released June 28, 2018. Prepared for: NASSCO, Inc. Marriottsville, MD.

Najafi, M., 2010. Trenchless Technology: Installation and Inspection. The McGraw-Hill Companies, Inc., New York, NY.

Najafi, M. \& Gokhale, S., 2005. Trenchless Technology: Pipeline and Utility Design, Construction, and Renewal. The McGraw-Hill Companies, Inc., NY.

NASSCO, Inc. (National Association of Sewer Service Companies, Inc.), 2017. Guidelines for the Safe Use and Handling of Styrene Based Resins in Cured-In-Place-Pipe. Prepared by Pipe Rehab Committee. NASSCO, Inc., Marriottsville, MD.

NASSCO, Inc., 2011. Manual for Inspector Training and Certification Program (ITCP) for the Inspection of Cured in Place Pipe Installation, Version 3.0. NASSCO, Inc., Marriottsville, MD.

NASSCO, Inc., 2009. Guideline for the Use and Handling of Styrenated Resins in Cured-In-Place-Pipe. Created Sept. 2008, revised Aug. 19, 2009. Prepared by Pipe Rehab Committee, NASSCO, Inc., Marriottsville, MD.

Nuruddin, Md., Mendis, G., Ra, K., Sendesi, S.M.T., Futch, T., Goodsell, J., Whelton, A.J., Youngblood, Y.P., \& Howarter, J.A. 2019. Evaluation of the physical, chemical, mechanical, and thermal properties of steam-cured PET/polyester cured-in-place pipe. Journal of Composites Technology. 53, 2687-2699. https://doi.org/10.1177/0021998319839132.

NYSDOT (New York State Department of Transportation), 2016. Chapter 8: Highway Drainage. Revision 87Metric. Highway Design Manual. NYSDOT, Albany, NY. www.dot.ny.gov/divisions/engineering/design/dqab/hdm/hdm-repository/chapt_08_metric.pdf.

Noh, J.H., Patala, R., \& Meijboom, R. Catalytic evaluation of dendrimer and reverse microemulsion template Pd and Pt nanoparticles for the selective oxidation of styrene using TBHP. Applied Catalysis A: General. 514, 253266. https://doi.org/10.1016/j.apcata.2016.01.033.

O'Reilly, M., 2008. Summary of Water Sampling - CIPP for 4 Culverts. New York State Department of Transportation, Albany, NY.

Panofsky, N. Infiltration and Inflow Master Plan prepared for Ojai Valley Sanitary District. MNS Engineers, Inc. 2014. http://www.ojaisan.org/reports/pdfs/InfiltrationInflowMasterPlan-2014report.pdf. 
Persoons, R., Richard, J., Herve, C., Montlevier, S., Marques, M. \& Maitre, A. 2018. Biomonitoring of styrene occupational exposures: Biomarkers and determinants. Toxicology Letters. 298 (1), 99-105. https://doi.org/10.1016/j.toxlet.2018.06.1211.

Peterson, E., 2017. Worker Killed in Streamwood Sewer Line. Daily Herald. www.dailyherald.com/news/20171025/worker-killed-in-streamwood-sewer-line.

Piratla, K.R. \& Pang, W., 2017. Best Practices for Assessing Culvert Health and Determining Appropriate Rehabilitation Methods. Publication FHWA-SC-17-01. Prepared for the South Carolina Department of Transportation, Columbia, SC.

Puritan Products, Inc., 2016. Material Safety Data Sheet: N, N-Dimethylaniline. www.puritanproducts.com/wpcontent/uploads/2015/08/DIMETHYLANILINE-SDS.pdf.

Ra, K., Sendesi, S.M.T., Nuruddin, Md., Zyaykina, N., Conkling, E.N., Boor, B.E., Jafvert, C.T., Howarter, J.A., Youngblood, J.P., \& Whelton, A.J. 2019. Considerations for emission monitoring and liner analysis of thermally manufactured sewer cured-in-place-pipes (CIPP). Journal of Hazardous Materials. 371 (5), 540-549. https://doi.org/10.1016/j.jhazmat.2019.02.097.

Ra, K., Teimouri Sendesi, S.M., Howarter, J.A., Jafvert, C.T., Donaldson, B., \& Whelton, A.J. 2018. Critical Review: Surface and Storm Water Quality Impacts of Cured-in-Place-Pipe (CIPP) Repairs. Journal of the American Water Works Association. 110 (5), 15-32. https://doi.org/10.1002/awwa.1042.

RIVM (Rijksinstituut voor Volksgezondheid en Milie, Netherlands National Institute for Public Health and the Environment). Sewer renovation with stocking methods: backgrounds in the information sheet, Report Number 609021038/2006 (2006). Amsterdam, Netherlands.

RIVM. Styrene measurements sewer renovation Apeldoorn, Report Number 20050785 IMD es. Project number: M/609121/05/GZ-Health. August 2005. Amsterdam, Netherlands.

SAK, Inc. Contractor Submittal Summary, Pipeline Rehabilitation Services (2016), Project \#65A0588. SAK Construction of CA, LP. O’Fallon, MO.

Salem, O., Najafi, M., Salman, B., Calderon, D., Patil, R., \& Bhattachar, D., 2008. Use of Trenchless Technologies for a Comprehensive Asset Management of Culverts and Drainage Structures. Publication MRUTC 07-15. Prepared for Wisconsin Department of Transportation, Madison, WI.

SAERTEX Multicom GmbH (SMG), 2012. Installation Instructions for SAERTEX-LINER ${ }^{\circledR}$, Saerbeck Germany (2012), pp. 1-25.

SCRIT. Specification for Pipe Lining, Document Number: 10001-DE-GE-SP-0004. May 27, 2016. Christchurch, New Zealand.

Spectrum Analytical, Inc., 2013a. Laboratory Report - Project No. 08-220953.00, Weathersfield, VT. Report Date Sept. 17, 2013, Agawam, MA.

Spectrum Analytical, Inc., 2013b. Laboratory Report - Project No. 08-220953.00, Weathersfield, VT. Report Date Sept. 24, 2013, Agawam, MA.

Spectrum Analytical, Inc., 2013c. Laboratory Report - Project No. 08-220953.00, Weathersfield, VT. Report Date Oct. 11, 2013, Agawam, MA.

Spectrum Analytical, Inc., 2013d. Laboratory Report - Project No. 08-220953.00, Weathersfield, VT. Report Date Nov. 27, 2013, Agawam, MA.

Spiniello. Letter to Barletta Heavy Division. Re: Cause of Styrene Release. August 13, 2008. Fairfield, NJ.

Stratview Research, Inc., 2017. Global Cured-In-Place Pipe (CIPP) Market Likely to Grow at a Healthy CAGR During 2017 to 2022. www.stratviewresearch.com/press_details.php?name_id=140. 
Sullo, A., 2012. King Street Sewer Rehab and Water Quality Impacts. Presentation at the Underground Infrastructure Research International Conf. and Trenchless Technology Road Show, Center for Advancement of Trenchless Technologies, Waterloo, Ont, Canada.

Tabor, M.L., Newman, D., \& Whelton, A.J., 2014. Stormwater Chemical Contamination Caused by Cured-In-Place Pipe (CIPP) Infrastructure Rehabilitation Activities. Environmental Science and Technology. 48 (18), 1093810947. https://doi.org/10.1021/es5018637.

Teimouri, S.M., Ra, K., Conkling, E.N., Boor, B.E., Nuruddin, M., Howarter, J.A., Youngblood, J.P., Kobos, L.M., Shannahan, J.H., Jafvert, C.T., Whelton, A.J. 2017. Worksite Chemical Exposure and Air Emissions during Sanitary Sewer Pipe and Stormwater Culvert Rehabilitation Using Cured-In-Place-Pipe (CIPP). Environmental Science and Technology Letters. 4 (8), 325-333. https://doi.org/10.1021/acs.estlett.7b00237.

Test America Laboratories, Inc. 2017. Analytical Report: Pipe Liner Flushing, Report Number: 180-73341-1; Pittsburgh, PA.

United Initiators, Inc., 2017a. Material Safety Data Sheet: Norox ${ }^{\circledR}$ 600, Elyria, OH.

United Initiators, Inc., 2017b. Material Safety Data Sheet: Norox ${ }^{\circledR}$ TBPB, Elyria, OH.

United Initiators, Inc., 2015. Material Safety Data Sheet: Norox ${ }^{\circledR} 600$ (BCHPC), Elyria, OH.

UGA (University of Georgia), 2016. Water Testing VOC Analysis for 9/16/2016 and 9/21/2016. College of Agriculture and Environmental Services, Athens, GA.

U.S. ATSDR (Agency for Toxic Substances and Disease Registry), 2005. Health Consultation: Schlitz Park Office Building, Milwaukee, Milwaukee County. Atlanta, GA. https://www.atsdr.cdc.gov/HAC/pha/Schlitz\%20Park\%200ffice\%20Building/SchlitzParkHC091305.pdf. September 13, 2005.

U.S. CDC (Centers for Disease Control and Prevention), 2018. Carcinogen List. Atlanta, GA. https://www.cdc.gov/niosh/topics/cancer/npotocca.html.

U.S. EPA (Environmental Protection Agency), 2018. National Pollutant Discharge Elimination System (NPDES), About NPDES. Washington, DC. www.epa.gov/npdes/about-npdes.

U.S. EPA, 2017. Initial List of Hazardous Air Pollutants with Modifications. Washington, DC. https://www.epa.gov/haps/initial-list-hazardous-air-pollutants-modifications.

U.S. EPA, 2006. EPA Region III BTAG Freshwater Screening Benchmarks. Washington, DC. www.epa.gov/sites/production/files/2015-09/documents/r3 btag_fw benchmarks 07-06.pdf.

U.S. FHWA (Federal Highway Administration), 2010. Culvert Assessment and Decision-Making Procedures Manual for Federal Lands Highway, Publication No. FHWA-CFL/TD-10-005, Central Federal Lands and Highway Division (CFLHD), Ayers Associates, and Water Resource Learning Center: Washington, DC.

U.S. NIOSH (National Institute of Occupational Safety and Health), 2019. Health Hazard Evaluation Report: Evaluation of Exposures to Styrene During Ultraviolet Cured-in-Place-Pipe Installation. Prepared by: LeBouf RF, Burns, DA. U.S. Department of Health and Human Services, Centers for Disease Control and Prevention, NIOSH HHE Report No. 2018-0009-3334, Morgantown, WV. https://stacks.cdc.gov/view/cdc/70136

U.S. NRC (National Response Center), 2010. Incident Report. 957007.

U.S. NTP (National Toxicology Program), 2011. Report on Carcinogens, Styrene (14th ed.). https://ntp.niehs.nih.gov/pubhealth/roc/listings/s/styrene/summary/index.html.

U.S. OSHA (Occupational Safety and Health Administration), 2018. Citation and Notification of Penalty Inspection Number 1274028. U.S. Department of Labor, Des Plaines, IL.

VDOT (Virginia Department of Transportation), 2016. Special Provision for Pipe Rehabilitation. SP302-00014001, Richmond, VA. 
Walmer D. Fish \& Boat: 200+ LeTort trout killed in 'suspected pollution event' near Carlisle Barracks. The Sentinel. Aug 1, 2019. Carlisle, PA.

Wagener, B.D. \& Leagjeld, E.E., 2014. Culvert Repair Best Practices, Specifications and Special Provisions - Best Practices Guidelines. Publication MN/RC 2014-01. Prepared for Minnesota Department of Transportation, Saint Paul, MN.

Weidhaas, J.L., Dietrich, A.M., DeYonker, N.J., Dupont, R.R., Foreman, W.T., Gallagher, D., Gallagher, J.E.G., Whelton, A.J., \& Alexander, W.A., 2017. Enabling Science Support for Better Decision-Making When Responding to Chemical Spills. Journal of Environmental Quality. 45 (5), 1490-1500. https://doi.org/10.2134/jeq2016.03.0090.

Weldon, T. \& Morton, M., 2011. Report of CDOT I-70 Culvert Repair Project Styrene Release, Response, and Mitigation at Clear Creek County, Colorado. Colorado Department of Transportation. Denver, CO.

Whelton, A.J., Shannahan, J., Boor, B.E., Howarter, J.A., Youngblood, J.P., \& Jafvert, C.T. Cured-in-Place-Pipe (CIPP): Inhalation and Dermal Exposure Risks Associated with Sanitary Sewer, Storm Sewer, and Drinking Water Pipe Repairs. NIOSH Science Blog. September 26, 2017. Morgantown, WV. https://blogs.cdc.gov/nioshscience-blog/2017/09/26/cipp/.

Whelton, A.J., McMillan, L., Novy, C.L.R., White, K.D., \& Huang, X., 2017. Case Study: The Crude MCHM Chemical Spill. Environmental Science: Water Research and Technology. 3, 312-332. https://doi.org/10.1039/C5EW00294J.

Whelton, A.J., Salehi, M., Tabor, M., Donaldson, B., \& Estaba, J. 2012. Impact of infrastructure coating materials on storm-water quality: Review and experimental study. Journal of Environmental Engineering. 139 (5), 746756. https://doi.org/10.1061/(ASCE)EE.1943-7870.0000662.

Young, W.B. 1995. Compacting pressure and cure cycle for processing of thick composite laminates. Composites Science and Technology. 54 (3), 299-306. https://doi.org/10.1016/0266-3538(95)00067-4. 


\section{APPENDIX A. METHODS FOR CHARACTERIZING CIPPS TO DETERMINE CHEMICAL LEACHING POTENTIAL, STABILITY, AND RESIDUE CONTENT}




\section{A-1. Thermogravimetric Analysis (TGA) Method}

Purpose:

- Estimate the amount of volatile organic compound (VOC) and other materials that exist in the CIPP and can evaporate under nitrogen

- Estimate the CIPP's thermal stability in air

- Estimate the CIPP's residue content in air

Approach:

A TGA (Q-500, TA Instruments, Inc., New Castle, DE) was used.

- Platinum pans should be used and sample weight should be 10-15 mg.

- Samples should be heated at $10^{\circ} \mathrm{C} / \mathrm{min}$ to $160{ }^{\circ} \mathrm{C}$ under nitrogen atmosphere and held for $120 \mathrm{~min}$ to facilitate the evaporation of VOCs and other materials.

- Next, samples should be further heated at $10^{\circ} \mathrm{C} / \mathrm{min}$ to $900{ }^{\circ} \mathrm{C}$ in air to determine thermal stability and residue content of the composite.

- The gas purge flow should be $60 \mathrm{~mL} / \mathrm{min}$.

- To evaporate out residual volatile compounds including unreacted monomers, the samples should be kept inside the furnace isothermally at $160^{\circ} \mathrm{C}$.

- Nitrogen atmosphere should be applied to avoid sample oxidation.

- The materials remaining at $900{ }^{\circ} \mathrm{C}$ can be considered inert for the purposes of this test.

Disclaimer

Each method is limited by the conditions applied. Therefore, the selection of methods should be considered based on the specific questions being answered.

\section{A-2. Differential Scanning Calorimetry (DSC) Method}

Purpose:

- Estimate if a detectable level of uncured material remains in the CIPP specimen Approach:

A Q-2000 DSC (TA Instruments Inc., New Castle, DE) was used.

- Sample weight should be approximately $10 \mathrm{mg}$ in aluminum pans.

- Scans should be performed at $10^{\circ} \mathrm{C} / \mathrm{min}$ from $-25^{\circ} \mathrm{C}$ to $200^{\circ} \mathrm{C}$.

- If no exotherm peak is detected, it could be concluded that the samples did not contain an unreacted initiator and/or resin.

\section{Disclaimer}

Each method is limited by the conditions applied. Therefore, the selection of methods should be considered based on the specific questions being answered. 


\section{A-3. Liquid-Solid Extraction (LSE) Gas Chromatograph / Mass Spectrometry (GC/MS) Method}

Purpose:

- Identify which hazardous air pollutants and chemicals with water quality standards are extractable from the CIPP

- Estimate the chemical loading (extractable mass per weight of CIPP) present in the CIPP

Approach:

- Conduct liquid solid extractions.

o CIPPs can be chemically extracted by immersing $3 \mathrm{~g}$ of CIPP sample into dichloromethane and hexane at room temperature.

o To obtain specimens for extraction, all CIPP samples can be drilled into small spiral shapes. This approach enables increased wettable surface area in contact with each solvent.

o CIPP-solvent should be stored headspace free in a $20 \mathrm{~mL}$ amber glass vial with PTFE cap and in the dark until analysis.

o Chlorobenzene-d5 (1 mg/L) as internal standard should be added to the solvent.

o For each 3 g CIPP-solvent pair, three replicate glass containers should be used.

o Solvents without CIPP (controls) should also be filtered through PTFE filters and analyzed by GC/MS.

o Dichloromethane and hexane extracts should be analyzed using the GC/MS method.

- Conduct chemical identification in solvents.

o A Shimazu GC/MS-TQ8040 with an AOC-5000 plus autosampler was used.

o The GC column can be an Agilent Technologies HP-5ms (0.250 mm diameter, $30 \mathrm{~m}$ length, 0.25 $\mu \mathrm{m}$ film).

o Helium can be the carrier gas in purge and column flow at $3.0 \mathrm{~mL} / \mathrm{min}$ and $1.5 \mathrm{~mL} / \mathrm{min}$, respectively.

o The GC oven program can begin at $50{ }^{\circ} \mathrm{C}$ and ramp to $180{ }^{\circ} \mathrm{C}$ at $10{ }^{\circ} \mathrm{C} / \mathrm{min}$ using helium as the carrier gas $(1.48 \mathrm{~mL} / \mathrm{min})$.

o Samples can be injected in split mode with the ratio of $1: 10$ at $280{ }^{\circ} \mathrm{C}$, and cut time for dichloromethane can be $1.8 \mathrm{~min}$ to $27.5 \mathrm{~min}$ and cut time for hexane can be $2.5 \mathrm{~min}$ to $27.5 \mathrm{~min}$.

o Analytical standards are needed for the confirmation of each compound.

\section{Disclaimer}

Each method is limited by the conditions applied. For example, different chemical identification methods than those used could identify chemicals not found in the present study. Therefore, the selection of methods should be considered based on the specific questions being answered. 


\section{APPENDIX B. CONFIRMED AND POSSIBLE CONTAMINATION SOURCES AT CIPP SITES}


Table B-1. Confirmed and possible contamination source at steam-based CIPP installation sites by construction activity phase

\begin{tabular}{|c|c|c|c|c|}
\hline \multirow{2}{*}{ Activity } & \multicolumn{3}{|c|}{ Media } & \multirow{2}{*}{ Explanation } \\
\hline & A & W & S & \\
\hline \multicolumn{5}{|l|}{ Install setup } \\
\hline \multicolumn{5}{|l|}{ Host pipe inspection and cleaning } \\
\hline \multicolumn{5}{|l|}{ Standing water is pumped out from host pipe inlet work area } \\
\hline \multicolumn{5}{|l|}{$\begin{array}{l}\text { Scaffolding or work platform is setup at pipe inlet and/or } \\
\text { outlet }\end{array}$} \\
\hline Truck opened where uncured resin tube is stored & $\sqrt{ }$ & & & Chemicals may release from the outer layer of the uncured resin tube into air \\
\hline \multicolumn{5}{|l|}{$\begin{array}{l}\text { Plastic guide sheet is applied to the ground to prevent uncured } \\
\text { resin tube contact with the ground }\end{array}$} \\
\hline \multicolumn{5}{|l|}{$\begin{array}{l}\text { Plastic preliner is inserted into the host pipe on the top of } \\
\text { preliner }\end{array}$} \\
\hline $\begin{array}{l}\text { Uncured resin tube is pulled into the pipe on the top of } \\
\text { preliner }\end{array}$ & $\sqrt{ }$ & & & Chemicals may release from the outer layer of the uncured resin tube into air \\
\hline Extra length uncured resin tube is cut & $\sqrt{ }$ & & & $\begin{array}{l}\text { The uncured resin tube is longer than the designed length. Chemicals may release from } \\
\text { the outer layer of the uncured resin tube into air }\end{array}$ \\
\hline End of the uncured resin tube is unsealed (tape removed) & $\sqrt{ }$ & & & $\begin{array}{l}\text { Resin layers are exposed to air after cutting, and chemicals may release from the outer } \\
\text { layer of the uncured resin tube into air }\end{array}$ \\
\hline $\begin{array}{l}\text { Exhaust hose or steam injection hose is secured to the } \\
\text { uncured resin tube }\end{array}$ & $\sqrt{ }$ & & & $\begin{array}{l}\text { Resin layers are exposed to air after cutting, and chemicals may release from the outer } \\
\text { layer of the uncured resin tube into air }\end{array}$ \\
\hline $\begin{array}{l}\text { Forced air is applied to hold the resin tube against the pipe } \\
\text { wall }\end{array}$ & & $\sqrt{ } *$ & $\sqrt{*}$ & $\begin{array}{l}\text { Resin layers are exposed to air after cutting, and chemicals may release from the outer } \\
\text { layer of the uncured resin tube into air. When the uncured resin tube is suppressed to } \\
\text { the host pipe wall, resin may be squeezed out, but it has not been investigated yet }\end{array}$ \\
\hline \multicolumn{5}{|l|}{ Extra preliner is cut and removed } \\
\hline \multicolumn{5}{|l|}{ Plastic guide sheet is removed } \\
\hline \multicolumn{5}{|l|}{ Active curing } \\
\hline Steam is applied to facilitate CIPP manufacture & $\sqrt{ }$ & $\sqrt{*}$ & $\sqrt{*}$ & $\begin{array}{l}\text { Forced air/steam would strip chemicals from the inner surface and push them out the } \\
\text { end of the pipe through the liner itself, through the exhaust pipe, and at the front of the } \\
\text { uncured resin tube. This can include particulates, partially cured resin, and vapors. }\end{array}$ \\
\hline
\end{tabular}


(continued...)

\begin{tabular}{|c|c|c|c|c|}
\hline \multirow{2}{*}{ Activity } & \multicolumn{3}{|c|}{ Media } & \multirow{2}{*}{ Explanation } \\
\hline & $\mathbf{A}$ & $\mathbf{W}$ & $\mathbf{S}$ & \\
\hline \multicolumn{5}{|l|}{ Installation breakdown } \\
\hline \multicolumn{5}{|l|}{ Forced air is halted } \\
\hline $\begin{array}{l}\text { Exhaust hose is removed } \\
\text { from the end of the CIPP }\end{array}$ & $\sqrt{ } *$ & $\sqrt{ } *$ & $\sqrt{ } *$ & $\begin{array}{l}\text { Resin tube may not be } 100 \% \\
\text { cured and materials may be on } \\
\text { the exhaust hose. Workers put it } \\
\text { on the ground }\end{array}$ \\
\hline $\begin{array}{l}\text { Steam hose is removed } \\
\text { from the end of the CIPP }\end{array}$ & $\sqrt{ } *$ & $\sqrt{ } *$ & $\sqrt{ } *$ & $\begin{array}{l}\text { Resin tube may not be } 100 \% \\
\text { cured and materials may be on } \\
\text { the exhaust hose. Workers put it } \\
\text { on the ground }\end{array}$ \\
\hline $\begin{array}{l}\text { Before cutting of CIPP ends } \\
\text { some materials are removed }\end{array}$ & $\sqrt{ } *$ & $\sqrt{ } *$ & $\sqrt{ } *$ & $\begin{array}{l}\text { Condensation and other } \\
\text { materials are removed from the } \\
\text { bottom of the resin tube / CIPP. } \\
\text { If not, these materials can be } \\
\text { emitted into air, water, and } \\
\text { ground. }\end{array}$ \\
\hline $\begin{array}{l}\text { Ends of new CIPP are } \\
\text { mechanically cut }\end{array}$ & $\sqrt{ }$ & $\sqrt{ }$ & $\sqrt{ }$ & $\begin{array}{l}\text { Particulates can be emitted into } \\
\text { air, water and ground }\end{array}$ \\
\hline New CIPP is inspected & $\sqrt{ } *$ & $\sqrt{ } *$ & $\sqrt{ } *$ & $\begin{array}{l}\text { CCTV used after CIPP was } \\
\text { manufactured can come into } \\
\text { contact with particulates that } \\
\text { may be brought to the } \\
\text { environment with CCTV device }\end{array}$ \\
\hline $\begin{array}{l}\text { Cut CIPP ends are collected } \\
\text { and transported to the } \\
\text { contractor's vehicle }\end{array}$ & $\sqrt{ } *$ & $\sqrt{ } *$ & $\sqrt{ } *$ & $\begin{array}{l}\text { Particulates and other solid } \\
\text { waste may fall to water or } \\
\text { ground }\end{array}$ \\
\hline $\begin{array}{l}\text { Work platform at pipe inlet } \\
\text { and/or outlet and is } \\
\text { collected and transported to } \\
\text { a vehicle }\end{array}$ & $\sqrt{ } *$ & $\sqrt{ } *$ & $\sqrt{ } *$ & $\begin{array}{l}\text { Particulates and other solid } \\
\text { waste may fall to water or } \\
\text { ground }\end{array}$ \\
\hline \multicolumn{5}{|l|}{ Possible treatment } \\
\hline \multicolumn{5}{|l|}{$\begin{array}{l}\text { Rinse water is discharged } \\
\text { into new CIPP }\end{array}$} \\
\hline $\begin{array}{l}\text { Rinse water is captured } \\
\text { exiting new CIPP }\end{array}$ & $\sqrt{ }$ & $\sqrt{ }$ & $\sqrt{ }$ & $\begin{array}{l}\text { Rinse water has an odor, } \\
\text { contains particulate, dissolved } \\
\text { chemicals }\end{array}$ \\
\hline $\begin{array}{l}\text { Air is injected into the new } \\
\text { CIPP }\end{array}$ & & & & \\
\hline
\end{tabular}




\begin{tabular}{|c|c|c|c|c|}
\hline $\begin{array}{l}\text { Air is captured exiting the } \\
\text { new CIPP }\end{array}$ & $\sqrt{ } *$ & $\sqrt{ } *$ & $\sqrt{ } *$ & $\begin{array}{l}\text { Air may strip chemicals from } \\
\text { the inner surface and/or } \\
\text { contaminated air inside the CIPP } \\
\text { may be displaced from the new } \\
\text { CIPP }\end{array}$ \\
\hline
\end{tabular}

NOTES: A = Air, $\mathrm{W}=$ Water, $\mathrm{S}$ = Soil; Workers may encounter resin and other materials on their apparel (i.e., gloves, boots, etc.) during the installation. The magnitude and significance of contact of those contaminated materials with air, water, soil is unclear. An asterix $\left(^{*}\right)$ indicates that contamination may be possible from a certain activity/media, but no studies were found that had investigated the activity. 
Table B-2. Confirmed and possible contamination source at UV-based CIPP installation sites

\begin{tabular}{|c|c|c|c|c|}
\hline \multirow{2}{*}{ Activity } & \multicolumn{3}{|c|}{ Media } & \multirow{2}{*}{ Explanation } \\
\hline & A & $\mathbf{W}$ & $\mathbf{S}$ & \\
\hline \multicolumn{5}{|l|}{ Install setup } \\
\hline \multicolumn{5}{|l|}{ Host pipe inspection and cleaning } \\
\hline \multicolumn{5}{|l|}{ Standing water is pumped out from host pipe inlet work area } \\
\hline \multicolumn{5}{|l|}{ Scaffolding or work platform is setup at pipe inlet and/or outlet } \\
\hline Truck opened where uncured resin tube is stored & $\sqrt{ }$ & & & Chemicals may release from the outer layer of the uncured resin tube into air \\
\hline \multicolumn{5}{|l|}{$\begin{array}{l}\text { Plastic guide sheet is applied to the ground to prevent uncured } \\
\text { resin tube contact with the ground }\end{array}$} \\
\hline \multicolumn{5}{|l|}{ Plastic preliner is inserted into the host pipe on the top of preliner } \\
\hline Uncured resin tube is pulled into the pipe on the top of preliner & $\sqrt{ }$ & & & Chemicals may release from the outer layer of the uncured resin tube into air \\
\hline Extra length uncured resin tube is cut & $\sqrt{ }$ & & & $\begin{array}{l}\text { The uncured resin tube is longer than the designed length. Chemicals may release } \\
\text { from the outer layer of the uncured resin tube into air }\end{array}$ \\
\hline End of the uncured resin tube is unsealed (tape removed) & $\sqrt{ }$ & & & $\begin{array}{l}\text { Resin layers are exposed to air after cutting, and chemicals may release from the } \\
\text { outer layer of the uncured resin tube into air }\end{array}$ \\
\hline Cap for the UV light system is secured to the uncured resin tube & $\sqrt{ }$ & & & $\begin{array}{l}\text { Resin layers are exposed to air after cutting, and chemicals may release from the } \\
\text { outer layer of the uncured resin tube into air }\end{array}$ \\
\hline Forced air is applied to hold the resin tube against the pipe wall & & $\sqrt{ } *$ & & $\begin{array}{l}\text { Resin layers are exposed to air after cutting, and chemicals may release from the } \\
\text { outer layer of the uncured resin tube into air. When the uncured resin tube is } \\
\text { pressed to the host pipe wall, resin may be squeezed out. }\end{array}$ \\
\hline UV light train is inserted into the uncured resin tube & $\sqrt{ }$ & & & $\begin{array}{l}\text { Resin layers are exposed to air after cutting, and chemicals may release from the } \\
\text { outer layer of the uncured resin tube into air }\end{array}$ \\
\hline \multicolumn{5}{|l|}{ Extra preliner is cut and removed } \\
\hline Plastic guide sheet is removed & & & & \\
\hline
\end{tabular}

\section{Active curing}

Forced air is applied to keep the resin tube against the pipe wall UV light train is operated down the length of the uncured resin tube
Forced air would strip chemicals from the inner surface and push them out the end of the pipe. Diffusion.

Forced air would strip chemicals from the inner surface and push them out the end of the pipe. Diffusion. 
(continued...)

\begin{tabular}{|c|c|c|c|c|}
\hline \multirow{2}{*}{ Activity } & \multicolumn{3}{|c|}{ Media } & \multirow{2}{*}{ Explanation } \\
\hline & $\mathbf{A}$ & W & $\mathrm{S}$ & \\
\hline \multicolumn{5}{|l|}{ Installation breakdown } \\
\hline \multicolumn{5}{|l|}{ Forced air is halted } \\
\hline Cap for UV light system is removed & $\sqrt{ } *$ & $\sqrt{ } *$ & $\sqrt{ } *$ & $\begin{array}{l}\text { Resin tube may not be } 100 \% \text { cured and may hardened resin coating the cap. Workers put } \\
\text { it on the ground }\end{array}$ \\
\hline UV light train is removed & $\sqrt{ } *$ & $\sqrt{ } *$ & $\sqrt{*}$ & $\begin{array}{l}\text { The light train contacts with the inner layer of the uncured resin tube, and the inner layer } \\
\text { contained chemicals that may be brought out with the light train. But it has not been } \\
\text { investigated }\end{array}$ \\
\hline Ends of new CIPP are mechanically cut & $\sqrt{ }$ & $\sqrt{ }$ & $\sqrt{ }$ & Particulates were emitted into air, water and ground \\
\hline New CIPP is inspected & $\sqrt{ } *$ & $\sqrt{ } *$ & $\sqrt{ } *$ & $\begin{array}{l}\text { CCTV was used after CIPP was manufactured. Particulates may be brought to the } \\
\text { environment with CCTV device }\end{array}$ \\
\hline $\begin{array}{l}\text { Cut CIPP ends are collected and transported to the } \\
\text { contractor's vehicle }\end{array}$ & $\sqrt{ } *$ & $\sqrt{ } *$ & $\sqrt{*}$ & $\begin{array}{l}\text { Particulates and other solid waste may fall to water or ground if workers do not handle } \\
\text { them carefully }\end{array}$ \\
\hline $\begin{array}{l}\text { Work platform at pipe inlet and/or outlet and is } \\
\text { collected and transported to a vehicle }\end{array}$ & $\sqrt{ } *$ & $\sqrt{ } *$ & $\sqrt{ } *$ & $\begin{array}{l}\text { Particulates and other solid waste may fall to water or ground if workers do not handle } \\
\text { them carefully }\end{array}$ \\
\hline
\end{tabular}

\section{Possible treatment}

Rinse water is discharged into new CIPP

Rinse water is captured exiting new CIPP

Air is injected into the new CIPP

Air is captured exiting the new CIPP

\begin{tabular}{|ccc|l}
$\sqrt{ }$ & $\sqrt{ }$ & $\sqrt{ }$ & Rinse water has an odor, contains particulate, dissolved chemicals \\
$\sqrt{ }$ & & & \\
$\sqrt{ } *$ & $\sqrt{ } *$ & $\sqrt{ } *$ & $\begin{array}{l}\text { Air may strip chemicals from the inner surface and/or contaminated air inside the CIPP } \\
\text { may be displaced from the new CIPP }\end{array}$ \\
\hline
\end{tabular}

NOTES: A = Air, $\mathrm{W}=$ Water, $\mathrm{S}=$ Soil; Workers may encounter resin and other materials on their apparel (i.e., gloves, boots, etc.) during the installation. The magnitude and significance of contact of those contaminated materials with air, water, soil is unclear. An asterix $(*)$ indicates that contamination may be possible from a certain activity/media, but studies were not found that had investigated the activity. 


\section{APPENDIX C. LISTS OF CURRENTLY KNOWN CHEMICALS ASSOCIATED WITH CIPP USE AND STATE WATER QUALITY LIMITS}


Table C-1. As of July 2019, different states had different water quality standards for chemicals that have been associated with field- and pilot-scale CIPP installations or chemicals found during CIPP bench-scale testing as reviewed in this project

\begin{tabular}{|c|c|c|c|c|c|c|c|c|c|}
\hline \multirow[t]{2}{*}{ Compound Name } & \multirow{2}{*}{$\begin{array}{c}\text { Most } \\
\text { Stringent } \\
\text { in Table, } \mathrm{mg} / \mathrm{L}\end{array}$} & \multicolumn{6}{|c|}{$\begin{array}{l}\text { State Code Water Quality Standards, Criteria, } \\
\text { and Concentrations Found for Six States, mg/L }\end{array}$} & \multicolumn{2}{|c|}{$\begin{array}{c}\text { Example CIPP } \\
\text { Specification } \\
\text { Requirements }\end{array}$} \\
\hline & & CA & KS & NY & $\mathbf{O H}$ & NC & VA & VA & VT \\
\hline Acetophenone $*^{*+}$ & 3.500 & & & & & 3.500 & & & \\
\hline Acetone ${ }^{\theta \neq \S \Delta \uparrow \rho}$ & 2.0 & & & & & 2.0 & & & \\
\hline Aniline $^{\beta}$ & 0.0041 & & & & 0.0041 & & & & \\
\hline Benzene $\theta \Delta \uparrow \beta$ & 0.001 & 0.001 & 0.0012 & 0.001 & 0.005 & 0.00119 & 0.0058 & & \\
\hline Benzoic acid ${ }^{\theta *+\beta}$ & 140 & & & & & 140 & & & \\
\hline Benzyl alcohol ^ & 17 & & & & & 17 & & & \\
\hline 2-Butanone (Methyl ethyl ketone) $₫ \beta$ & 20 & & & & 22 & 20 & & & \\
\hline tert-Butyl benzene ${ }^{\rho}$ & 0.0039 & 0.260 & & & & 0.0039 & & & \\
\hline tert-Butyl alcohol ${ }^{\S}$ & 0.012 & 0.012 & & & & 64 & & & \\
\hline Butyl benzyl phthalate (BBP) ${ }^{\#}$ & 0.001 & & 1.500 & & 3.000 & 0.0051 & 0.001 & & \\
\hline Chloroform $\pi$ & 0.007 & 0.080 & 0.0057 & 0.007 & 0.057 & 0.0056 & 0.060 & & \\
\hline Di-n-butyl phthalate (DBP) $₫ \$ * Z$ & 0.003 & & 0.003 & 0.050 & 2.700 & 0.0045 & 0.020 & & \\
\hline Diethyl phthalate (DEP) & 0.600 & & 17.000 & & 23.000 & 1.2 & 0.600 & & \\
\hline 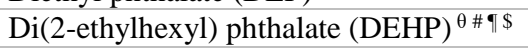 & 0.0018 & 0.004 & 0.0018 & 0.005 & 0.006 & 0.012 & & & \\
\hline Phthalates, total & 0.003 & & 0.003 & & & & & & \\
\hline Ethylbenzene $^{\theta \ddagger Z}$ & 0.068 & 0.300 & 0.700 & & 0.700 & 0.097 & 0.068 & & \\
\hline Isopropylbenzene $\theta \ddagger \S \Delta \uparrow \Psi \mathrm{Z}$ & 0.048 & & & & 0.048 & 0.320 & & & \\
\hline Methylene chloride I $\Psi$ & 0.005 & 0.005 & 0.005 & 0.005 & 0.005 & 0.0026 & 0.020 & & \\
\hline Phenol $\uparrow \Delta^{*+}+$ & 0.001 & & 2.560 & & 0.001 & & 4.000 & & \\
\hline$N$-Propylbenzene $\ddagger \S \Delta \uparrow \Psi \mathrm{Z}$ & 0.200 & 0.200 & & & & (LD) & & & \\
\hline Styrene $¥ \uparrow \neq \S \theta q \Delta \rho * \mathrm{Z}+\mathrm{H}$ & 0.005 & & 0.100 & 0.005 & 0.100 & (LD) & & 2.5 & 1.0 \\
\hline Toluene $^{\theta \Delta}$ & 0.057 & 0.150 & 1.000 & & 1.000 & 0.36 & 0.057 & & \\
\hline 1,2,3-Trimethylbenzene $\mathrm{z}$ & 0.005 & & & 0.005 & & & & & \\
\hline 1,2,4-Trimethylbenzene ${ }^{\theta \neq \S \Delta \uparrow \Psi \mathrm{Z}}$ & 0.005 & 0.330 & & 0.005 & & 0.390 & & & \\
\hline 1,3,5-Trimethylbenzene ${ }^{\theta \ddagger \S \Delta \uparrow \Psi \rho \mathrm{Z}}$ & 0.005 & 0.330 & & 0.005 & & 0.630 & & & \\
\hline Xylene (total) $\Delta \mathrm{Z}$ & 0.005 & 1.750 & 10.000 & 0.005 & 10.000 & 0.370 & & & \\
\hline
\end{tabular}

NOTES: More than 90 other tentatively identified compounds have been reported that are not shown in the table above. Tentatively identified compounds are chemicals that were detected, but the exact chemical structure/identified was not confirmed. Therefore, the Table above does not list all chemicals that can be released from CIPP processes, but just those that have been confirmed. "ns" = no standard found; Some results found were reported as $\mu \mathrm{g} / \mathrm{L}$ concentration in the document reviewed and were then converted to $\mathrm{mg} / \mathrm{L}$ concentration for the table shown above. Blank cell indicates no limit was found for the states surveyed. ** Two asterix is a requirement only for styrene-free resin. *** Three asterix represents VOC effluent limits for California remediation sites; California discharge limits are established by 9 water quality control boards and information from the Central Valley (one board) is shown. Limits for each board may differ. For other states shown, information above represents the most stringent criteria, standards, or concentrations according to each State's code. Values in some states represent discharge into waters specific to those states include, but are not limited to, fresh water, salt water, sensitive ecosystems, and waters used as a public 
water supply. (LD) represents limited data available and North Carolina recommends persons contact the North Carolina clean water act agency for information. Symbols next to each compound name represent the studies and reports where they were reported and associated with CIPP installations. References for the documents are listed below. Compounds in table were detected by prior investigators who examined CIPP waste or water sampling included ${ }^{\sharp} \mathrm{NRC}$ (2010),

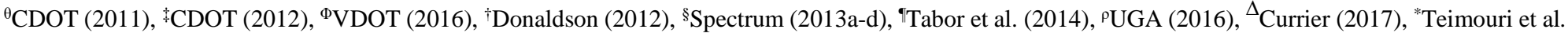
(2017), ${ }^{\mathrm{H} P A}$ DEP (2019b), ${ }^{\Psi}$ Tentatively identified compounds in Tabor et al. (2014), ${ }^{\mathrm{Z}} \mathrm{Li}$ et al. (2019), ${ }^{+} \mathrm{Ra}$ et al. (2019). ${ }^{\beta}$ Initiator degradation product reported by Ra et al. (2019). References for each column can be found in the references section as "State of X" with an associated web link. References for each column can be found in the references section as "State of X" with an associated web link. 
Table C-2. As of July 2019, the chemicals in this list have been associated with field-and pilot-scale CIPP installations or chemicals found during CIPP bench-scale testing as reviewed in this project but no water quality standards were found for these compounds in the six partner states

Compounds detected at CIPP worksites (uncured resin tube, rinse water, CIPPs themselves) and known degradation products of CIPP ingredients

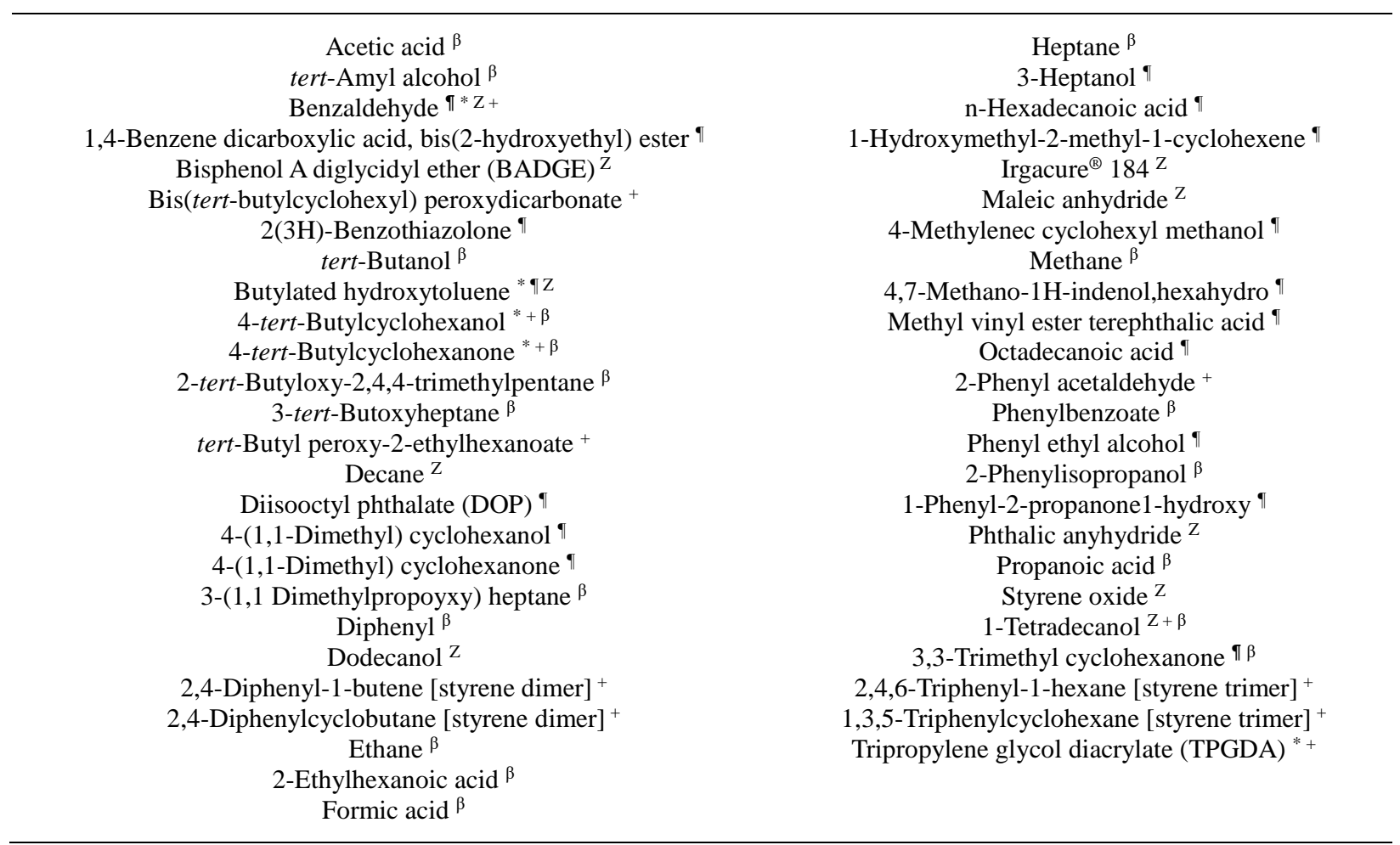

NOTES: Compounds in table were detected by prior investigators who examined CIPP waste or water sampling included ${ }^{\ddagger}$ NRC (2010), ${ }^{\theta}$ CDOT (2011), ${ }^{\ddagger}$ CDOT (2012), ${ }^{\Phi}$ VDOT (2016), ${ }^{\dagger}$ Donaldson (2012), ${ }^{\S}$ Spectrum (2013a-d), ${ }^{\oplus}$ Tabor et al. (2014), ${ }^{\rho}$ UGA (2016), ${ }^{\Delta}$ Currier (2017), *Teimouri et al. (2017), ${ }^{\Psi}$ Tentatively identified compounds in Tabor et al. (2014), ${ }^{\mathrm{Z}} \mathrm{Li}$ et al. (2019), ${ }^{+} \mathrm{Ra}$ et al. (2019). ${ }^{\beta}$ Initiator degradation product reported by Ra et al. (2019). References for each column can be found in the references section as "State of $\mathrm{X}$ " with an associated web link.

\section{State Water Quality References Consulted}

Commonwealth of Virginia. 9VAC25-260-140. Criteria for Surface Water. June 2017. Accessible at: https://law.lis.virginia.gov/admincode/title9/agency25/chapter260/section140/

State of California, California Regional Water Quality Control Board Central Valley Region, Waste Discharge Requirements - Limited Threat Discharges To Surface Water. October 14, 2016. Accessible at: https://www.waterboards.ca.gov/centralvalley/board_decisions/adopted_orders/general_orders/r5-20160076 mod.pdf

State of Kansas. Kansas Water Quality Standards - Tables of Numeric Criteria Effective July 18, 2017. Accessible at: https://www.epa.gov/sites/production/files/2014-12/documents/ks-numeric-criteria.pdf

State of New York. New York Codes, Rules, and Regulations. Title 6 Department of Environmental Conservation, Chapter X Division of Water Resources, Subchapter A, General Article 2. Classifications and Standards of Quality and Purity, Part 703 Surface Water and Groundwater Quality Standards and Groundwater Effluent Limitations. Accessible at: https://govt.westlaw.com/nycrr/Browse/Home/NewYork/NewYorkCodesRulesandRegulations?guid=I070d30d 
0b5a111dda0a4e17826ebc834\&originationContext=documenttoc\&transitionType=Default\&contextData=(sc.D efault)

State of North Carolina. North Carolina Administrative Code (NCAC). Title 15A Environmental Quality, Chapter 02B Environmental Management, Water Quality Standards for Surface Waters. Accessible at: https://deq.nc.gov/about/divisions/water-resources/planning/classification-standards/surface-water-standards and http://reports.oah.state.nc.us/ncac.asp.

State of Ohio. Ohio Administrative Code (OAC). Chapter 3745-1 Water Quality Standards. Accessible at: http://www.epa.ohio.gov/dsw/rules/3745_1.aspx

State of Vermont. Vermont Statues (VSA). Accessible at:

http://dec.vermont.gov/sites/dec/files/documents/WSMD_WaterQualityStandards_2014.pdf 